\title{
WestVirginiaUniversity
}

THE RESEARCH REPOSITORY @ WVU

Graduate Theses, Dissertations, and Problem Reports

2010

\section{Field development strategies for Bakken shale formation}

\author{
Saeed Zargari \\ West Virginia University
}

Follow this and additional works at: https://researchrepository.wvu.edu/etd

\section{Recommended Citation}

Zargari, Saeed, "Field development strategies for Bakken shale formation" (2010). Graduate Theses, Dissertations, and Problem Reports. 2193.

https://researchrepository.wvu.edu/etd/2193

This Thesis is protected by copyright and/or related rights. It has been brought to you by the The Research Repository @ WVU with permission from the rights-holder(s). You are free to use this Thesis in any way that is permitted by the copyright and related rights legislation that applies to your use. For other uses you must obtain permission from the rights-holder(s) directly, unless additional rights are indicated by a Creative Commons license in the record and/ or on the work itself. This Thesis has been accepted for inclusion in WVU Graduate Theses, Dissertations, and Problem Reports collection by an authorized administrator of The Research Repository @ WVU. For more information, please contact researchrepository@mail.wvu.edu. 
By

Saeed Zargari

Thesis submitted to the

College of Engineering and Mineral Resources

at West Virginia University

in partial fulfillment of the requirements

for the degree of

Master of Science

in

Petroleum and Natural Gas Engineering

Approved by

Shahab D. Mohaghegh, PhD., Chair

Samuel Ameri, PhD.

Razi Gaskari, PhD.

Department of Petroleum and Natural Gas Engineering

Morgantown, West Virginia

2010

Keywords: Tight Oil Reservoirs, Bakken Shale, Production Analysis, Top-down Intelligent Reservoir Model, Intelligent History Matching 


\section{Abstract \\ FIELD DEVELOPMENT STRATEGIES FOR BAKKEN SHALE FORMATION \\ Saeed Zargari}

Bakken shale has been subjected to more attention during the last decade. Recently released reports discussing the high potential of the Bakken formation coupled with advancements in horizontal drilling, increased the interest of oil companies for investment in this field. Bakken formation is comprised of three layers. In this study upper and middle parts are the core of attention. Middle member which is believed to be the main reserve is mostly a limestone and the upper member is black shale. The upper member plays as a source and seal which has been subject to production in some parts as well.

In this study, we implement Top-Down Intelligent Reservoir Modeling technique to a part of Bakken shale formation in Williston basin of North Dakota. In this study, two different Top-Down approaches have been followed for building reservoir models: Static Reservoir Modeling and Spontaneous History Matching-Predictive Modeling. This innovative technique utilizes a combination of conventional reservoir engineering methods, data mining and artificial intelligence to analyze the available data and to build a full field model that can be used for field development. Unlike conventional reservoir simulation techniques which require wide range of reservoir characteristics and geological data; Top-Down modeling utilizes the publicly available data (minimum required data: production data and well logs) in order to generate reservoir model. The model accuracy can be enhanced as more detail data becomes available. The model can be used for proposing development strategies.

Static and predictive reservoir models for Bakken Shale formation are developed. The static reservoir model is then used to identify remaining reserves and sweet spots that can help operators identify infill locations. Furthermore economical analysis for some proposed new wells is performed. The intelligent predictive model was trained, calibrated and verified using production, log and completion data. The history matched predictive model can be further implemented for predicting the production. 
Hereby 1 am going to dedicate this thesis to my parents who has helped me to succeed and instilled in me the confidence that 7 am capable of doing anything 7 put my mind ta.

Thank you for all the unconditional love, guidance, and support that you have always given me. 


\section{Acknowledgement}

I would like to show my gratitude and appreciation to my research advisor Dr. Shahab Mohaghegh for his advice, guidance, and encouragement during the course of this research.

My appreciation goes to Dr. Samule Ameri, and Dr. Razi Gaskari, who generously accepted to be a member of my thesis committee and all made significant contribution to this work. Their continuous and constructive critiques and suggestions have helped me a lot to improve this work.

Special thanks go to my professors in the PNGE Department for their support and for their time to share their knowledge with me. I express my thankfulness to the administrative associate of PNGE department, Beverly Matheny, for her kindness, friendship, and her presence to help the students.

Also, I would like to express my gratitude to Department of energy for financially supporting the Project and Intelligent Solution Inc. for providing us with IPDA, IDEA and IMAGINE softwares to perform the reservoir simulations in this work.

My profound gratitude is expended to my parents. Although they have been miles away from me I have always been supported by their understanding, trust and wholehearted help they have been giving to me.

This research was performed in support of the NETL-RUA- Project No. 4000.4.650.920.004, Reference No.: RES047, TPR-3280 


\section{Table of Contents}

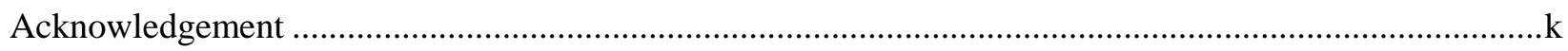

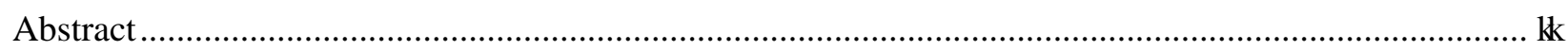

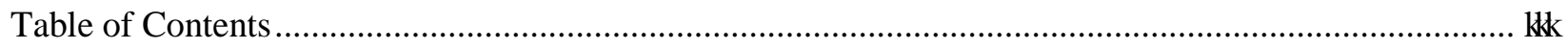

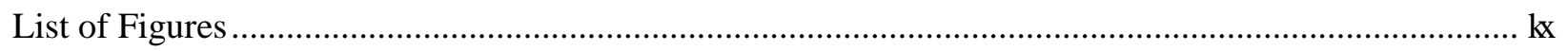

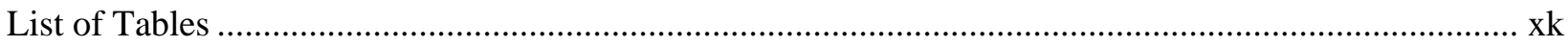

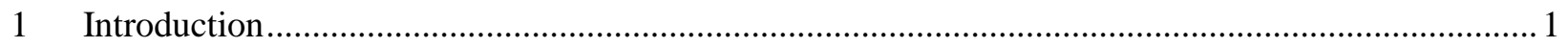

1.1 Unconventional Resources..............................................................................................

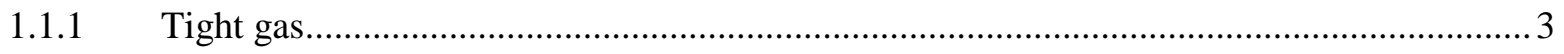

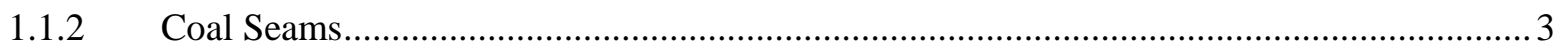

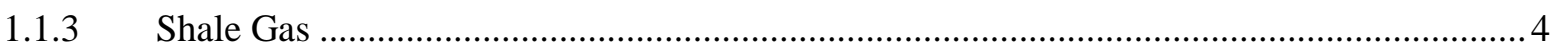

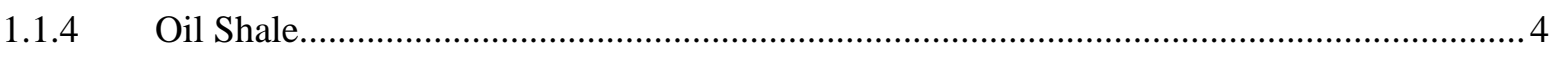

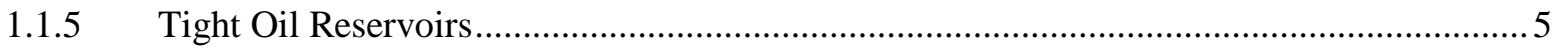

1.2 Bakken Formation..........................................................................................................

1.3 Well Completion and Stimulation in Bakken Formation............................................................ 10

$1.4 \quad$ Top-Down Intelligent Reservoir Modeling............................................................................... 12

1.5 Reservoir Management ………………………………………………………………..... 14

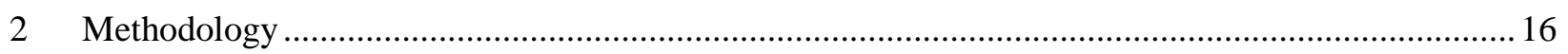

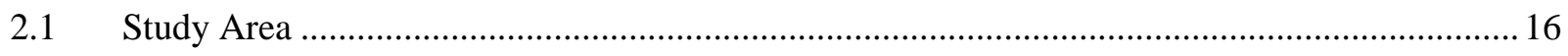

$2.2 \quad$ Static Reservoir Modeling ………………………………………………………………... 17

2.2.1 Fuzzy Pattern recognition ......................................................................................... 19

2.3 Intelligent History Matching - Predictive Modeling ………………………………………….... 21

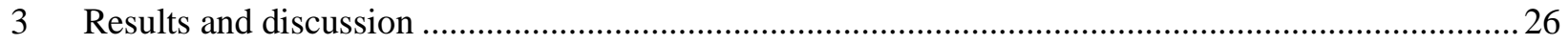

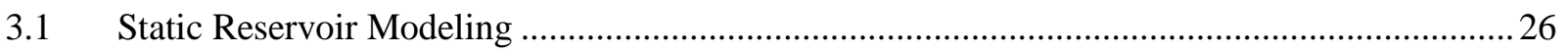

3.1.1 Results of Fuzzy Pattern Recognition ........................................................................... 27

3.1.2 Infill Drill Locations ............................................................................................... 28

3.2 Intelligent History Matching - Predictive Modeling …………………………………………... 32

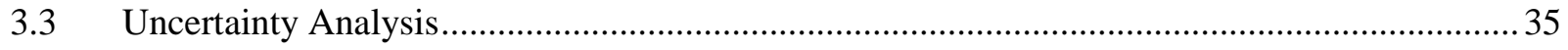

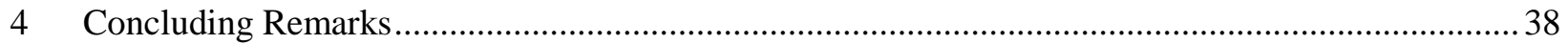

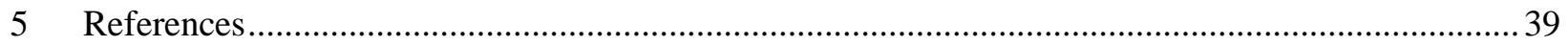

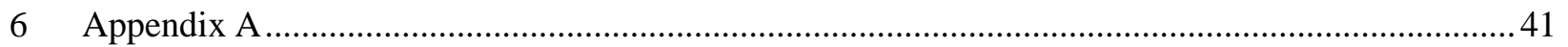




\section{List of Figures}

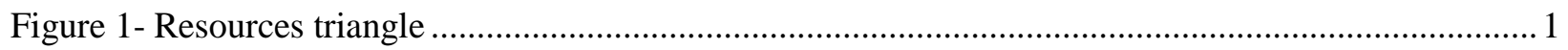

Figure 2- Distribution of Unconventional oil and gas plays in the United States (3) ................................. 2

Figure 3- Location of the Bakken Formation in Williston Basin (5) ....................................................... 5

Figure 4- Typical well log from Bakken formation - distinctly shows the configuration of all layers and

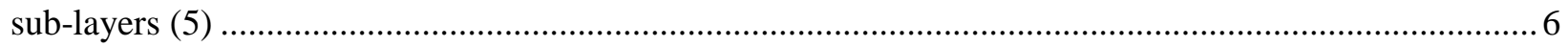

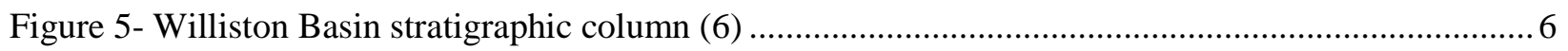

Figure 6- Structural map on the top of Bakken formation in North Dakota (5) ....................................... 7

Figure 7- Isopach map of Middle Bakken member in North Dakota (5) ................................................. 7

Figure 8- Isopach map of Upper Bakken member in North Dakota (5) ................................................ 8

Figure 9- Bakken Montana and North Dakota daily production rates since 1971(8) ................................. 8

Figure 10- Schematic of a well trajectory in Middle Bakken member ................................................... 11

Figure 11- Schematic of hydraulic fracturing treatment showing several numbers of tanks and pump

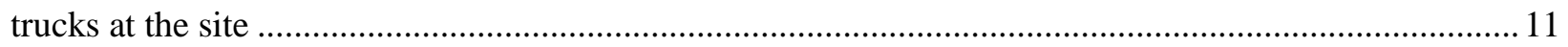

Figure 12- Certainties and uncertainties associated with Tradition and Top-Down Approaches of reservoir

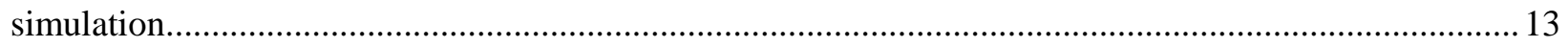

Figure 13- Schematic flowchart of Top-Down Intelligent Reservoir Modeling process........................... 14

Figure 14- Location of sections selected for modeling Upper and Middle Bakken layers in state of North

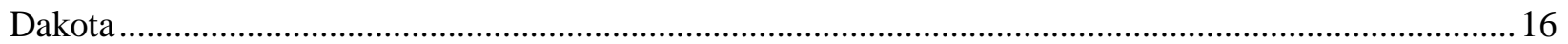

Figure 15- Steps of reservoir boundary identification and delineation (Middle Bakken model)................17

Figure 16- Geo models of measured log values for Middle Bakken member .........................................19

Figure 17- Geo models of measured log values for Middle Bakken member .......................................... 19

Figure 18- Process of delineation in Fuzzy Pattern Recognition technology ..........................................20

Figure 19- Tornado diagram shows average values and number/percentage of wells existing in different

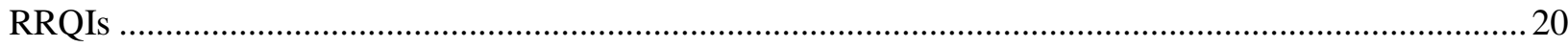

Figure 20- Greater length of exposure to rock surface in a horizontal well (A) than in a vertical well (B)

(21)

Figure 21- fracture initiation and intersection with wellbore (23) ........................................................2 23

Figure 22- Data Partitioning for building and history matching the Middle Bakken model .....................24

Figure 23- Data Partitioning for building and history matching the Upper Bakken model........................25

Figure 24- Results of Statistically Estimated Models of Middle Bakken for First 6 Months Cum.

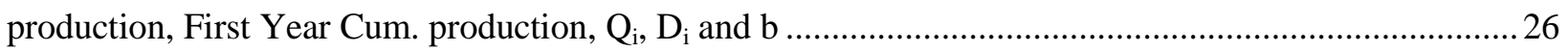

Figure 25- Results of Statistically Estimated Models of Upper Bakken for First 3 Years Cum. production,

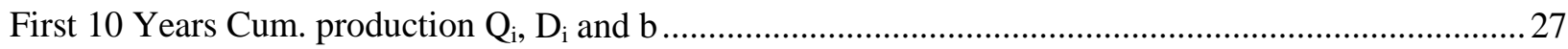

Figure 26- Fuzzy pattern recognition of Remaining reserve in Middle Bakken model as of 2010 to 202028

Figure 27- Location of proposed new wells in Middle Bakken model (15 new wells) ............................ 29

Figure 28- Location of proposed new wells in Upper Bakken model (12 new wells).............................. 29

Figure 29- Results of history matching for the well number 17040 in Middle Bakken............................ 32

Figure 30- Results of history matching for the well number 16671 in Middle Bakken............................ 32

Figure 31- Results of history matching for the well number 16905 in Middle Bakken............................. 33

Figure 32- Results of history matching for the well number 16936 in Middle Bakken............................. 33 
Figure 33- Field wide cumulative production (upper chart) and number of producing wells (lower chart)

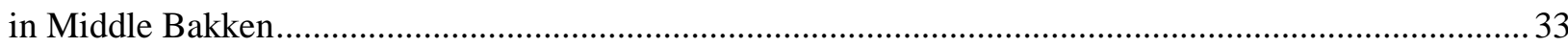

Figure 34- Results of history matching for the well number 9273 in Upper Bakken ............................... 34

Figure 35- Results of history matching for the well number 12484 in Upper Bakken ............................. 34

Figure 36- Results of history matching for the well number 12542 in Upper Bakken ............................. 34

Figure 37- Results of history matching for the well number 12570 in Upper Bakken ..............................35

Figure 38- Field wide cumulative production (upper chart) and number of producing wells (lower chart)

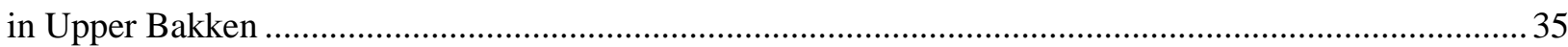

Figure 39- Effect of depth and lateral length on production rate (Middle Bakken model)........................ 36

Figure 40- Effect of volume of injected fracturing fluid and lateral length on production rate (Middle

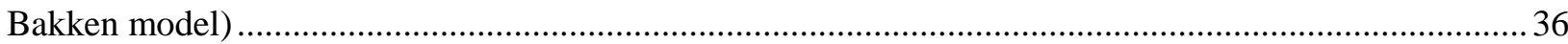

Figure 41- Effect of pay thickness and lateral length on production rate (Middle Bakken model) ............ 37

Figure 42- Effect of TOC and porosity log reading on production rate (Upper Bakken model)................ 37 


\section{List of Tables}

Table 1- List of data implemented in generation of comprehensive data set for the purpose of building intelligent model in Middle Bakken layer’s model.

Table 2- Name, type and source of different kerogens (24) .............................................................. 24

Table 3- List of data implemented in generation of comprehensive data set for the purpose of building intelligent model in Upper Bakken layer's model .............................................................................. 24 Table 4- Estimated results of production and recovery factor for the new wells in Middle Bakken Member

Table 5- Estimated results of production and recovery factor for the new wells in Upper Bakken Member 30

Table 6- Economical analysis in Middle Bakken model for new wells.................................................. 31

Table 7- Economical analysis in Upper Bakken model for new wells ................................................... 31 


\section{Introduction}

\subsection{Unconventional Resources}

Oil and gas have been supplying a significant energy demand of societies during the last centuries. A considerable fraction of energy demand at industries and homes has been supplied from oil and gas resources. Exploiting energy resources has always been restricted to economy of the process and available technology. Oil and gas production was started from shallower reservoirs which required fewer amounts of investment and lower level of technology. As time passed, technology was improved and rapid demand of energy with increase in oil and gas price motivated the oil and gas industries to exploit deeper and more challenging resources.

When looking for a natural resource, the best or highest-grade deposits are undersized and, once found, are easy to extract. The challenge is finding the high quality resources or in the case of our subject, highpermeability oil fields. Once a high-grade reservoir is found, extracting the oil is rather easy and straightforward. At the bottom of the resource triangle, the reservoirs are lower grade, which means the reservoirs have lower permeability. These low permeability reservoirs, however, are usually more vast than the higher quality reservoirs. As with other natural resources, low quality reservoirs require improved technology and adequate oil prices before they can be developed and produced economically. However, the amount of the reserve can be very large, when compared to conventional or high-quality reservoirs (1).

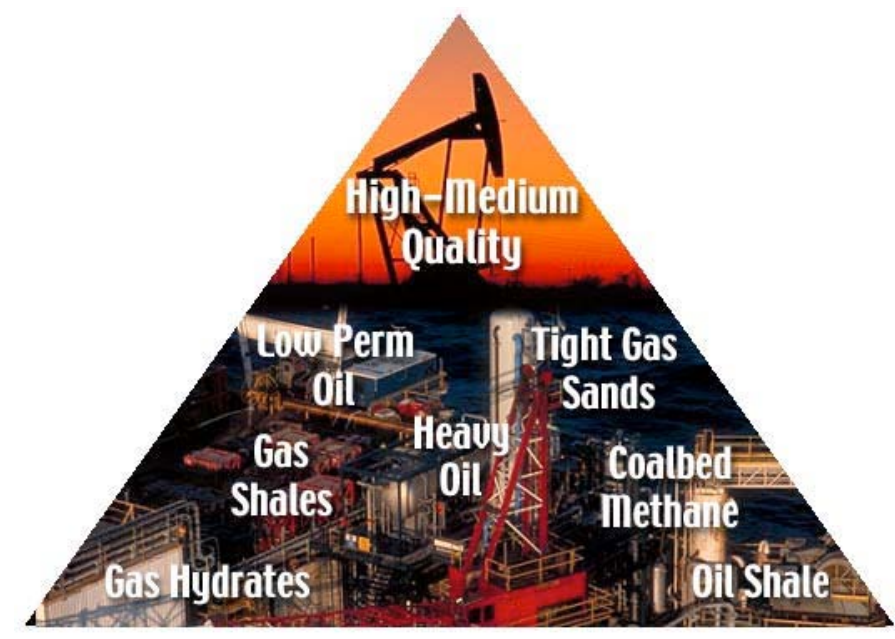

Figure 1- Resources triangle 
The resources have always been categorized into different classes based on ease of access. Access to the resources highly depends on the current technology. Conventional resources are those that are producible using the most developed technologies at the time (2). Unconventional resources are those that have not been considered economically feasible to be produced for decades.

Unconventional oil and gas resources encompass as follows:

- Tight oil and gas formations

- Coal bed methane

- Oil shale

- Shale gas

- Heavy oil

- Gas hydrates

Each of these resource plays requires special development strategies and must meet growing challenges of water availability and transportation to produce.

A very rough estimate of unconventional resources in the United States highlights 293 TCF of recoverable natural gas from coal bed methane and shale gas reserves in the lower 48 states (Figure 2). Significant amount of tight oil and gas plays in other parts of US and unconventional resource plays in Alaska and Gulf of Mexico supply a valuable domestic resource.

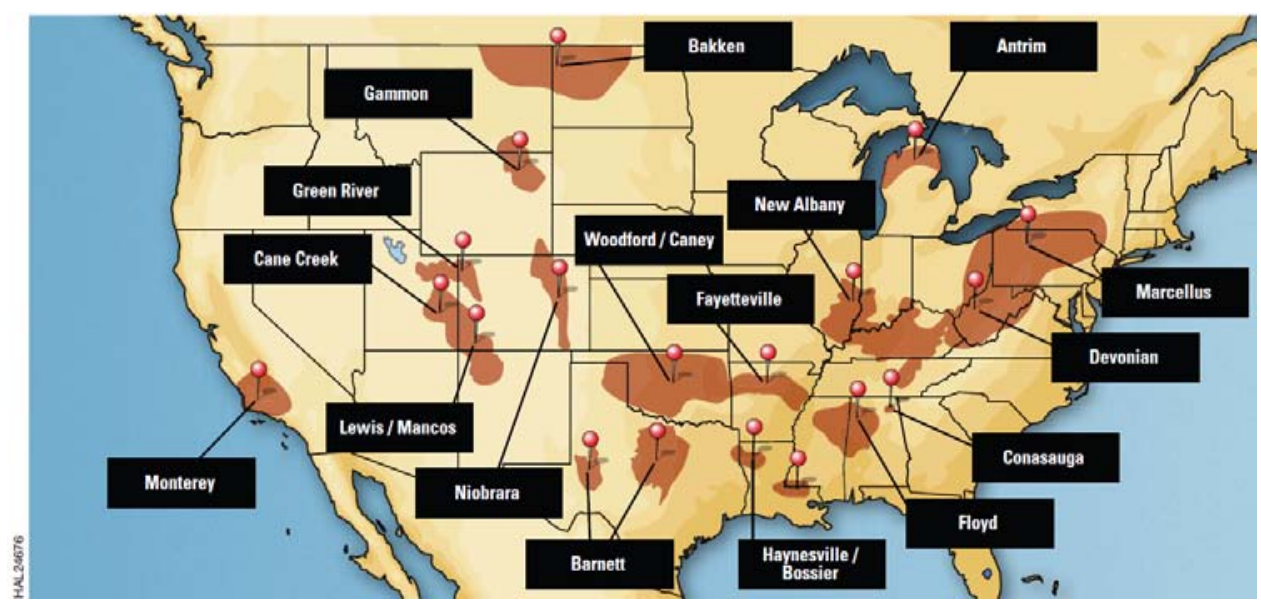

Figure 2- Distribution of Unconventional oil and gas plays in the United States (3) 


\subsubsection{Tight gas}

Tight gas sand resources are generally vast, but globally undefined. The magnitude and distribution of worldwide gas resources in gas shales, tight sands, and coalbed methane formations has not been determined yet. However there is some worldwide estimation as higher than 32,000 Tcf. The strength of this idea is supported by information and experiences with similar resources in North America. This estimate is most likely lower than unconventional gas reserve worldwide, because fewer data is available to evaluate the reserve abroad. As more resources are developed, more data will be available, and the estimates of worldwide unconventional gas volumes increase (2.)

Unconventional resources, defined as having low permeability and requiring advanced drilling or stimulation technologies to be produced at economical rates, have been one of main portion of the U.S. domestic natural gas supply for many years. Nowadays unconventional resources, mainly tight sands, grant almost 30\% of domestic gas supply in the United States. The gas production from unconventional resources in the United States is expected to increase vastly over the next 25 years, exceeding 9.0 Tcf per year. Since the technical challenges have been overcome for tight gas resources plays, they will provide a long-term gas supply. Development of these resources created a significant onshore exploration activity in the lower 48 states (2.)

\subsubsection{Coal Seams}

Production from coalbed methane resources is one of the best examples of how technology has affected the development of a natural gas resource. While existence of gas has been in coal stratum since the start of the coal mining industry, significant gas production has been realized since 1989. Although coalbed methane (CBM) was observed for many years, yet never produced and sold as a resource. New technology and researches finally solved the problem of resource complexity and unlocked its production potential. Only in United States 1.6 Tcf of gas is being produced per and is under development worldwide such as Canada, Australia, India, China, and etc. Similar factors control coalbed methane production behavior as for conventional gas resources from many angles. In coal seams natural gas adsorbs to the coal surface which allows significantly more gas to be stored than conventional rocks in shallow and lowpressure formations. A substantial pressure decrease is required for the adsorbed gas to be released from the coal seam formation. Volume of adsorbed gas is not important in conventional gas resources but is very important for CBM reservoirs. One of the main differences between coal seams reservoirs and sandstone gas reservoirs is that many of the CBMs are initially saturated with water. Therefore, the coal seams must be drained from water to reduce the pressure so that desorption occurs before gas production 
starts. Many countries worldwide have deposits of coal reserves. Over 70 countries have minable coal reserves that have potential CBM recovery. Worldwide estimation of gas in place of coal seams ranges from 2,400 to 8,400 Tcf. Having analogy of the United States, it is more likely to expect that coal seams hold potential for coal bed methane production worldwide. It should be noted that economically feasible coal mining takes place in relatively shallow coal seams. CBM production takes place in coal seams too deep to be mined (2.)

\subsubsection{Shale Gas}

Shale gas formations act as both a source and reservoir. Natural gas in shale occurs in three different forms: free gas in pores, free gas in natural fractures, and adsorbed gas on organic matter and mineral surfaces. These three storage mechanisms affect the rate and economy of gas production from gas shales. Recent estimates of the resource reveal an amount from 1,483 to 1,859 Tcf in the U.S., and 500 to 600 Tcf in Canada. Commercial production of shale gas occurs mostly in the USA, distributed in the Appalachian basin, Illinois basin, San Juan basin, Fort Worth basin, and Michigan basin (2.)

\subsubsection{Oil Shale}

Oil shales are sedimentary rocks which are rich in kerogen. By heating oil shales, they release petroleum liquids due to a chemical process called pyrolysis. Since the late 1970s the enormous potential for recovery from oil shale deposits has been recognized in Colorado, Utah and Wyoming. The Green River Formation hold the largest oil shale reserve in the world, with an estimated reserve of 1.2 to 1.8 trillion equivalent barrels. A rough estimate of recoverable oil in the Green River Shale 800 million barrels which is three times the proven oil reserves of Saudi Arabia.Oil price increase in the 1970s,1980 and 2008 have periodically increased the interest of oil companies in developing oil shale resources by improving their production technologies. Production from Oil Shale resources takes place in two different methods: roomand-pillar method or surface mining. In a process called retorting, the mined rocks will be heated such that oil fraction separates from mineral part. The oil must be upgraded in further processes before being sent to refineries. Oil shale can be mined using one of two methods: underground mining using the roomand-pillar method or surface mining. After mining, the oil shale is transported to a facility for retorting, a heating process that separates the oil fractions of oil shale from the mineral fraction. After retorting, the oil must be upgraded during further processing before it can be sent to a refinery, and the spent shale must be disposed of (2.) 


\subsubsection{Tight Oil Reservoirs}

Bakken shale formation is the most significant tight oil play in the United States. The Bakken formation is an oil-bearing stratum which covers parts of Montana and North Dakota in its US share. Production from Bakken started more than 50 years ago. Bakken formation is comprised of three distinct layers (Upper, Middle and Lower members). The Middle member of the Bakken Formation is very fine- to finegrained argillaceous, dolomitic sandstone to siltstone (4). The Middle member lies between two black Upper and Lower shale members of the Bakken. Based on the latest release of USGS in 2008, the undiscovered resources of Bakken formation in US part is estimated to be 3.65 billion barrels of oil and relevant amount of associated gas. The latest estimate was 25 times higher than the previous estimate in 1995 of 151 million barrels. The reason of increase in this estimated value was the unique success of hydraulic fracturing and horizontal drilling in this field.

\subsection{Bakken Formation}

The Bakken formation belongs to late Devonian / early Mississippian age, covering 200,000 square miles of Williston basin in North Dakota and Montana continued up to Canada. Figure below shows the location of Bakken formation in Williston basin.

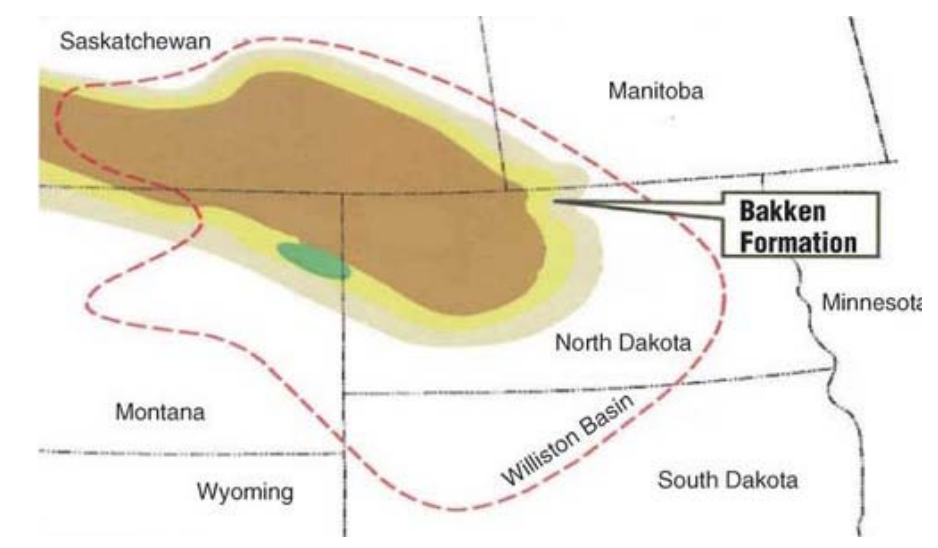

Figure 3- Location of the Bakken Formation in Williston Basin (5)

Figure below shows a typical density log of Bakken formation. Configuration of Upper and Lower shale members and Middle member are clearly highlighted in this picture. 


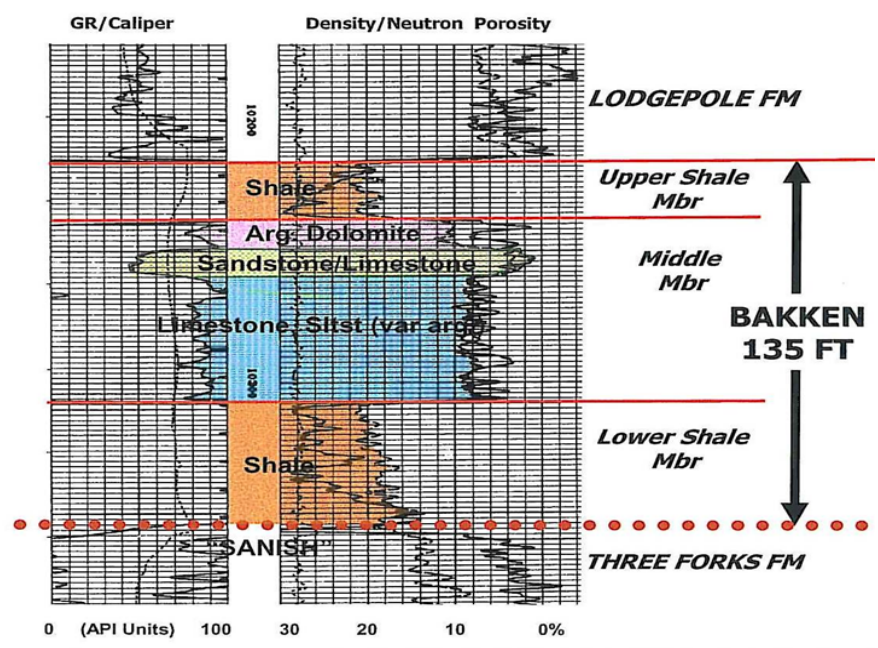

Figure 4- Typical well log from Bakken formation - distinctly shows the configuration of all layers and sub-layers

(5)

Stratigraphic Map of Williston basin is shown in figure below. Bakken formation's position is highlighted in the column.

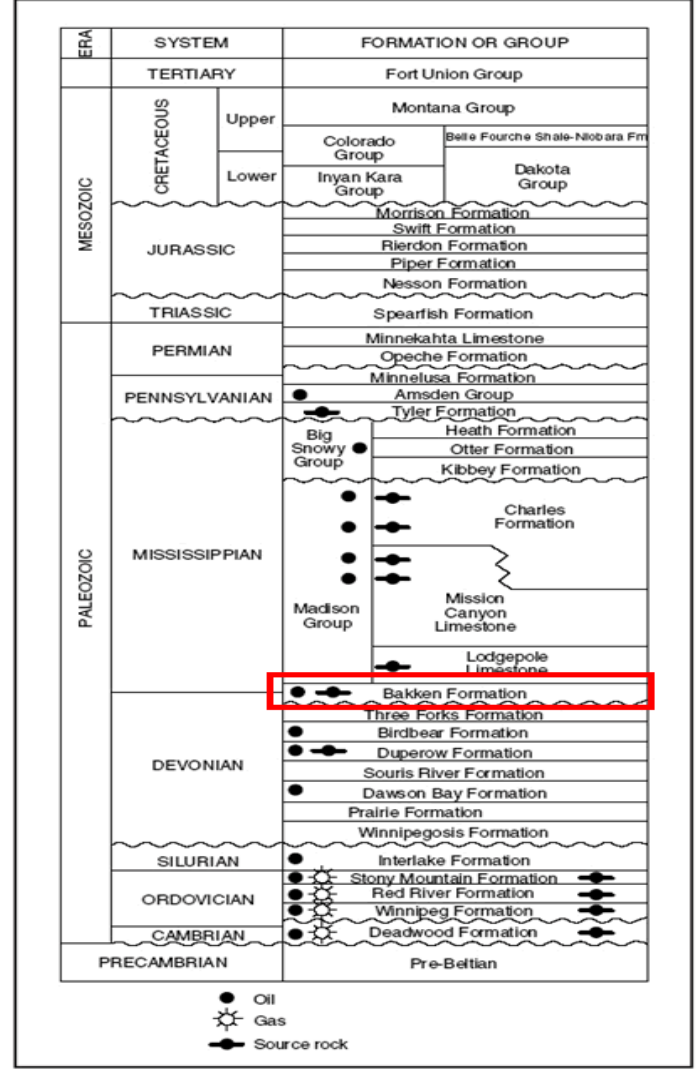

Figure 5- Williston Basin stratigraphic column (6)

Bakken formation may be observed in a wide range of depths over North Dakota state. Bakken formation in the study area of this research was found at the depth range of 9,000 to 10,600 $\mathrm{ft}$ (Figure 6). 


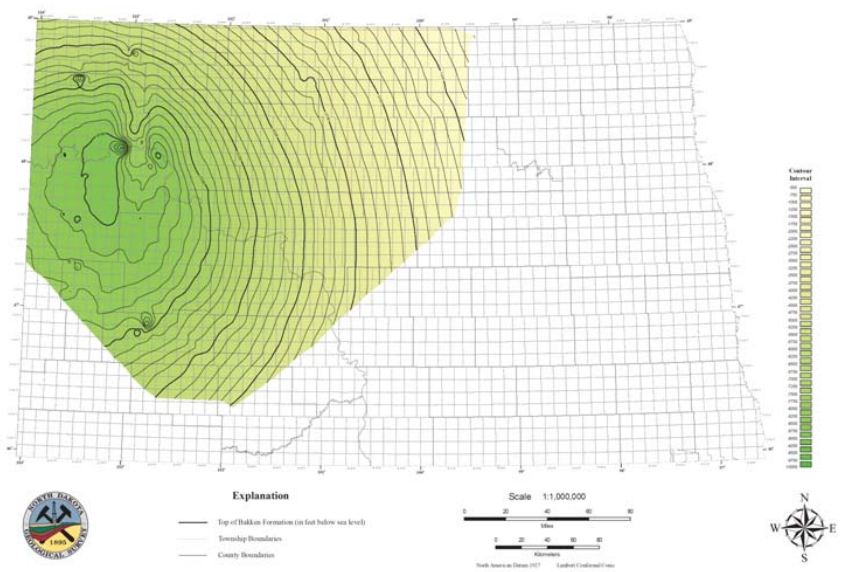

Figure 6- Structural map on the top of Bakken formation in North Dakota (5)

The thickness of Middle Bakken member increases as we go more North-West (Figure 7). The thickness of Middle Bakken member in this study area varies from 20 to $70 \mathrm{ft}$.

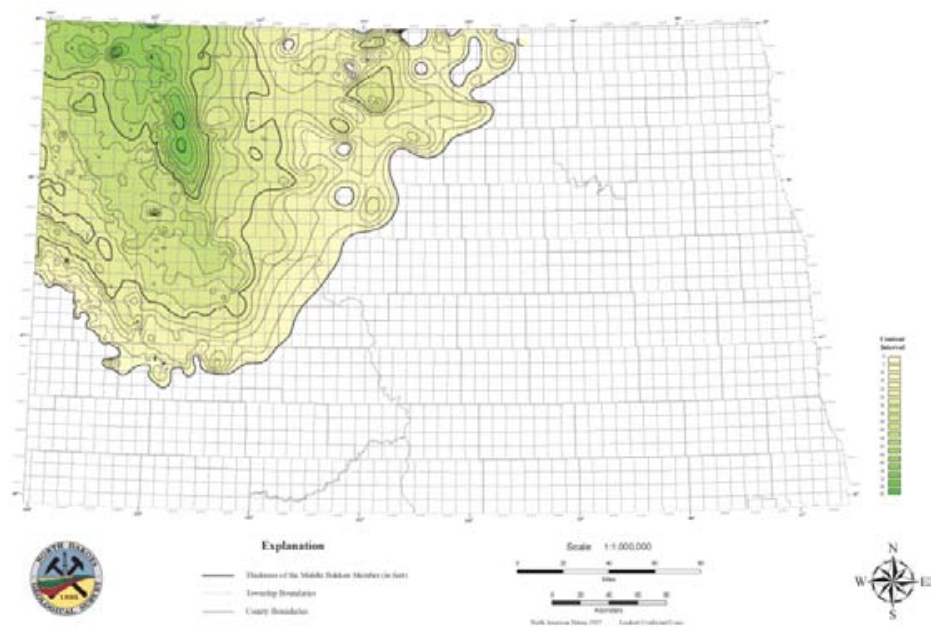

Figure 7- Isopach map of Middle Bakken member in North Dakota (5)

The thickest part of Upper Bakken member in its North Dakota share is located at the center of the basin (Figure 8). The thickness of Upper Bakken member in the study area varies from 4 to $12 \mathrm{ft}$. 


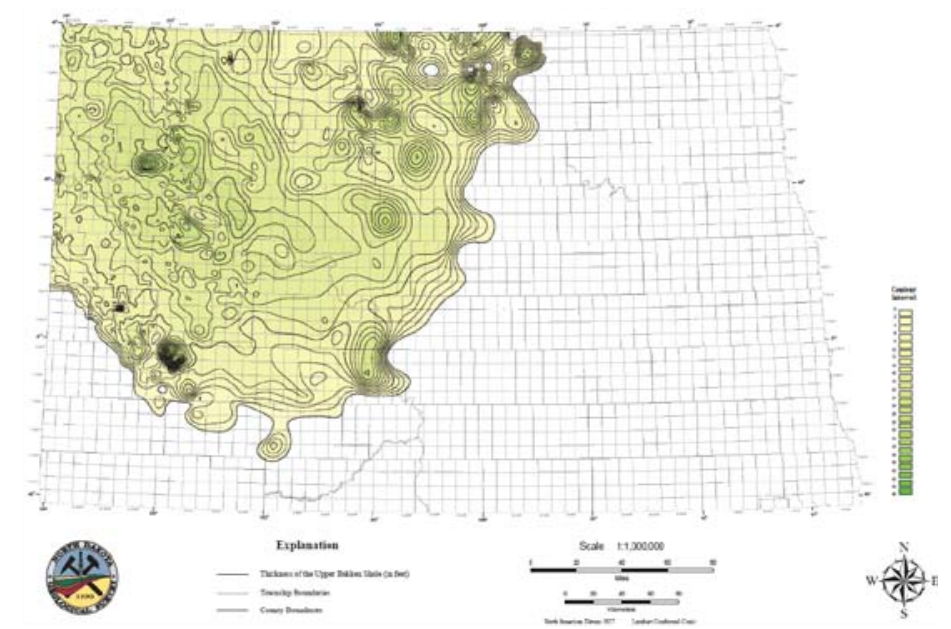

Figure 8- Isopach map of Upper Bakken member in North Dakota (5)

Bakken formation is a relatively tight sedimentary rock with average porosity of $5 \%$ and average permeability of $0.04 \mathrm{mD}$ (7) As a result of such low porosity and permeability, the recoverable reserve was estimated too low until latest report of USGS. The latest reports stated a huge change in reserve influenced by technology advancement in the last decades. Extensive application of horizontal drilling and hydraulic fracturing has brought lots of attention to the Bakken formation. Figure below shows daily production of Bakken formation in North Dakota and Montana since 1971.

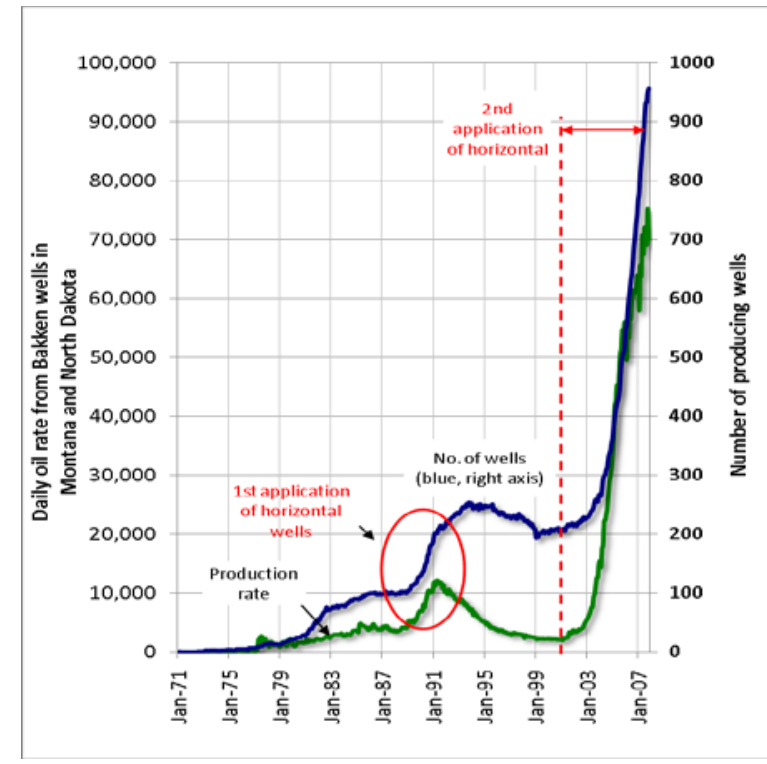

Figure 9- Bakken Montana and North Dakota daily production rates since 1971(8)

This figure clearly shows how production from Bakken formation has been increased after application of horizontal drilling. 
There is a complete agreement that the Bakken Formation is a tremendous source rock. Although we still doubt how much oil has been generated, the formations that Bakken may have sourced, and amount of ultimate recovery. Early research on the Bakken started with a work by Wallace Dow, a University of North Dakota Geology graduate, who concentrated on the oil generation capacity of the Bakken shale. Since that time, several additional papers have re-evaluated the Bakken, each of them has been discussing how much oil has been generated and how much is possibly recoverable (9.)

A breaking news paper by Dow and an accompanying paper by Williams (1974) recognized the Bakken as a tremendous source for the oil production in the Williston Basin. Based on the discussion in these papers, Bakken was found to be capable of generating 10 billion barrels of oil (BBbls). As result of a work by Webster $(1982,1984)$ which was a part of a Master's Thesis at the University of North Dakota, Bakken formation was further sampled and analyzed. Webster estimated the hydrocarbon generation to be about 92 BBbls. Next update was released by Schmoker and Hester (1983) who estimated 132 BBbls of oil generation capabilities in North Dakota and Montana. In an unpublished study, Price used a more complete database and estimated between 271 and 503 BBbls of oil with an average of 413 BBbls. The latest estimates of hydrocarbons generated by the Bakken were presented by Meissner and Banks (2000) and by Flannery and Kraus (2006). The first study tested a new computer model which utilized Bakken data and estimated generated oil of 32 BBbls. Flannery and Kraus applied a more sophisticated computer program with extensive data input supplied by the ND Geological Survey and Oil and Gas Division. Early estimation from this information was 200 BBbls which was later revised to 300 BBbls (9.)

When oil generation in organic-rich, low permeability shales starts, petroleum fluid which is non conductive, replaces the conductive pore brine. As a result of this migration, formation resistivity increases from low levels and can reach hundreds of ohm-m if considerable amount of oil is generated to displace most pore brine. Therefore, the formation resistivity is a sign for in situ petroleum formation.

In 1989, a paper was published by: James W. Schmoker and Timothy C. Hester from US geological survey (10)

Upper and lower shale members of the Upper Devonian and Lower Mississippian Bakken Formation were studied in this study. Increase in percentage of volatile hydrocarbons in core samples was observed at resistivity of about 35 ohm-m in these organic-rich shales. This resistivity value may be used to identify thermally mature regions of the Bakken Formation (10).

Based on crossplots of formation resistivity versus vitrinite reflectance (Ro) in the upper Bakken, the level of thermal maturation of about about $\mathrm{R}=0.44 \%$ is required to initiate oil generation, whereas in the lower memBer is about $\mathrm{R}=0.50 \%$. The $35 \mathrm{ohm}-\mathrm{m}$ resistivity contour of the lower Bakken member shifted 20-25 mi (32-40 km) relative to contour of the upper member, which indicates that slightly higher level of thermal maturation required to initiate oil generation in the lower member. 
Dimensionless analysis of integrated time-temperature history which can be indicated from crossplots of formation resistivity versus Lopatin's time-temperature index (TTI) show that the level of timetemperature exposure of about TTI=ll required to initiate oil generation in the upper member, whereas about TTI=23 for Lower member (10).

The extensive application did not happen until April 2006 (5). That was the time when Bakken formation became more attractive for the producers. Since then, most of the researches on Bakken formation have been focused on design of drilling and completion in the formation. A very recent study on experiences of a company in application of horizontal drilling and hydraulic fracturing in Bakken formation was published in SPE ATCE 2010. Authors in this study try to investigate experiences from almost 150 wells which were drilled in Bakken or Three Forks formations (11.) the progress of this study increased well production from 300 BOEPD in initial wells to recent wells of 5,000 BOEPD. Finding and development costs in this field were reduced from about $\$ 40$ to $\$ 15$. As a result of this study, effect of multilateral completion was found less cost-effective than single lateral completion with multiple transverse fractures. Recommendation of this study is lateral length of 9,500 $\mathrm{ft}$ and some specific completion and stimulation materials (11.)

\subsection{Well Completion and Stimulation in Bakken Formation}

The oil production from Bakken formation has significantly increased after the intensive application of horizontal drilling and hydraulic fracturing during the last decade (8). Horizontal lateral opens up greater exposure to the formation and hydraulic fracturing generates fractures which facilitate fluid flow to the wells. Hydraulic fracturing technology has been applied to latterly drilled wells (cases present in this study are mostly completed in Middle Bakken member.)

Lateral length of the wells present in this study ranges from $1200 \mathrm{ft}$ to $13,000 \mathrm{ft}$ in Middle Bakken hundreds of feet to 10,000 ft in Upper Bakken (Figure 10.) 


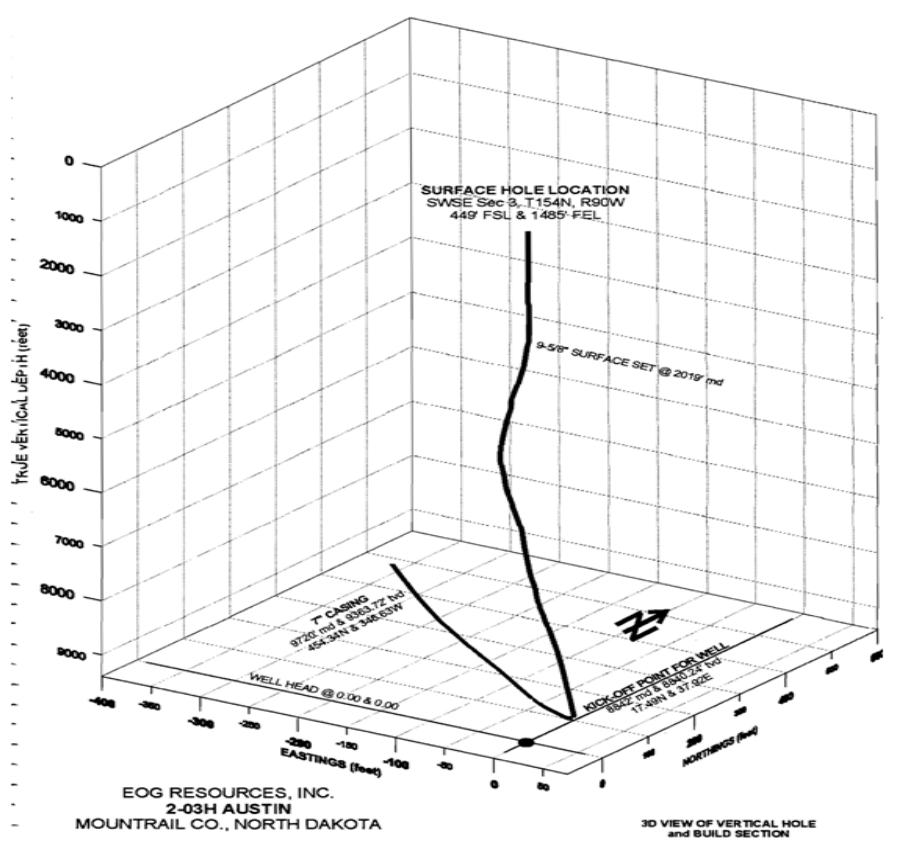

Figure 10- Schematic of a well trajectory in Middle Bakken member

Application of advanced drilling and completion technologies in Bakken formation is relatively expensive. Recent wells drilled in Bakken formation are having as long as 10,000 ft of horizontal leg and several stages of hydraulic fracturing. Hydraulic fracturing process requires huge amount of injecting fluid whose base is mostly water or gasoline. Several pump trucks inject the fracturing fluid at high rate and pressure in order to reach the yield point of formation (Figure 11).

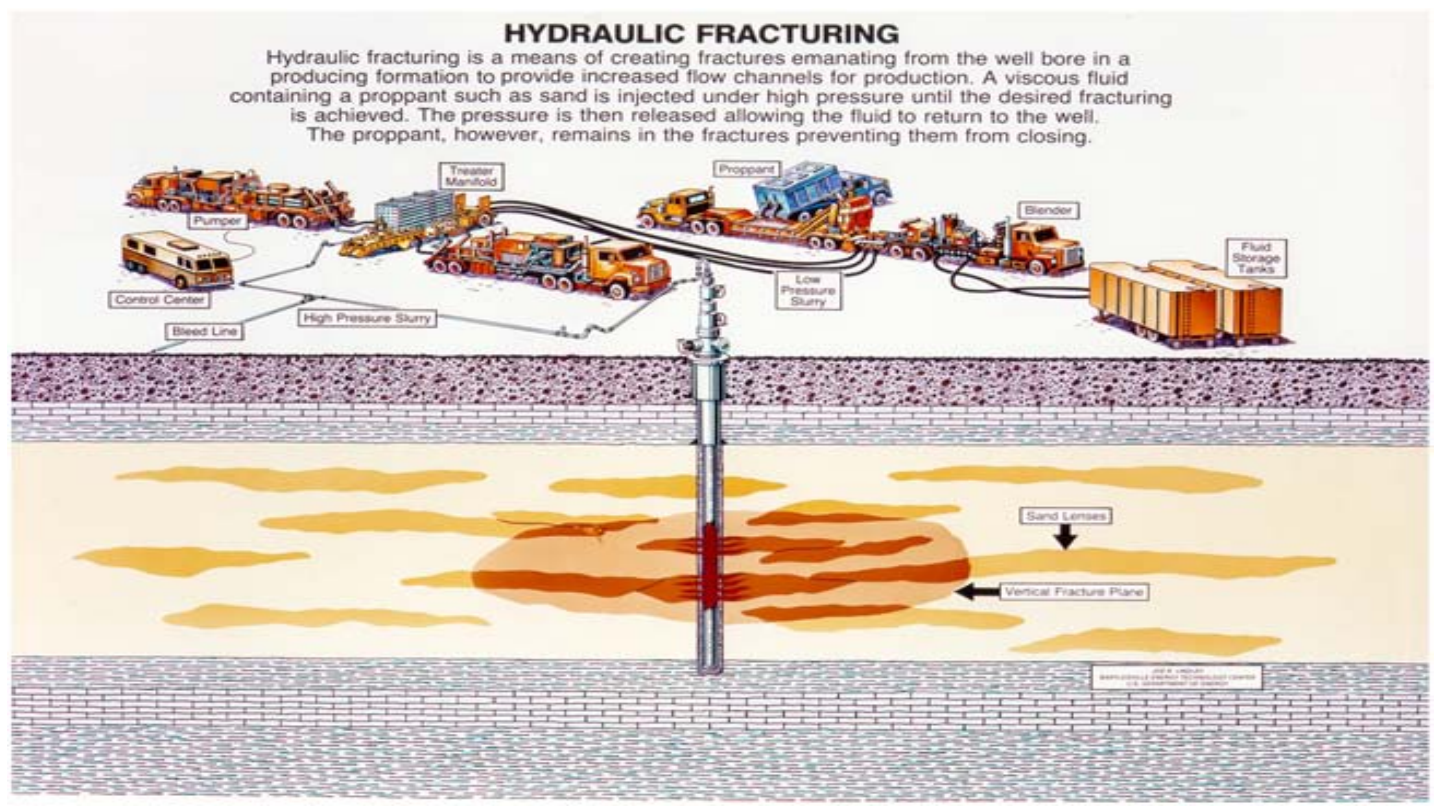

Figure 11- Schematic of hydraulic fracturing treatment showing several numbers of tanks and pump trucks at the site 
The most recent released amount of drilling cost in Bakken formation is between 3,500,000 to \$5,000,000 (14). Therefore, economical considerations are the most important issues in development of the field.

\subsection{Top-Down Intelligent Reservoir Modeling}

Traditional reservoir simulation and modeling is the science of understanding the reservoir behavior and predicting the future of the field. Reservoir models are set of evaluated and calculated data which are combined and analyzed using certain correlation. The fluid flow correlations keep functional relationship between reservoir characteristics, completion data and production constrains. In this study, Top-Down Intelligent Reservoir Modeling has been utilized in order to generate a cohesive reservoir model which is coordinated such that it can be implemented in field development. In Top-Down Intelligent Reservoir Modeling, solid reservoir engineering techniques are coupled with geostatistic, data mining and artificial intelligence $(15,16)$. A comprehensive reservoir model is generated which will be applied as the foundation of decision makings in the future. Like any other data driven method, the reliability of the results of Top-Down Intelligent Reservoir Modeling technique is highly dependent on the accuracy of data preparation task.

Top-Down Modeling is comprised of several tasks which can be listed as follow:

- Data Preparation

- Reservoir Boundary Identification and Delineation

- Volumetric Calculation

- Geostatistics

- $\quad$ Decline Curve Analysis

- $\quad$ Field Wide Pattern Recognition

- Intelligent History Matching

- Infill Location Determination

- Economical Analysis

Data preparation is one of the most crucial tasks when performing Top-Down Intelligent Reservoir Modeling. Reservoir characteristics and production data are the most frequent type of the data utilized in reservoir simulation. Forecasting the production of existing and upcoming wells is a key to successful development strategies. Production forecasting vastly depends on the extent of our understanding about productivity and accessibility of hydrocarbon all around the field. Decline curve analysis technique is implemented to analyze the production behavior of the wells. The results of decline curve analysis will afterward be part of a data set which forms the reservoir model. 
In both conventional reservoir modeling and Top-Down Modeling, reservoir characteristics are uncertain. Reservoir characteristics are result of sets of laboratory measurements and log interpretations in which lots of uncertainties are involved. Another and the main difference between Top-Down modeling and numerical modeling is in governing functional relationship between reservoir characteristics and production. In traditional reservoir simulation in which Darcy's law governs the relation between reservoir characteristics and production data and is fixed. However in Top-Down modeling artificial intelligence recognizes the relation between the data and is subject to change during history matching process (Figure 12).

\begin{tabular}{|c|c|c|}
\hline & Numerical Model & Top-Down Model \\
\hline $\begin{array}{l}\text { Reservoir } \\
\text { Characteristics }\end{array}$ & $\begin{array}{l}\text { Uncertain: } \\
\text { - Measurements } \\
\text { - Interpretations } \\
\text { (subject to modification during the } \\
\text { history matching) }\end{array}$ & $\begin{array}{l}\text { Uncertain: } \\
\cdot \text { Measurements } \\
\text { - Interpretations } \\
\text { (subject to modification during } \\
\text { the history matching) }\end{array}$ \\
\hline $\begin{array}{l}\text { Functional } \\
\text { Relationships }\end{array}$ & $\begin{array}{l}\text { Certain: } \\
\text { - Conservation of Mass } \\
\text { - Darcy's Law } \\
\text { (unchanged during the history } \\
\text { matehing) }\end{array}$ & $\begin{array}{l}\text { Uncertain: } \\
\text { - Relationship between } \\
\text { reservoir characteristics } \\
\text { and production. } \\
\text { (subject to modification during } \\
\text { history matching) }\end{array}$ \\
\hline
\end{tabular}

Figure 12-Certainties and uncertainties associated with Tradition and Top-Down Approaches of reservoir simulation

In Top-Down modeling we usually start with collecting the data and preparation of comprehensive data set. Static and predictive models will be built afterwards and predictive model is history matched. Using different design tools such as fuzzy pattern recognition or statistic predictive models, we are able to make development decisions and forecast the production. The resulting prediction will be afterwards utilized in the model for further predictions (Figure 13). 


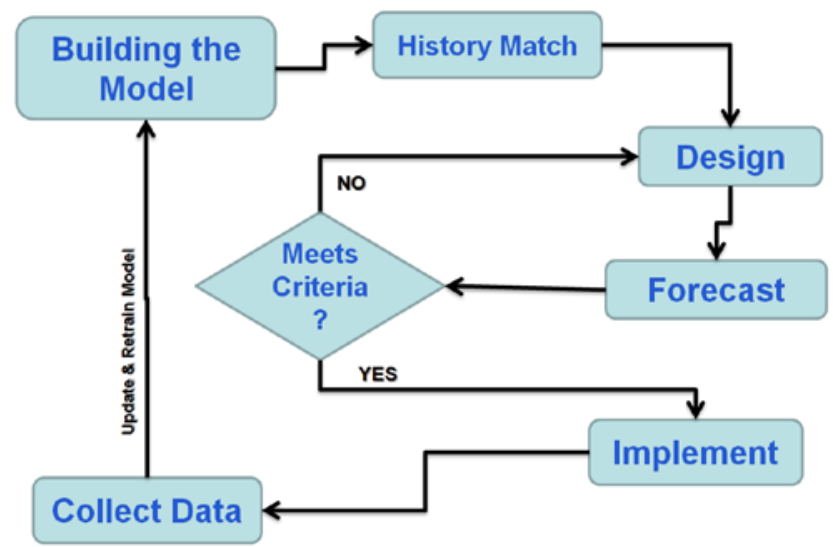

Figure 13- Schematic flowchart of Top-Down Intelligent Reservoir Modeling process

There are several advantages and disadvantages associated with Top-Down modeling listed below.

Advantages:

- $\quad$ Minimum data requirement

- Short development time

- Simplicity of analysis

- Organic in nature

Disadvantages:

- $\quad$ Not applicable to Green Fields

- Requires tens of wells (more than 35)

- $\quad$ Long production history is required(more than 2 years)

\subsection{Reservoir Management}

Petroleum reservoir management is the application of state of- the-art technology to exploit a reservoir while minimum capital investment and operation cost is used to achieve the maximum economic recovery of oil or gas from the field. Reservoir management is comprised of set of operations and decisions, by which a reservoir is identified, estimated, developed and evaluated from its exploration through depletion (18.) Development of a field primarily starts with drilling some exploratory wells in the field. More wells will be drilled when productivity of the field was proved. There are many aspects which should be considered when making decisions for development of a field. Reservoir properties, geological and environmental consideration are the keys to field development. 
In this study, Top-Down Intelligent Reservoir Modeling has been utilized in order to generate a cohesive reservoir model which is coordinated such that it can be implemented in field development. 


\section{Methodology}

Two concurrent approaches of Top-Down modeling were carried out in this study. One "Static Reservoir Model” and an “Intelligent History Matched-Predictive Model” were generated.

In the static reservoir model, a set of volumetric and geo-models were built, then fuzzy pattern recognition was performed. This part of study is a combination of production analysis (decline curve analysis (DCA)), production statistics, volumetric analysis, geostatistics and data clustering. Static models can provide us with general maps of the reservoir and verify distribution of reservoir characteristics. Geostatistical maps of DCA parameters and clustered cumulative production has been generated. Geostatistical results of production behavior which provides us with grid based models can be used as estimative models to determine production of new wells in the field. Economical analysis was also performed in order to obtain estimated rate of return for new wells.

Reservoir characteristics, completion data and production strains and reports are employed for training an intelligent model. The model correlates static information with production data. A spontaneous process of history matching and creating a predictive model is carried out. An intelligent model is built which carries completion information and reservoir characteristics. The intelligent model is trained, calibrated and verified using the static and dynamic information of the field. The process of generating an appropriate trained intelligent model can be carried out consecutively until the least error in calibration results is achieved.

\subsection{Study Area}

Two different sections of the formation were selected for modeling Middle and Upper members of Bakken. One of the study areas is having all the wells completed in Upper Bakken and the other one in Middle Bakken. Locations of selected areas are shown in the following figure.

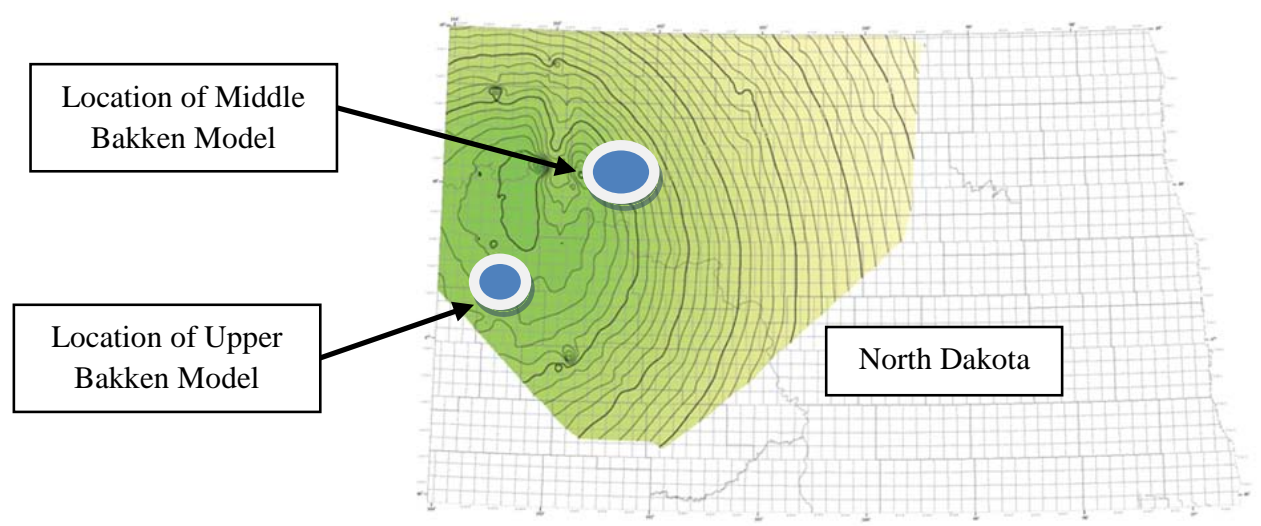

Figure 14- Location of sections selected for modeling Upper and Middle Bakken layers in state of North Dakota 
Two different models are generated for two sections. The Upper Bakken model has an area of 68,000 acres and the Middle Bakken model's area is 165,000 acres.

\subsection{Static Reservoir Modeling}

Location of the existing wells is shown in the maps below. The reservoir model was delineated into 5 acre square grids. Reservoir boundary was identified considering location of the wells. Using voronoi graph theory, the reservoir has been delineated into segments around the wells; each section has been assigned to be drainage zone of each well.

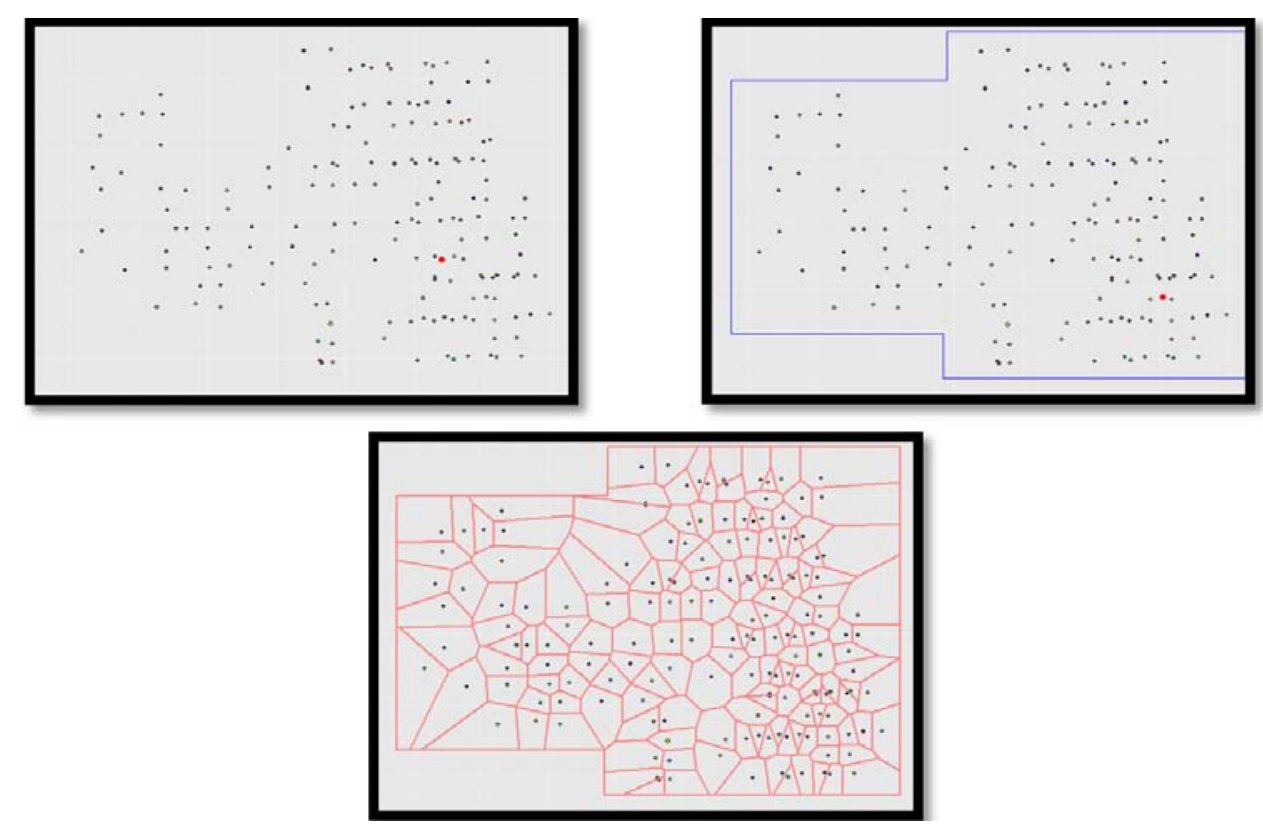

Figure 15- Steps of reservoir boundary identification and delineation (Middle Bakken model)

Production data from the wells have always been a valuable data for petroleum engineers. The production from a field is the final goal and brings lots of evidences with it to the surface. Rate is the most real response of nature to the producer. Trend of changes in production tells us about depletion of the reservoir. Declination models of production have been studied widely in the past. Arps (19) presented a set of rate-time decline curves. Arps decline equation is

$$
q=\frac{q_{i}}{\left(1+\mathrm{b} \mathrm{D}_{\mathrm{i}} \mathrm{t}\right)^{1 / \mathrm{b}}}
$$

Reservoir characteristics are measured from logs. Different log readings at the location of wells were measured to generate a well based data set for reservoir characteristics. 
Well logs were downloaded from the website of North Dakota Geological Survey. At some parts of the formation the Middle Bakken layer itself is comprised of three distinct lithologies, a dolomitie layer on top, a middle Sandstone/Limestone and lower part which is mostly Limestone/Siltstone. Although these different layers have different characteristics, the values of different characteristics were averaged through the layer. Log readings of each sub-layer (lithology) were assigned a weight based on its thickness. For example at a point where limestone sub-layer has a thickness of $20 \mathrm{ft}$ and the total thickness of Middle Bakken is 50ft, a weight factor of 20/50 has been assigned to the log readings of limestone layer.

Using geostatistics, well based data set was transformed to respective grid based models. Reservoir characteristic maps have been generated as shown in following figures.

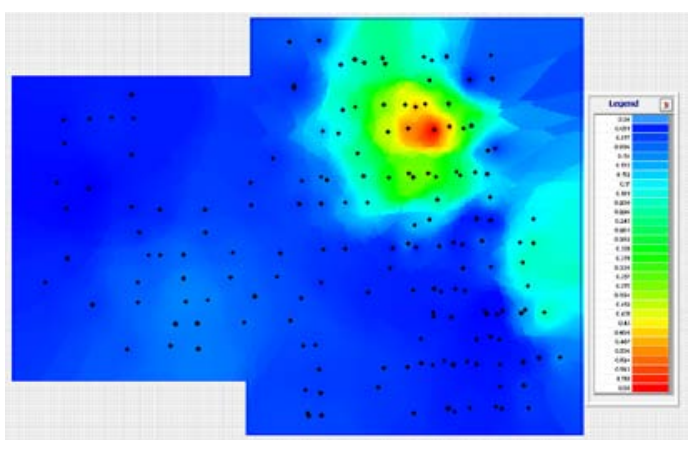

Density Porosity

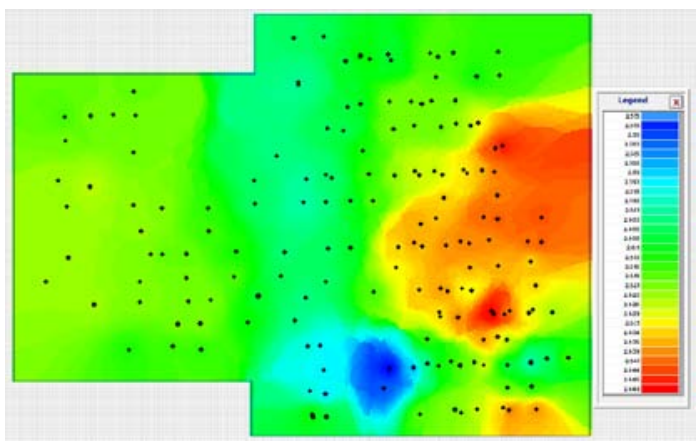

Bulk Density

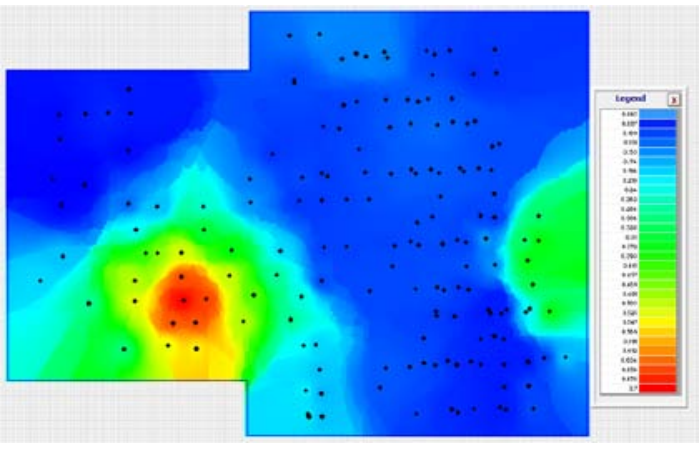

Neutron Porosity

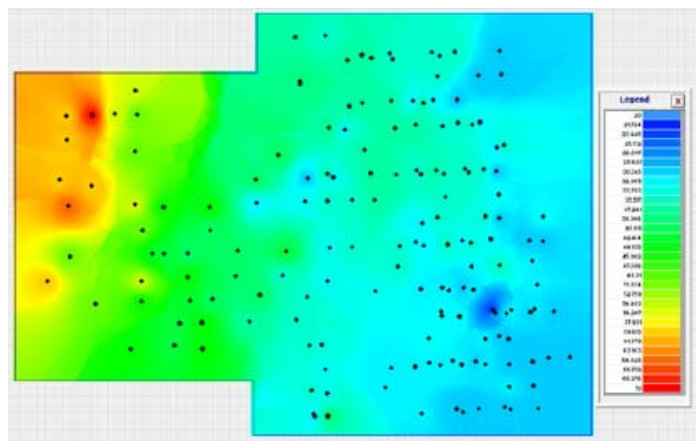

Pay Thickness 


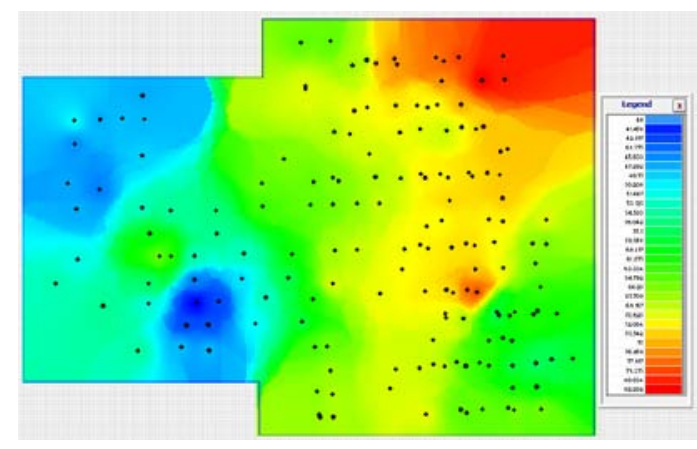

Gamma Ray

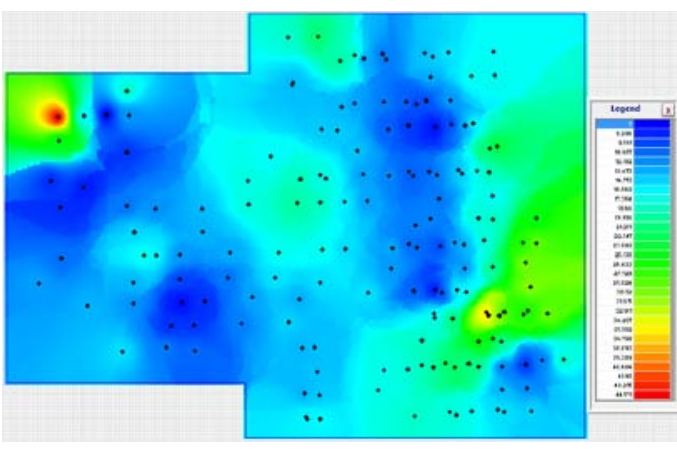

Resistivity

Figure 16- Geo models of measured log values for Middle Bakken member

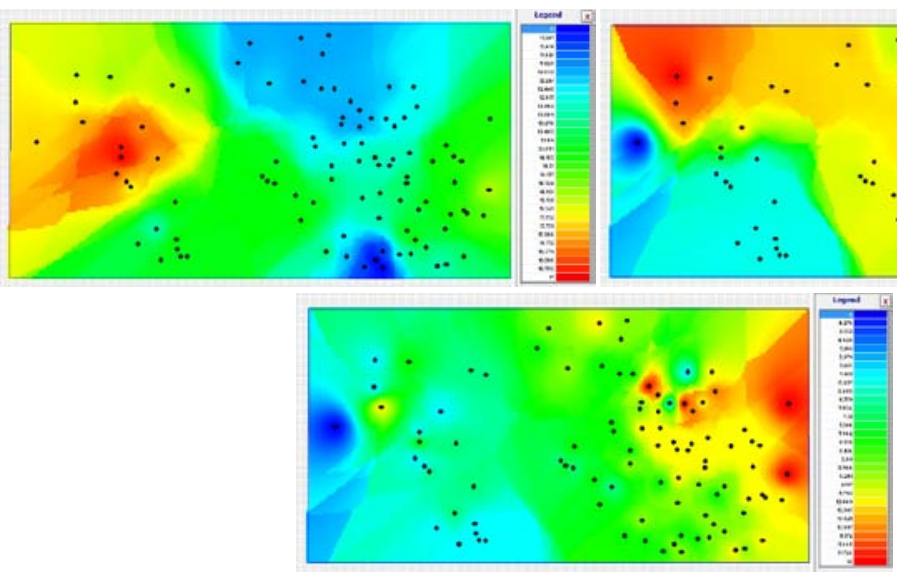

Figure 17- Geo models of measured log values for Middle Bakken member

Volumetric analysis, which acquires its rudiments from results of decline curve analysis and reservoir characteristics, has been implemented to calculate original oil in place, remaining hydrocarbon in place and recovery factor. Well based and field wide recovery factors were calculated.

\subsubsection{Fuzzy Pattern recognition}

After completion of abovementioned steps, fuzzy pattern recognition has been performed. This technology enables us to delineate the reservoir qualitatively. This technology is also applicable to recognition of sweet spots in the reservoir. As result of pattern recognition approach, the reservoir will be delineated into different quality sections. Respective relative reservoir quality index (RRQI) will be assigned to each delineated portion.

In Fuzzy Pattern recognition, actual data is plotted along latitude and longitude of the model. Gray dots in figure below show actual data. as we see, there is no specific trend recognizable in actual data. Using 
Fuzzy Logic, a pattern is discovered in data (pink dots) as shown in the figure. Discovered pattern will be delineated into three clusters of High, Medium and Low values (both longitudinally and latitudinal). The intersection of delineated patter and delineation lines are thereafter superimposed on a two dimensional map. Where High Longitudinal delineate meats High Latitudinal delineate, is the highest quality index region, called High-High region.

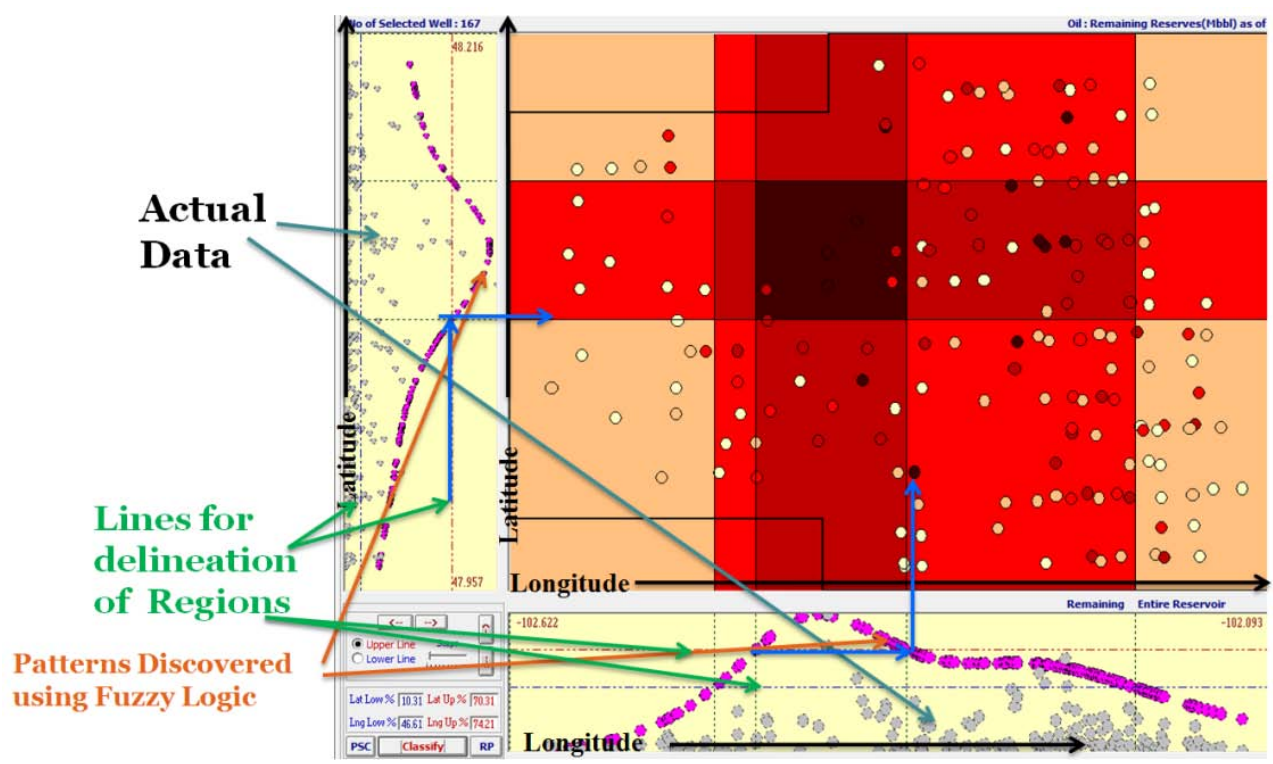

Figure 18- Process of delineation in Fuzzy Pattern Recognition technology

By superimposition of all the intersecting point on the two dimensional map, we will get all quality indexes. Different relative reservoir quality indexes will be recognized and the reservoir will be delineated qualitatively. Different quality regions are painted differently to be easier distinguished. Darker colors show higher qualities for the selected property.

\begin{tabular}{|c|c|c|c|c|}
\hline \multirow{2}{*}{ Partition Type } & \multirow{2}{*}{ RRQI } & \multicolumn{2}{|c|}{ Remaining Reserves[Mbbl] as } & \multirow{2}{*}{$\begin{array}{c}10 / 11 / 2015-0 i l \\
\% \text { Wells }\end{array}$} \\
\hline & & Arg. Value & if wells & \\
\hline High-High & 1 & 3.478 .890 & 4 & 2.4 \\
\hline High-Mid & 2 & 1.026 .825 & 33 & 19.76 \\
\hline High-Low \& Mid-Mid & 3 & 403.244 & 87 & 52.1 \\
\hline Mid-Low & 4 & 245.141 & 43 & 25.75 \\
\hline Low-Low & 5 & 0 & 0 & 0 \\
\hline Total Wells & & & 167 & 100 \\
\hline
\end{tabular}

Figure 19- Tornado diagram shows average values and number/percentage of wells existing in different RRQIs

Statistical analysis on production rates and results of decline curve analysis provides a lot of valuable data. Cumulatively clustered production in the forms of first few months, first year and first few years of production can generate a new set of information related to production behavior which is very useful. By mapping these clusters of production history as a model, a grid based estimated model of production behavior will be generated. 


\subsection{Intelligent History Matching - Predictive Modeling}

History matching is an essential part of reservoir modeling. By history matching, the reservoir model will be tuned with the production behavior of the reservoir in the past. In conventional reservoir simulation, history matching is the process in which the predictive result of the model is compared with actual data. A recurrent process of modifying the reservoir characteristics and pressure constrains takes place until the best match is achieved. The history matched model will be used for forecasting the future behavior of the reservoir.

In conventional reservoir simulation, fluid flow equations govern the relation between static and dynamic aspects of the reservoir, whereas in Top-Down Modeling the intelligent model estimates relationship in data. Top-Down Modeling technique has a different approach to history matching than conventional reservoir simulation.

Reservoir characteristics, completion data and production strains and reports are employed for training an intelligent model. The model correlates static information with production data. A spontaneous process of history matching and creating a predictive model is carried out. An intelligent model is built which carries completion information and reservoir characteristics. The intelligent model is trained, calibrated and verified using the static and dynamic information of the field. The process of generating an appropriate trained neural network can be carried out consecutively until the least error in calibration results are achieved.

Reservoir characteristics are components of fluid flow behavior of the reservoir. Porosity and permeability of the rock and fractures (natural or induced fractures) control the fluid migration from entire reservoir toward producing wells.

Organic nature of intelligent models provides us with such an infinite liberty in feeding the model with any sort of information that could be influential in rate of flow. A wide range of data might be available to engineers with clear evidence of effectiveness. In some cases, the data might not be in the form that traditional reservoir simulators can manage to process nor is any direct method of interrelating to meaningful records available. Intelligent process of modeling and history matching provides us with an unlimited capability of treating raw data.

Most of the oil and gas reservoirs are more extended in their horizontal dimension than their vertical dimension. By drilling horizontal wells the wellbore is exposed into more area of the reservoir than in a 
vertical well. However horizontal wells may cost up to 300 percent more than a vertical well, but they produce 2.5 to 7 times the rate and reserve of vertical wells (20).

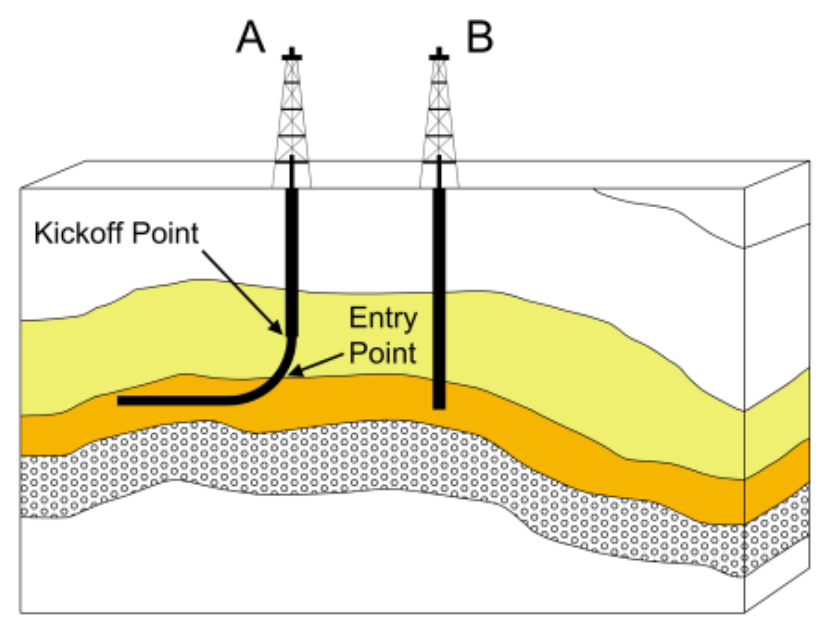

Figure 20- Greater length of exposure to rock surface in a horizontal well (A) than in a vertical well (B) (21)

Hydraulic fracturing has been widely used during the last decade in tight reservoirs. Hydraulic fracturing creates fractures of fissures inside the rock which facilitates the flow from formation to the well. Tight oil reservoirs which have restricted pore space and conduits, are fractured with specific amount of fluid and sand or proppants under sufficient pressure which can create fractures in the rock (22). Sand or proppant is used to keep the fractures open after releasing the hydraulic pressure. The fractures mostly open along the minimum horizontal stress in the formation. The most successful fracturing jobs happen in well laterals which are drilled in the direction of minimum horizontal stress. The configuration of induced fractures are perpendicular to the direction of well. Figure below shows the configuration of induced fractures in different well orientations. The longest and most effective fractures will be produced in the cases where the well is drilled along minimum horizontal stress.

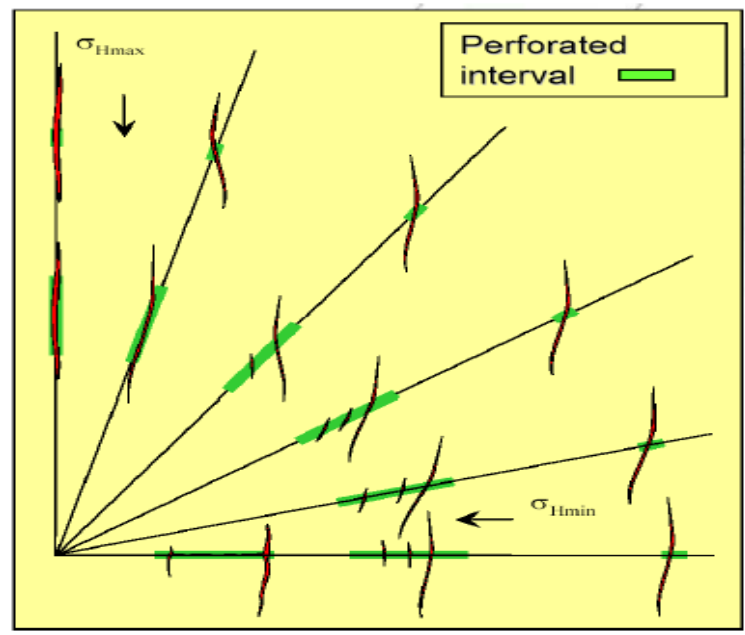


The model was provided with log readings of neutron and density porosity, density, gamma ray and resistivity. Lateral length of the wells was also included in the data set. Effect of hydraulic fracturing process was considered as well. Intensity of fracturing process was considered by utilizing measure of injected fracturing fluid's volume and weight of injected proppant.

For the case of Middle Bakken member, completion reports and well files were thoroughly studied to identify lateral length, number of lateral legs and intensity of fracturing process. Volume of injected fluid and weight of injected proppant were considered as a measure of intensity of fracturing job is implemented in generating the intelligent model.

Completion and stimulation reports coupled with production data and reservoir characteristics generate the comprehensive data set. Table below shows the list of data implemented for generating intelligent model of Middle Bakken member.

Table 1- List of data implemented in generation of comprehensive data set for the purpose of building intelligent model in Middle Bakken layer's model

\begin{tabular}{|c|c|}
\hline \multicolumn{2}{|c|}{ Implemented Data } \\
\hline Time & Pay Thickness(ft) \\
\hline Latitude & Resistivity \\
\hline Longitude & Vol. of Injected Fluid \\
\hline Days of production(t) & Weight of Inj. proppant \\
\hline Days of production(t-1) & $\mathrm{q}(\mathrm{t}-1)$-Gas \\
\hline Days of production(t-2) & $\mathrm{q}(\mathrm{t}-1)$-Oil \\
\hline Density Porosity & DOFP-Oil \\
\hline Bulck Density & $\mathrm{q}(\mathrm{t}-1)$-Water \\
\hline Depth(ft) & Days of Production(t-1)(1P) \\
\hline Fracturing Job Index & Days of Production(t-1)(2P) \\
\hline Gamma Ray & q(t-1)-Oil(2P) \\
\hline Lateral length &
\end{tabular}

Generated data set was partitioned into three parts to be implemented in training, calibration and verification of intelligent model. Partitioning was made in a time based manner. Meaning different periods of production history were considered to be used in different steps of the process.

In the case of Middle Bakken model, production data was available as early as April 2006 until very recent (July 2010). Production data from April 2006 to February 2010 was used for training the network. 
This data set is comprised of $60 \%$ of available data. The rest of the data was utilized for the purpose of calibration (3 months) and verification (3 months).

Figure below shows the data partitioning in generation of Middle Bakken model.

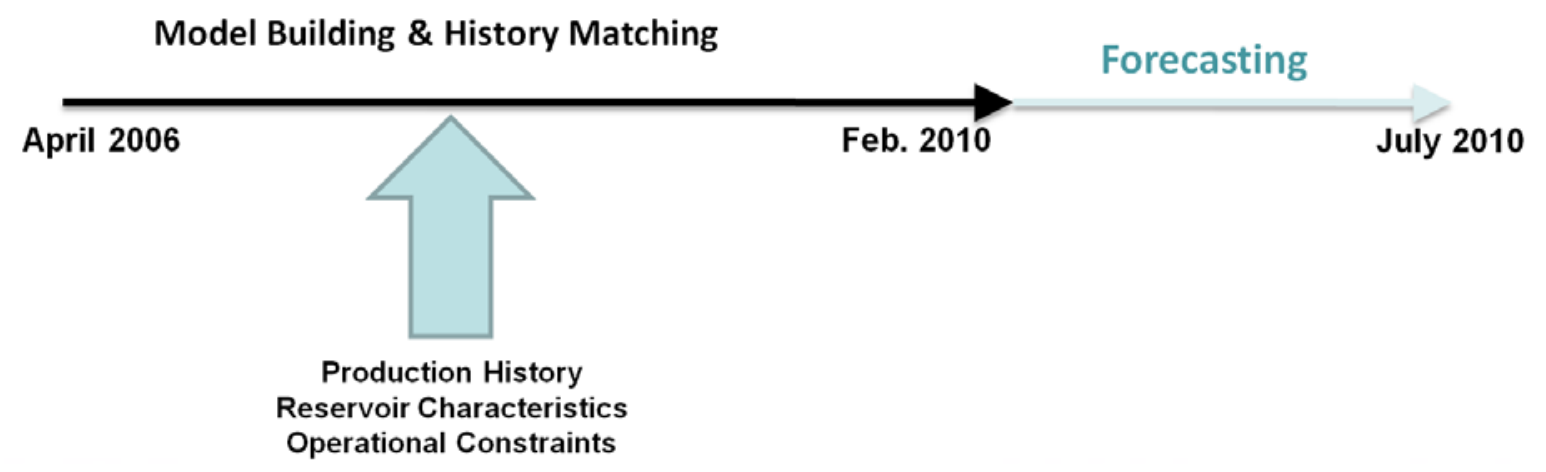

Figure 22- Data Partitioning for building and history matching the Middle Bakken model

Total organic carbon (TOC) is an indicator of potential hydrocarbon source rocks in shales or silty shales. May be the best indicators of high TOC are high resistivity and relatively considerable porosity. There are different sources of organic matters in shales which generate different type of organic material. Table below shows some of the different types (24).

Table 2- Name, type and source of different kerogens (24)

\begin{tabular}{ccc} 
Maceral & Kerogen Type & Original Organic Matter \\
\hline Alginite & I & Fresh water algae \\
Exinite & II & Pollen , Spores \\
Cutinite & II & Land-plant cuticle \\
Resinite & II & Land-plant resins \\
Liptinite & II & All land-plant lipids; marine algae \\
Vitrinite & III & Woody and cellulosic material from land plants \\
Inertinite & IV & Charcoal; highly oxidized or reworked material \\
& & of any origin \\
\hline
\end{tabular}

In the case of Upper Bakken formation, completion information and reservoir characteristics were utilized as listed in table below. TOC as a measure of organic matter existence was implemented.

Table 3- List of data implemented in generation of comprehensive data set for the purpose of building intelligent model in Upper Bakken layer's model 


\begin{tabular}{|c|c|}
\hline \multicolumn{2}{|c|}{ Implemented Data } \\
\hline Time & Porosity from log \\
\hline Latitude & $\mathrm{q}(\mathrm{t}-1)$-Gas \\
\hline Longitude & $\mathrm{q}(\mathrm{t}-1)$-Oil \\
\hline No. of Days of production(t) & $\mathrm{q}(\mathrm{t}-2)$-Oil \\
\hline No. of Days of production(t-1) & DOFP-Oil \\
\hline No. of Days of production(t-2) & $\mathrm{q}(\mathrm{t}-1)$-Water \\
\hline Depth(ft) & No. of Days of Production(t-1)(1P) \\
\hline Lateral length & No. of Days of Production(t-1)(2P) \\
\hline Pay Thickness(ft) & $\mathrm{q}(\mathrm{t}-1)$-Oil(2P) \\
\hline TOC &
\end{tabular}

In the case of Upper Bakken model, a long period of production data was available. Production from the first wells has been started from June 1988. Field production is available until very recent (August 2010).

Partitioning of data was performed in a time based manner. Production from June 1988 until end of year 2001 was considered for training purpose. Production of years 2002 to 2004 were considered for calibration and the rest (2005 to Aug. 2010) for verification purpose.

Figure below shows the data partitioning in generation of Upper Bakken model.

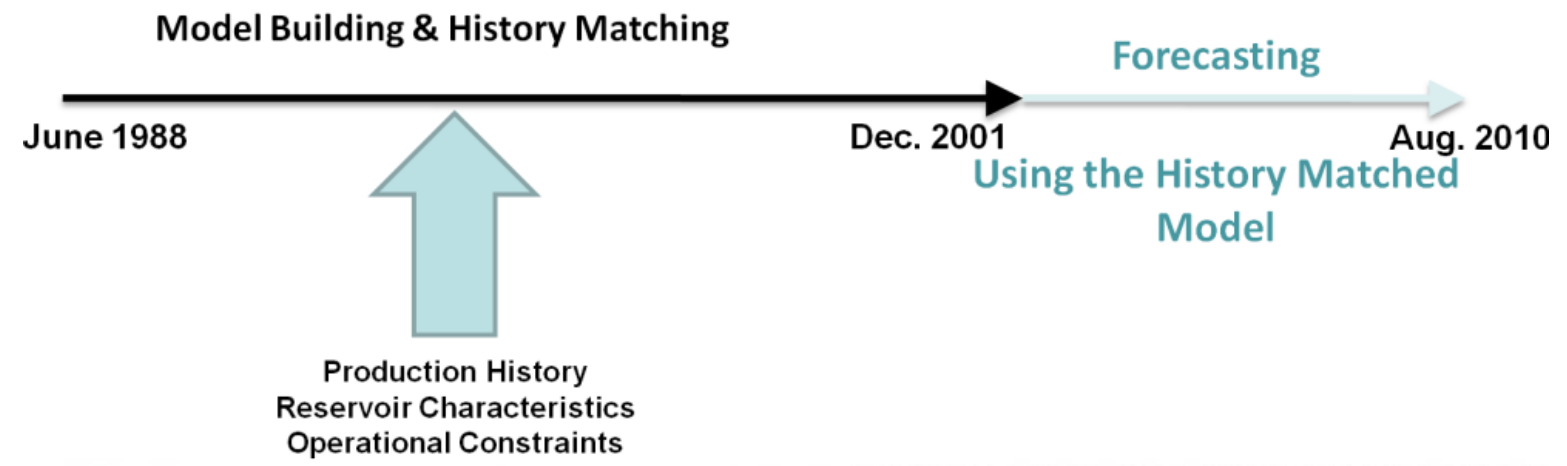

Figure 23- Data Partitioning for building and history matching the Upper Bakken model 


\section{Results and discussion}

\subsection{Static Reservoir Modeling}

The static reservoir modeling was performed for decline curve parameters $\left(Q_{i}, D_{i}\right.$ and $\left.b\right)$ and clustered cumulative production data for both strata (Upper Bakken and Middle Bakken). The static models of cumulative production show the statistical success of existing wells all around the reservoir (Figures 24, 25).

Generated estimated models are shown as simple geo-models in the following figures. Based on the resulting maps of estimated models sweet spots can be identified.

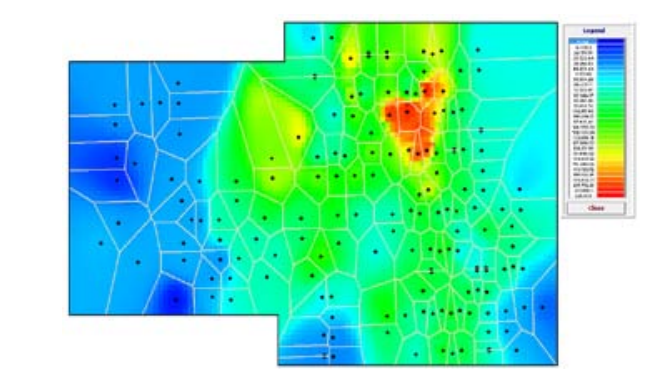

First 6 Months Cumulative Production

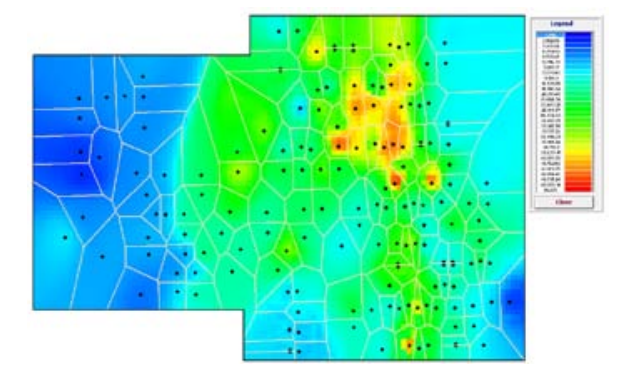

$\mathrm{Q}_{\mathrm{i}}$

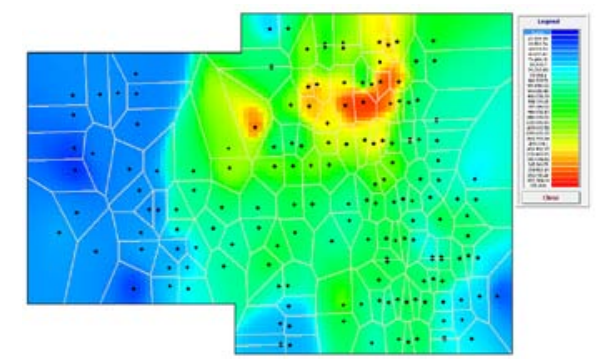

First Year Cumulative Production

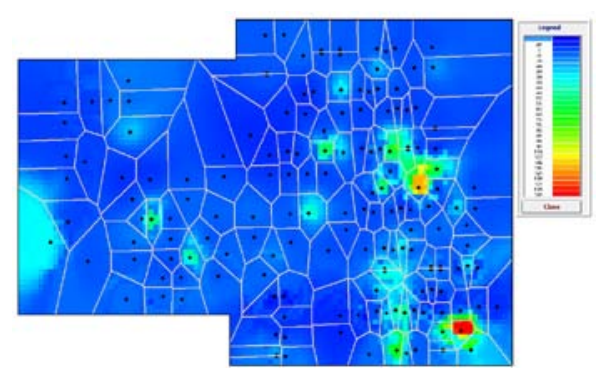

$\mathrm{D}_{\mathrm{i}}$

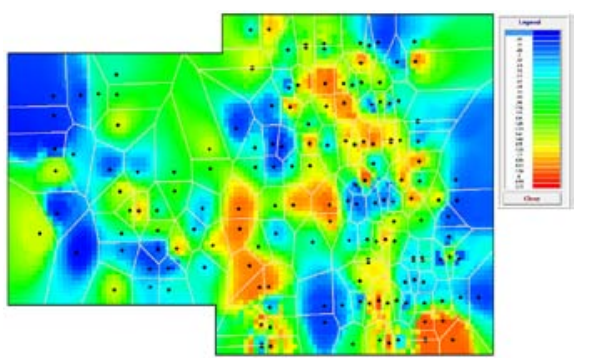

b

Figure 24- Results of Statistically Estimated Models of Middle Bakken for First 6 Months Cum. production, First Year Cum. production, $Q_{i}, D_{i}$ and $b$ 


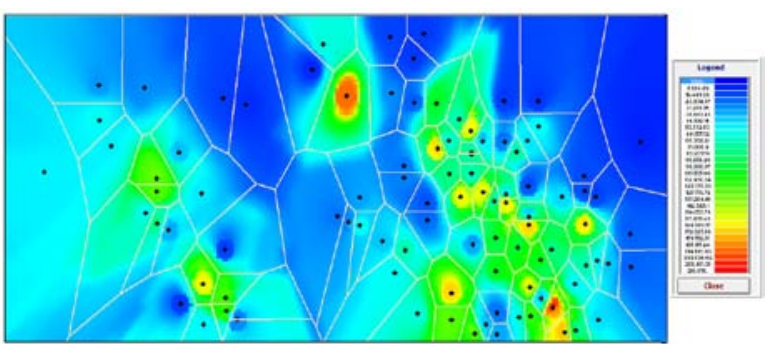

First 3 Years Cumulative Production

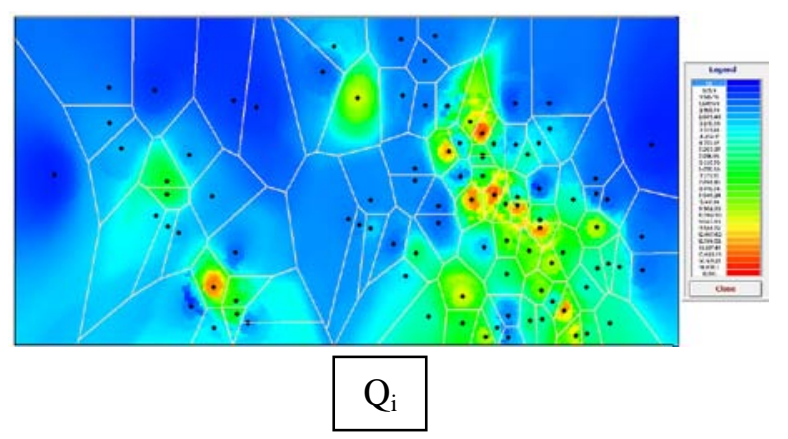

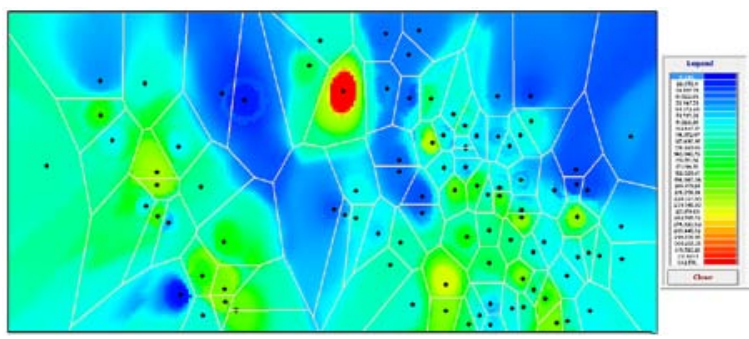

First 10 Years Cumulative

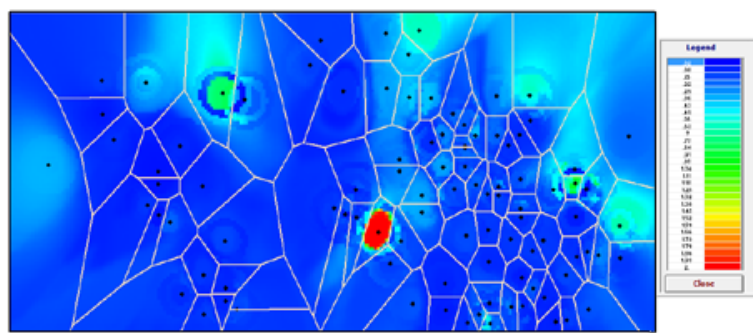

$\mathrm{D}_{\mathrm{i}}$

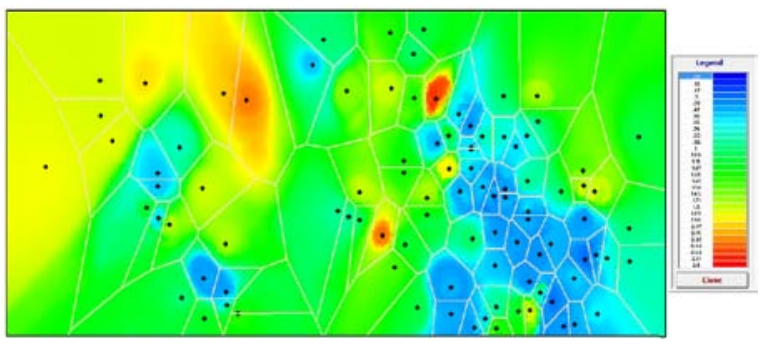

$\mathrm{b}$

Figure 25- Results of Statistically Estimated Models of Upper Bakken for First 3 Years Cum. production, First 10 Years Cum. production $Q_{i}, D_{i}$ and $b$

\subsubsection{Results of Fuzzy Pattern Recognition}

In the case of Middle Bakken model, an extensive volumetric calculation was performed. Fuzzy pattern recognition for remaining reserve in Middle Bakken model was performed for different time targets. Remaining reserve is a function of original oil in place and decline rate was. The fuzzy pattern recognition model of remaining reserve highlights the most prolific areas with higher initial oil in place (Figure 23). Well ranking analysis was also performed which provides us with ranking the wells based on recognized RRQIs. The result of well ranking is also included in fuzzy maps in which wells are shown in different colors of RRQIs that they belong to. 


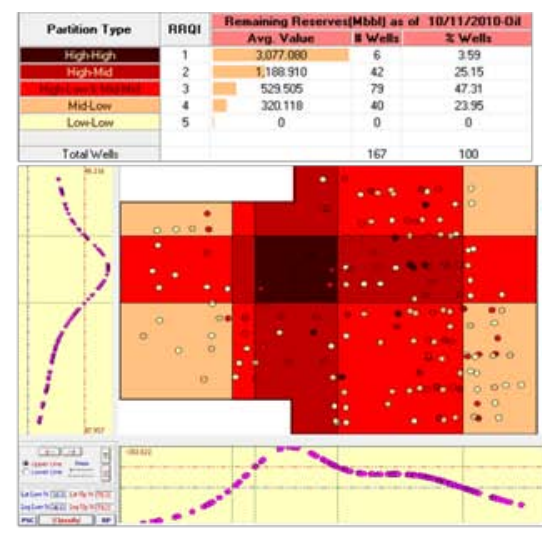

RR as of 2010

Middle Bakken Member

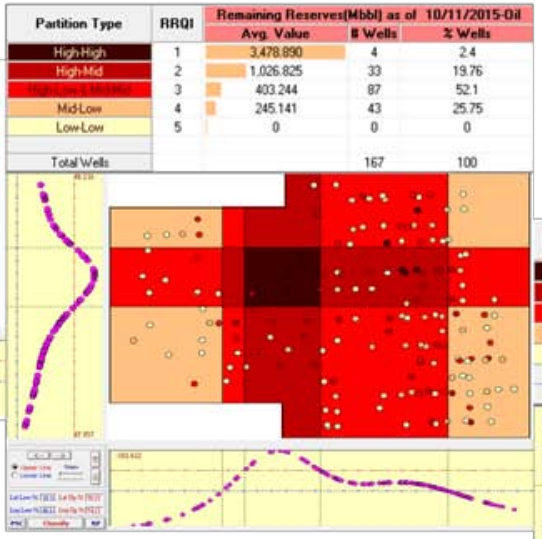

RR as of 2015 Middle Bakken Member

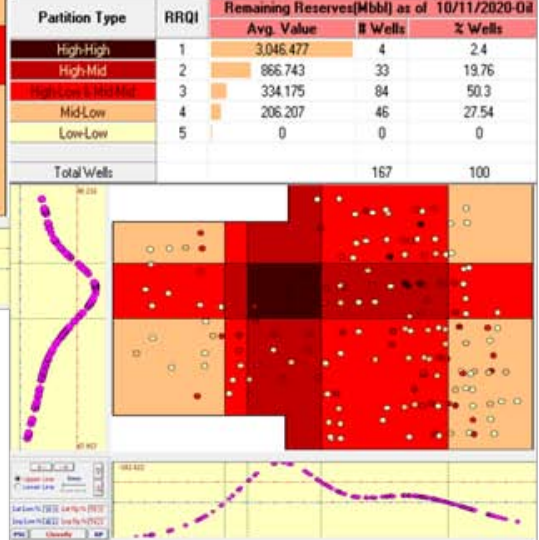

RR as of 2020

Figure 26- Fuzzy pattern recognition of Remaining reserve in Middle Bakken model as of 2010 to 2020

These models provide us with another implement for recognition for sweet spots. The High-High region is where more productive wells and considerable amount of oil in place exist. There are also several High quality wells in High-Medium region next to High-High region which shows good potential in that area as well.

\subsubsection{Infill Drill Locations}

Comparing results of statistical models with fuzzy pattern recognition may not be compatible completely. We need to keep in mind that results of statistical models come from experience of dealing with the field in the past. Making the best interpretation of both models in order to better identifying location of sweet spots also requires consideration of operational issues.

Since we do not have access to operational data, decisions should be made based on available information. Based on resulting models of fuzzy pattern and statistically estimated, several new wells were drilled which are shown in following figures. Purple squares show the location of new wells. 


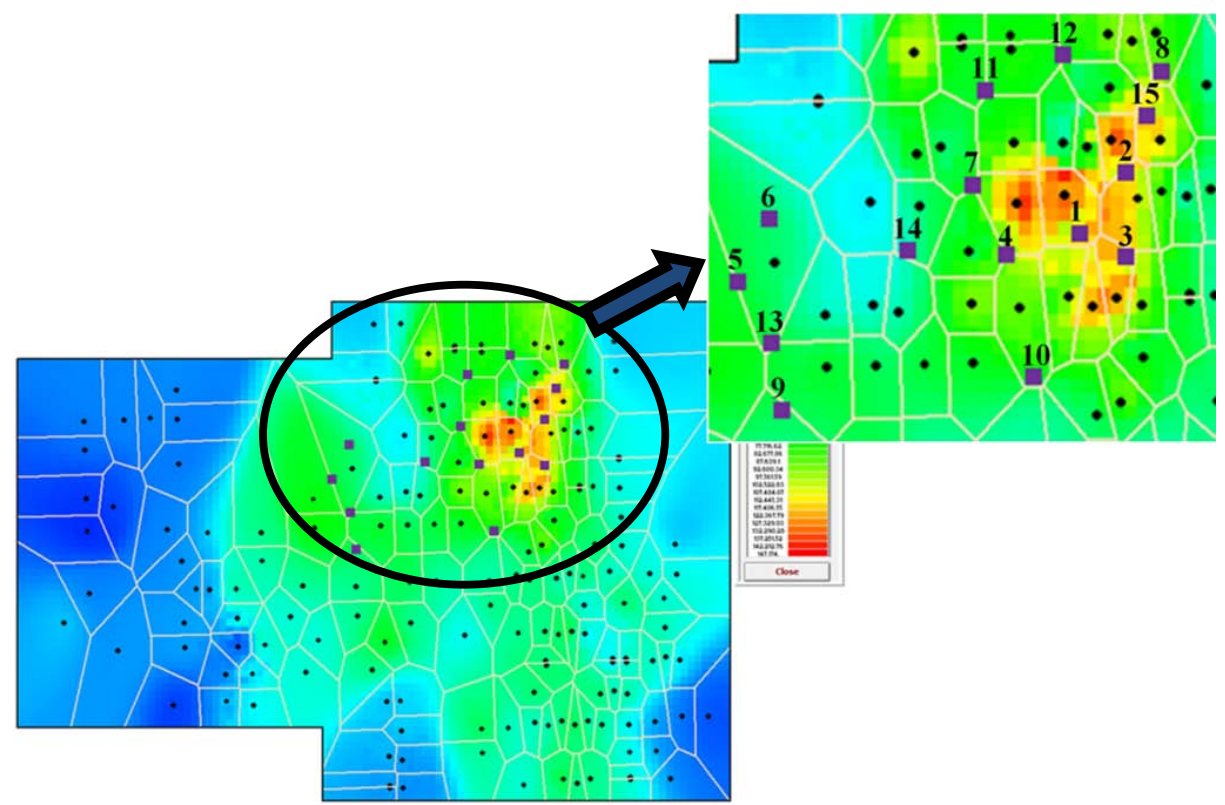

Figure 27- Location of proposed new wells in Middle Bakken model (15 new wells)

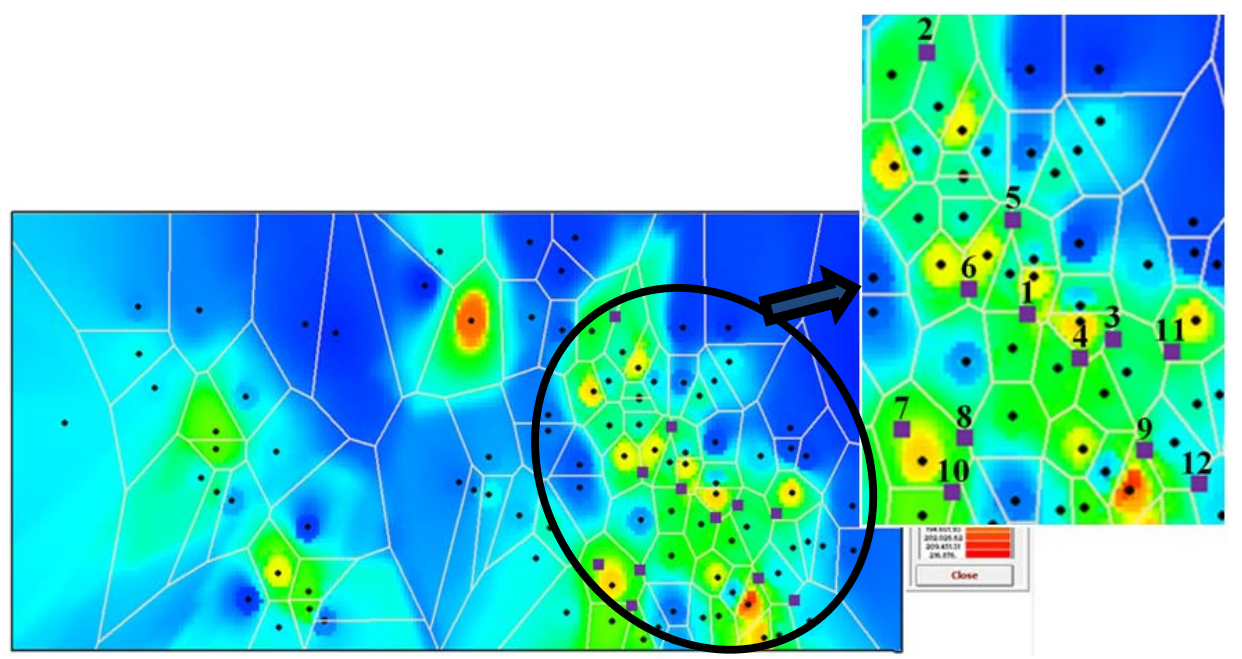

Figure 28- Location of proposed new wells in Upper Bakken model (12 new wells)

Estimated results of production behavior of new wells in terms of decline curve components are obtained. Recovery factor and EUR of the wells and the field is also calculated. Estimated results from statistical models are shown in tables below.

Table 4- Estimated results of production and recovery factor for the new wells in Middle Bakken Member 


\begin{tabular}{|c|ccccc|}
\hline Well Name & Qi & Di & b & RF\% & EUR \\
\hline New well1 & 38610.96 & 0.1 & 1.89 & 5.0634 & 2755 \\
\hline New well2 & 38736.19 & 0.1 & 0.73 & 2.793 & 1013 \\
\hline New well3 & 38545.32 & 0.19 & 0.96 & 4.0649 & 814 \\
\hline New well4 & 42686.09 & 0.27 & 1.78 & 15.2684 & 1742 \\
\hline New well5 & 25857 & 0.06 & 1.11 & 17.2408 & 1472 \\
\hline New well6 & 29826.55 & 0.06 & 0.13 & 3.1227 & 566 \\
\hline New well7 & 27297.93 & 0.1 & 1.44 & 12.6382 & 1466 \\
\hline New well8 & 34826.11 & 0.12 & 0.64 & 6.6527 & 684 \\
\hline New well9 & 22659.14 & 0.11 & 1.55 & 19.3583 & 1250 \\
\hline New well10 & 24701.31 & 0.11 & 1.31 & 5.3096 & 1129 \\
\hline New well11 & 27212.35 & 0.13 & 1.59 & 12.0451 & 1411 \\
\hline New well12 & 28555 & 0.12 & 1.29 & 9.939 & 1214 \\
\hline New well13 & 25304.21 & 0.07 & 0.94 & 9.9324 & 1115 \\
\hline New well14 & 22532.18 & 0.09 & 0.38 & 1.376 & 386 \\
\hline New well15 & 39613.82 & 0.14 & 1.48 & 12.9051 & 1809 \\
\hline
\end{tabular}

\begin{tabular}{|c|c|}
\hline Field-wide Oil in Place & $\mathbf{2 1 0 0 5 5 3}$ \\
\hline Field recovery Factor & 6.3235 \\
\hline $\begin{array}{c}\text { Field recovery Factor } \\
\text { (after drilling } 15 \text { new } \text { wells) }\end{array}$ & 6.7478 \\
\hline
\end{tabular}

Table 5- Estimated results of production and recovery factor for the new wells in Upper Bakken Member

\begin{tabular}{|c|c|c|c|c|c|}
\hline Well Name & Qi & Di & b & RF\% & EUR \\
\hline New well1 & 8613 & 0.13 & 0.44 & 1.36 & 106 \\
New well2 & 11686 & 0.22 & 0.68 & 6.9 & 125 \\
New well3 & 8861 & 0.15 & 0.49 & 4.17 & 101 \\
New well4 & 9560 & 0.13 & 0.45 & 10.48 & 120 \\
New well5 & 10357 & 0.17 & 0.49 & 5.78 & 106 \\
New well6 & 10298 & 0.15 & 0.63 & 9.55 & 147 \\
New well7 & 9312 & 0.11 & 0.51 & 4.45 & 150 \\
New well8 & 8274 & 0.1 & 0.43 & 3.85 & 130 \\
New well9 & 10657 & 0.12 & 0.36 & 10.15 & 130 \\
New well10 & 8937 & 0.1 & 0.45 & 10.29 & 145 \\
New well11 & 7323 & 0.12 & 0.41 & 3.66 & 93 \\
New well12 & 5792 & 0.11 & 0.53 & 5.15 & 92 \\
\hline
\end{tabular}

\begin{tabular}{|c|c|}
\hline Field-wide Oil in Place & 229261 \\
\hline Field recovery Factor & $\mathbf{5 . 6 2 6 9}$ \\
\hline $\begin{array}{c}\text { Field recovery Factor } \\
\text { (after drilling } 15 \text { new wells) }\end{array}$ & $\mathbf{5 . 8 6 5 8}$ \\
\hline
\end{tabular}

Economical analysis for new wells was performed in order to calculate net present value as a measure of rate of return. Investment in any field should be associated with acceptable rate of return. Economical feasibility of field development depends upon cost investing resources and rate of making benefits in the paying off period. Investments in an oil field are comprised of exploration and drilling, surface facilities and transportation. Considering all the resources that we invest in a field at one hand, production rate and 
oil price on the other hand, we are able to perform economical analysis. Oil price was assumed to be $\$ 50$ in these calculations. A range of 3,500,000 to $\$ 5,000,000$ of drilling cost was utilized in analysis.

Results of economical analysis for proposed new wells are shown in tables below.

Table 6- Economical analysis in Middle Bakken model for new wells

\begin{tabular}{|c|ccc|}
\hline \multirow{3}{*}{ Investment } & \multicolumn{3}{c|}{ NPV of 5 years } \\
\cline { 2 - 4 } & 3 million \$ & $\mathbf{4}$ million \$ & $\mathbf{5}$ million \$ \\
\hline Well\#1 & $32,038,000$ & $31,038,000$ & $30,038,000$ \\
Well\#2 & $21,578,000$ & $20,578,000$ & $19,578,000$ \\
Well\#3 & $22,114,000$ & $21,114,000$ & $20,114,000$ \\
Well\#4 & $15,507,000$ & $14,507,000$ & $13,507,000$ \\
Well\#5 & $21,329,000$ & $20,329,000$ & $19,329,000$ \\
Well\#6 & $16,846,000$ & $15,846,000$ & $14,846,000$ \\
Well\#7 & $19,298,000$ & $18,298,000$ & $17,298,000$ \\
Well\#8 & $15,728,000$ & $14,728,000$ & $13,728,000$ \\
Well\#9 & $15,299,000$ & $14,299,000$ & $13,299,000$ \\
Well\#10 & $15,606,000$ & $14,606,000$ & $13,606,000$ \\
Well\#11 & $17,692,000$ & $16,692,000$ & $15,692,000$ \\
Well\#12 & $17,500,000$ & $16,500,000$ & $15,500,000$ \\
Well\#13 & $18,191,000$ & $17,191,000$ & $16,191,000$ \\
Well\#14 & $9,755,000$ & $8,755,000$ & $7,755,000$ \\
Well\#15 & $25,178,000$ & $24,178,000$ & $23,178,000$ \\
\hline
\end{tabular}

Table 7- Economical analysis in Upper Bakken model for new wells

\begin{tabular}{|c|ccc|}
\hline & \multicolumn{3}{c|}{ NPV of 5 years } \\
\cline { 2 - 4 } Investment & 3 Million S & 4 Million S & 5 Million S \\
\hline Well\#1 & $1,218,000$ & 218,000 & $-782,000$ \\
Well\#2 & $1,597,000$ & 597,000 & $-403,000$ \\
Well\#3 & $1,027,000$ & 27,000 & $-973,000$ \\
Wel\#4 & $1,716,000$ & 716,000 & $-284,000$ \\
Well\#5 & $1,263,000$ & 263,000 & $-737,000$ \\
Well\#6 & $2,176,000$ & $1,176,000$ & 176,000 \\
Well\#7 & $2,418,000$ & $1,418,000$ & 418,000 \\
Well\#8 & $1,913,000$ & 913,000 & $-87,000$ \\
Well\#9 & $2,243,000$ & $1,243,000$ & 243,000 \\
Well\#10 & $2,381,000$ & $1,381,000$ & 381,000 \\
Well\#11 & 736,000 & $-264,000$ & $-1,264,000$ \\
Well\#12 & 516,000 & $-484,000$ & $-1,484,000$
\end{tabular}

The results of economical analysis for Middle Bakken member are very promising. Estimated production rate for the new wells completed in this layer is considerable enough to have reasonable investment justification.

Economical analysis of new wells completed in Upper Bakken member is quite challenging. Production from Upper Bakken layer in the area of study has been started from late eighties. Application of most recent drilling, completion and reservoir stimulation technologies may increase the production rate significantly. 


\subsection{Intelligent History Matching - Predictive Modeling}

Intelligent models were trained, calibrated and verified using comprehensive data sets. Comparison between results of prediction and real data are the best indication of history matching part of process. Minimum but sufficient number of data should be used in the model such that model is not overloaded by unnecessary data neither influential parameters are not supplied. Few examples of results of predictive modeling in Middle Bakken model are shown below. The rest of results are given in Appendix A.

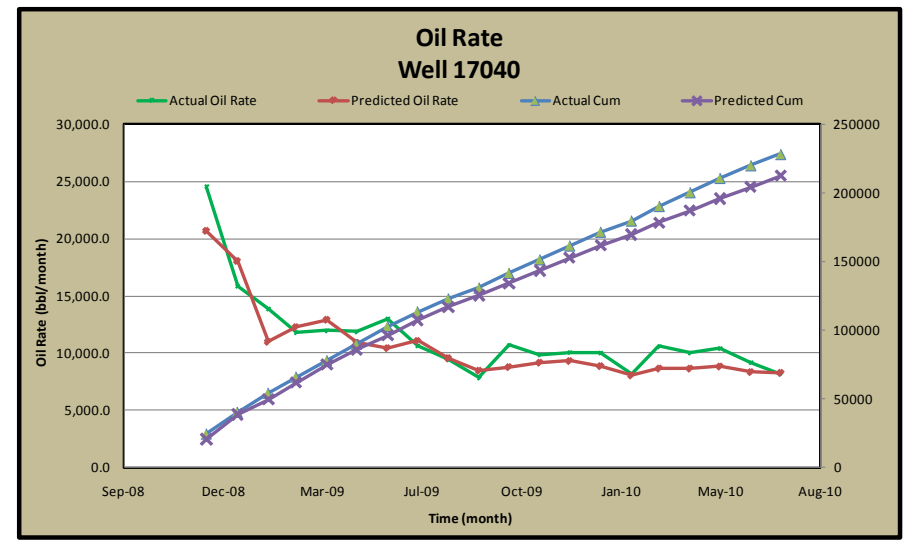

Figure 29- Results of history matching for the well number 17040 in Middle Bakken

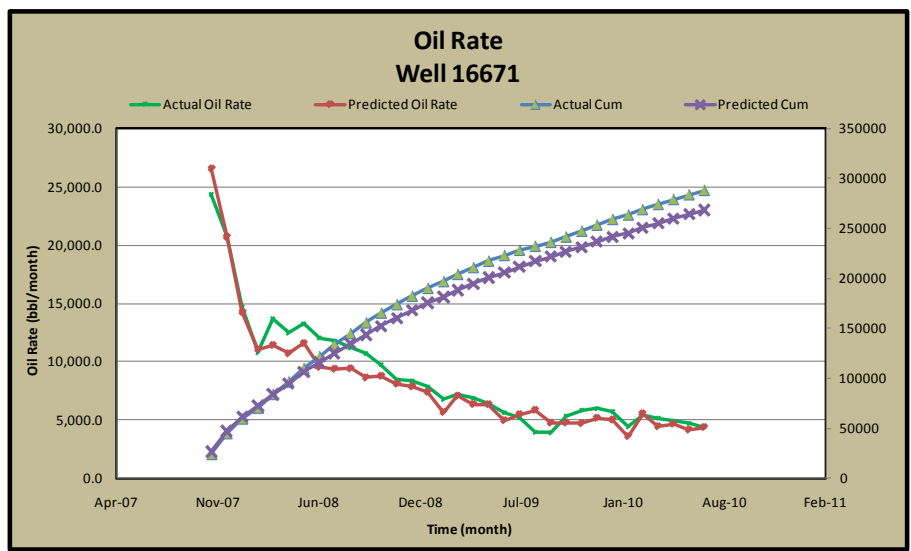

Figure 30- Results of history matching for the well number 16671 in Middle Bakken

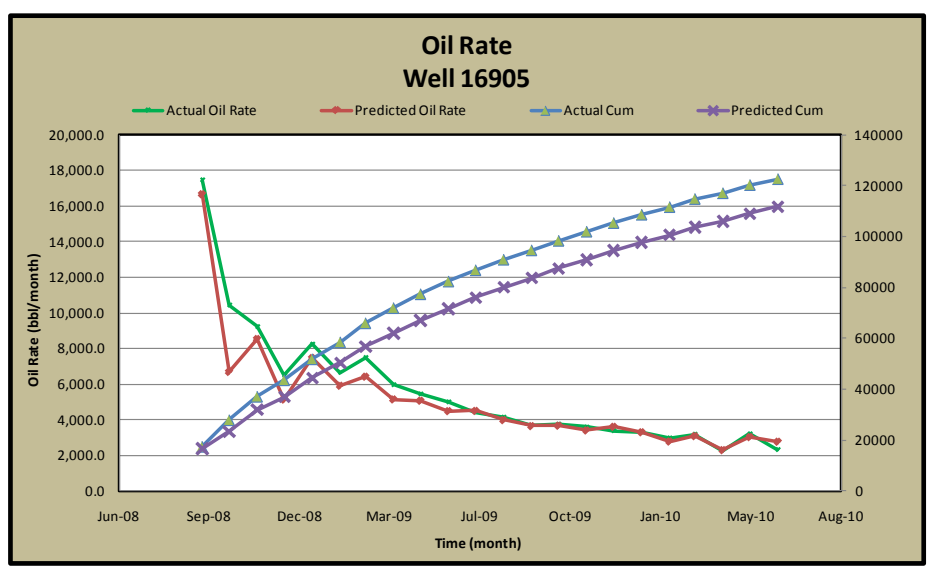


Figure 31- Results of history matching for the well number 16905 in Middle Bakken

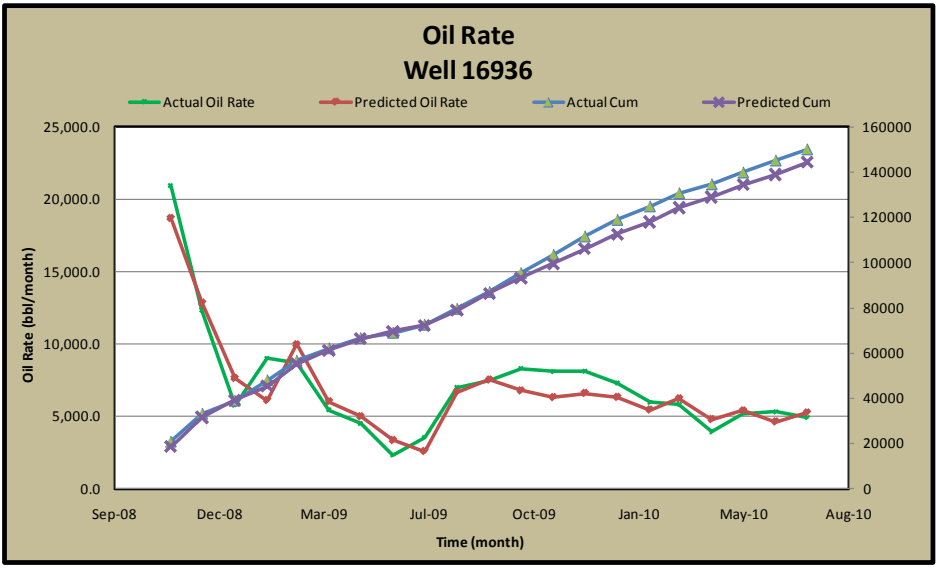

Figure 32- Results of history matching for the well number 16936 in Middle Bakken

Predicted and actual field wide cumulative production of Middle Bakken formation is shown in figure below. The production in the field starts increasing until maximum number of wells comes to production. Thereafter, the field production declines as time passes.

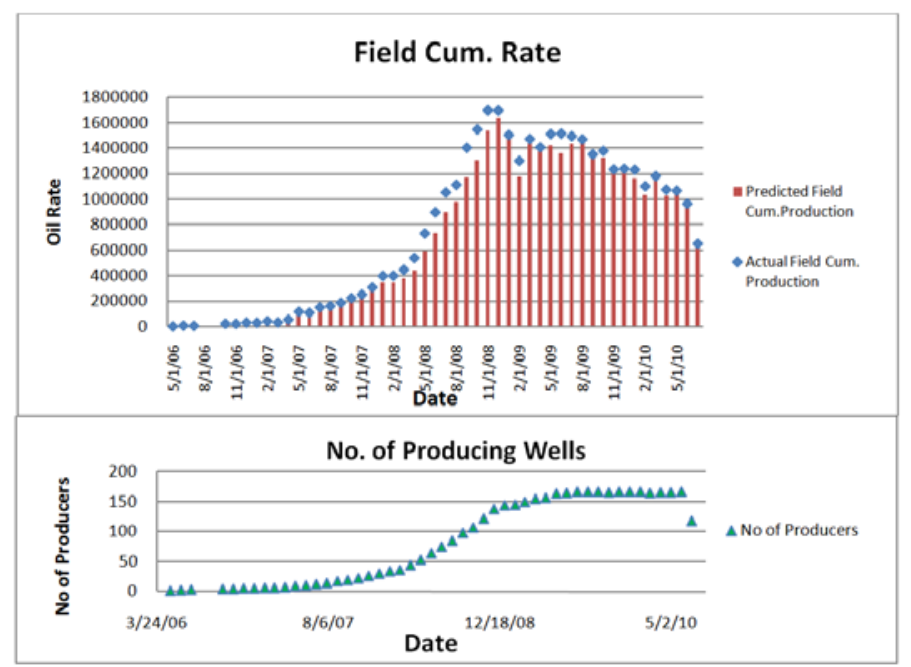

Figure 33- Field wide cumulative production (upper chart) and number of producing wells (lower chart) in Middle Bakken

Few examples of results of predictive modeling in Upper Bakken model are shown below. The rest of results are given in Appendix A. 


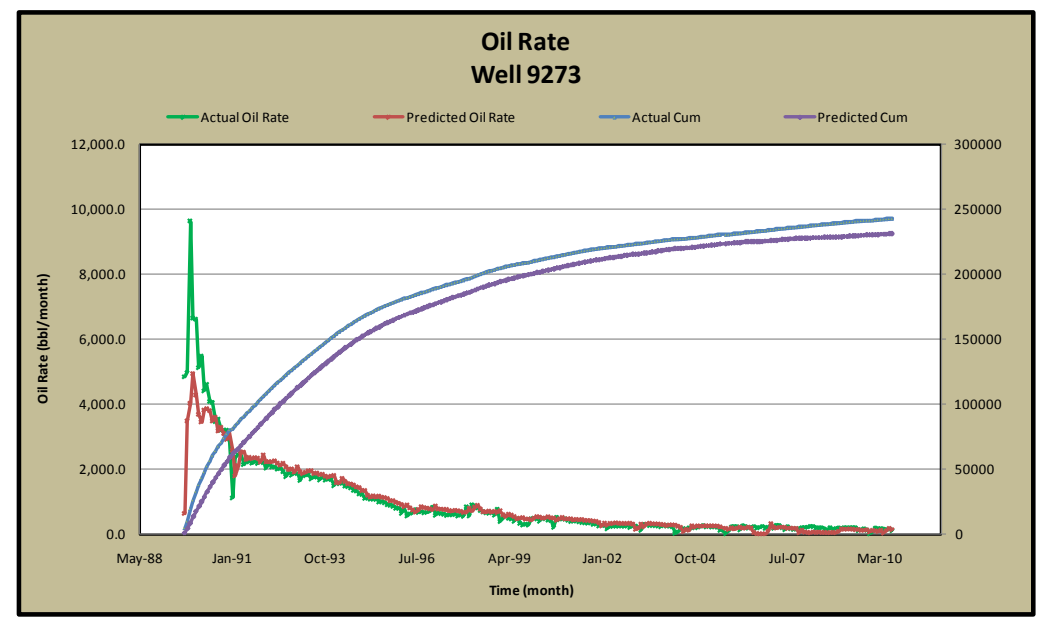

Figure 34- Results of history matching for the well number 9273 in Upper Bakken

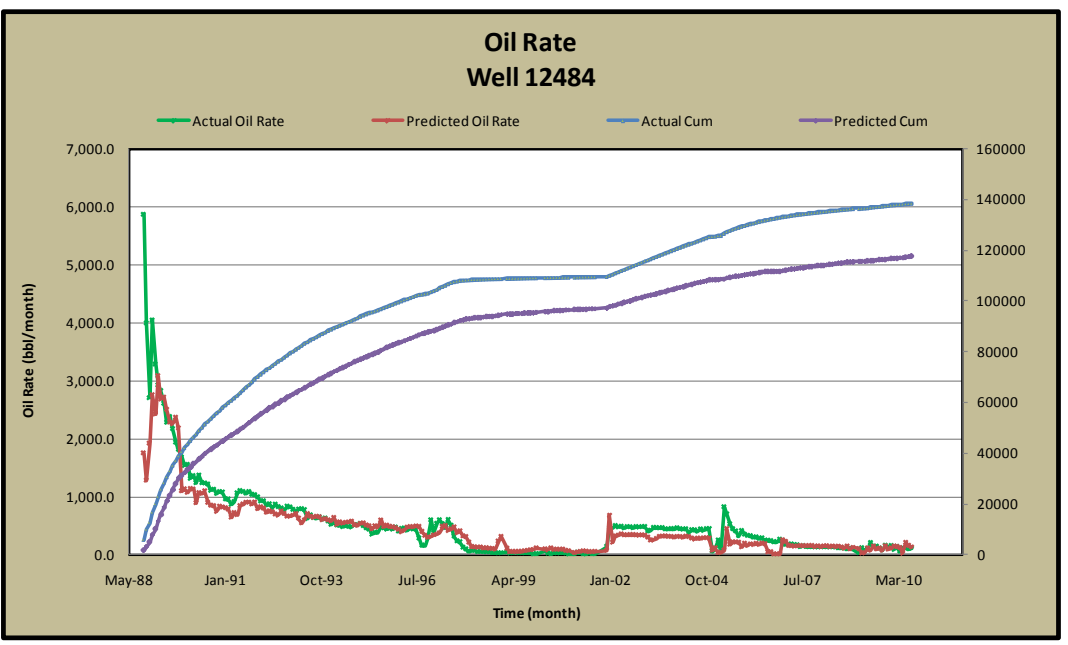

Figure 35- Results of history matching for the well number 12484 in Upper Bakken

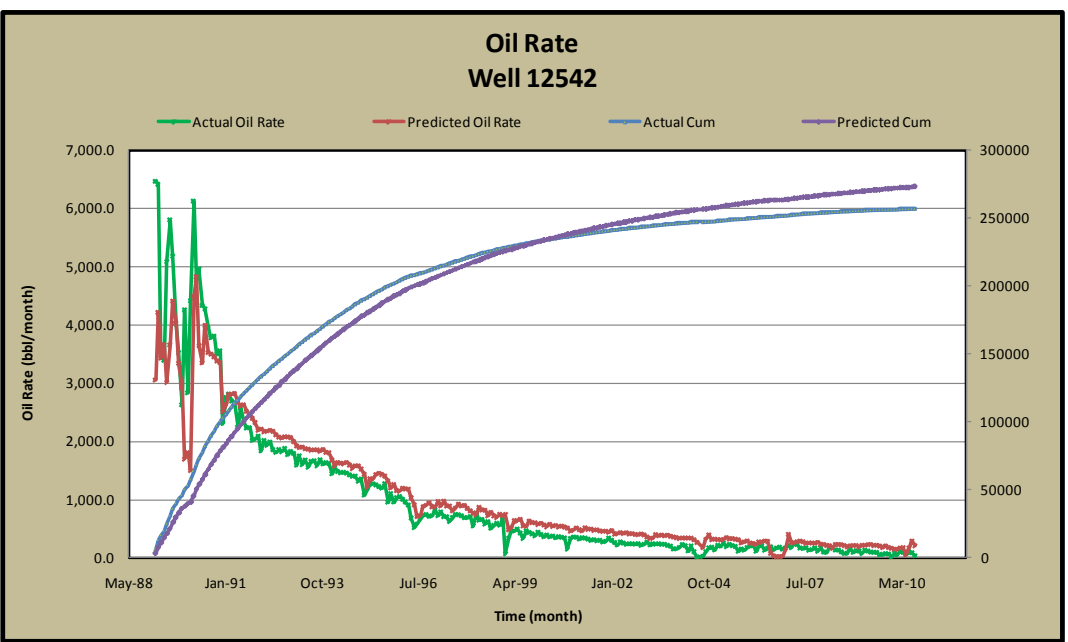

Figure 36- Results of history matching for the well number 12542 in Upper Bakken 


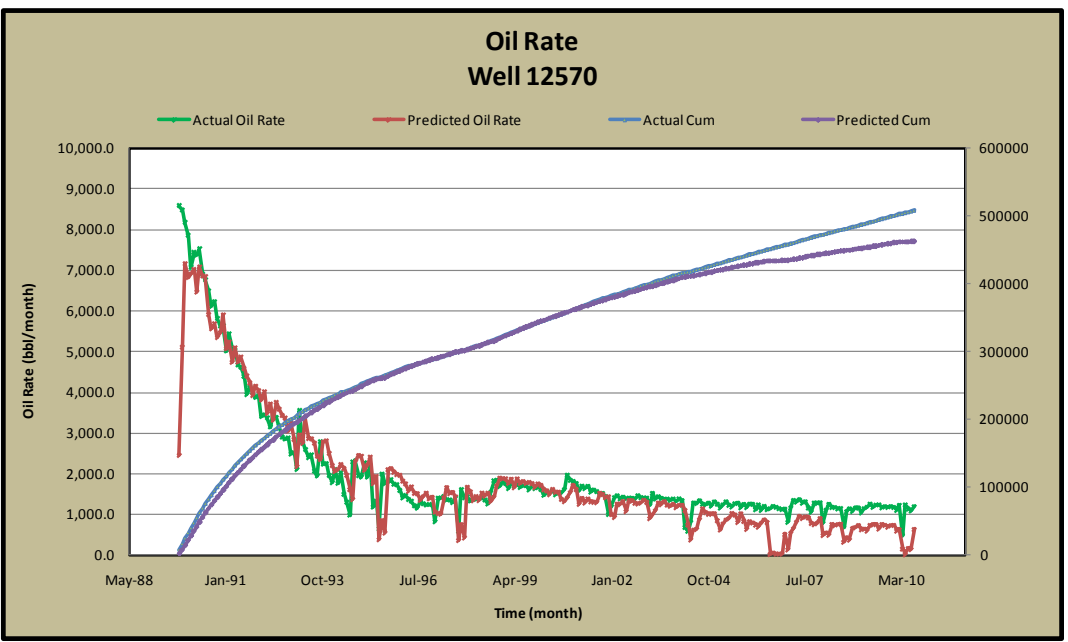

Figure 37- Results of history matching for the well number 12570 in Upper Bakken

Field wide monthly production from Upper Bakken formation is shown in figure below followed by number of producing wells.

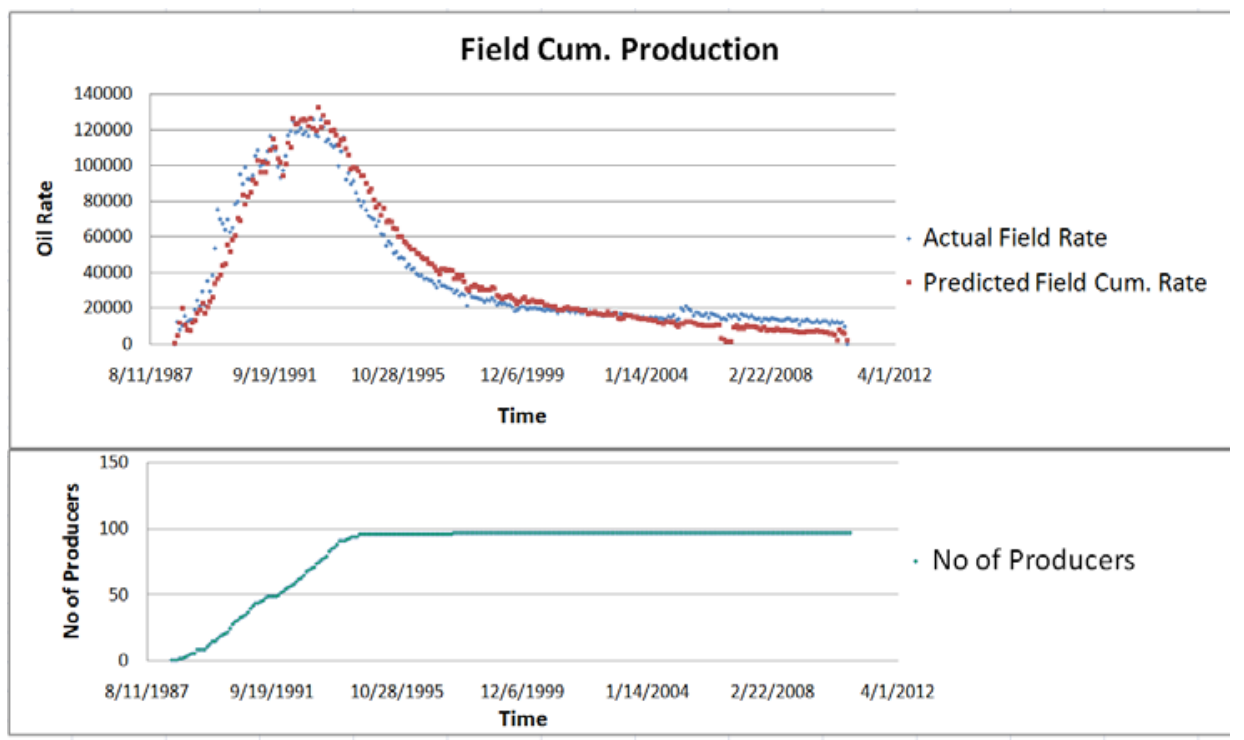

Figure 38- Field wide cumulative production (upper chart) and number of producing wells (lower chart) in Upper Bakken

\subsection{Uncertainty Analysis}

Effect of different completion and reservoir stimulation on production rate was investigated. Simultaneous effect of pay thickness and depth was considered in this part of study.

Effect of depth and lateral length on production is shown in figure below. 


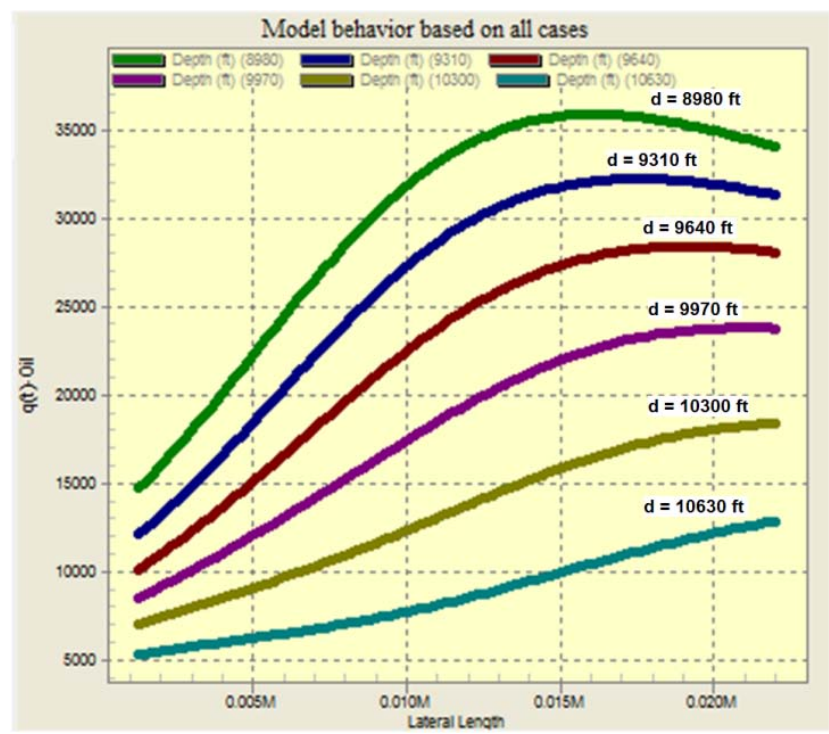

Figure 39- Effect of depth and lateral length on production rate (Middle Bakken model)

The model shows direct relationship between production rate and lateral length and reverse relationship with depth. The decline in production in long laterals is an indicator of operational difficulties associated with back production of the wells right after completion.

Effect of volume of injected fracturing fluid and lateral length is shown in following figure. The model shows direct relationship between both injected fluid or lateral length and production.

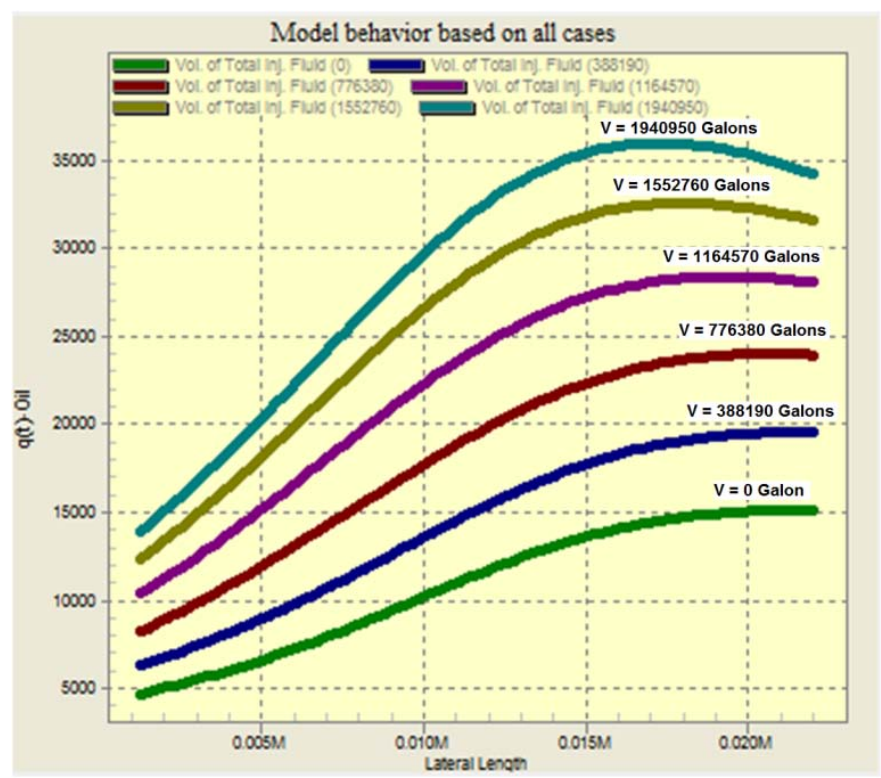

Figure 40- Effect of volume of injected fracturing fluid and lateral length on production rate (Middle Bakken model)

The same effect of long laterals on production drop is observed in this model as well. It can be concluded that a limit for length of lateral exists for Middle Bakken formation which is about 17,000 ft. 
Model below shows simultaneous effect of pay thickness and lateral length on production rate. The model shows non-significant effect of lateral length at thinner parts of the reservoir and more significant effect of lateral length at thicker pay thicknesses.

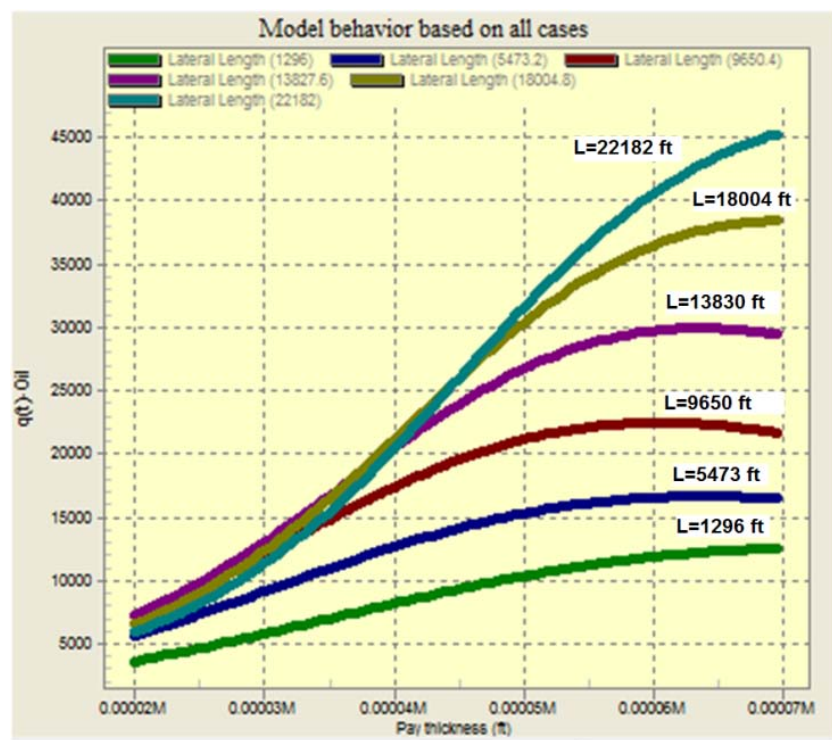

Figure 41- Effect of pay thickness and lateral length on production rate (Middle Bakken model)

Spontaneous effect of TOC and porosity in Upper Bakken model was also investigated. The result of this uncertainty analysis is shown in following figure.

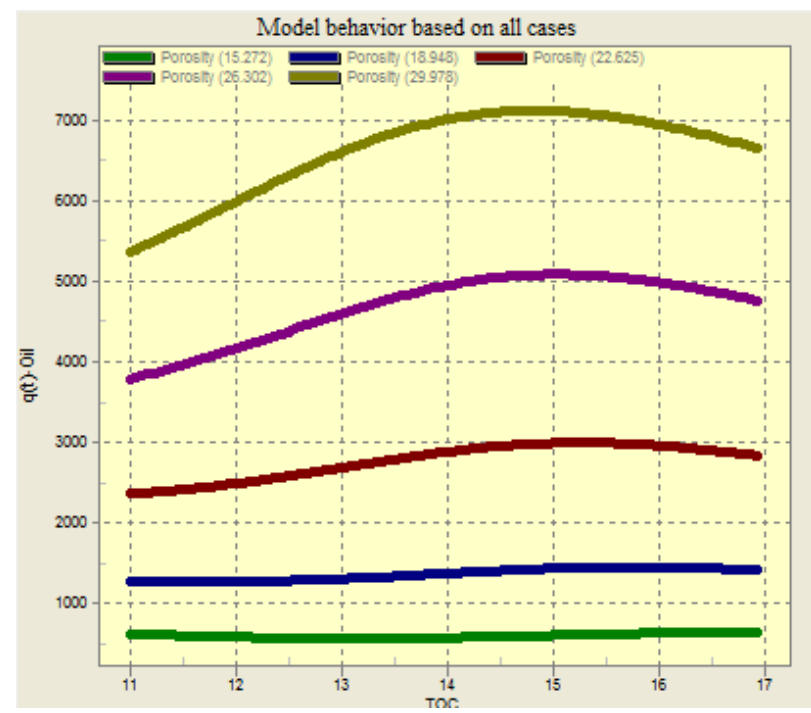

Figure 42- Effect of TOC and porosity log reading on production rate (Upper Bakken model)

This model shows effect of TOC in production at higher porosity values. 


\section{Concluding Remarks}

Two different Top-Down approaches in reservoir simulation were performed for Upper and Middle members of Bakken formation. Simple geo maps were generate for reservoir characteristics from log record. Application of production statistic and reservoir geological maps in generating Statistical Estimated Models was conducted.

Fuzzy pattern recognition technology was employed in order to analyze remaining reserve as a function of time in Middle Bakken.

Sweet spots were identified and new wells were proposed to be drilled. Production behavior of new wells, recovery factor and EUR of the field was calculated. Economical analysis was performed based on the results of estimated models. NPV as an indication of rate of return was calculated assuming different investment costs.

A history matched model of production and reservoir characteristics was generated for both Upper and Middle members of Bakken formation. This new approach to history matching generate a predictive model while history matching. The history matched predictive model has been built by utilizing all the reservoir characteristics, completion data and production rate.

The intelligent predictive model is capable of predicting the future production for existing and new wells.

Sensitivity analysis for several reservoir characteristics and completion extents were performed which guides us to better design wells and stimulation process. This type of information can be used in order to reduce the investment cost.

The combination of these two approaches of reservoir modeling is a very good tool in reservoir management. By performing all these analysis, sweet spots were identified and an extensive comprehension about future of the field was achieved. 


\section{References}

1. Working Document of the NPC Global Oil and Gas Study; http://www.npc.org/Study Topic Papers/29-TTG-Unconventional-Gas.pdf, July 18, 2007.

2. www.pttc.org; Forum for Transfer of Technology and Best-practices within the Oil \& Gas Community.

3. www.halliburton.com

4. J.N. Fox C.D. Martiniuk; Reservoir Characteristics and Petroleum Potential of the Bakken Formation, Southwestern Manitoba; JCPT, Vol. 33, No. 8, October 1994.

\section{United States Geological Survey Website}

6. Wikipedia Website

7. Wlliams, P., Defined and Described. Bakken Shale, The Playbook, Hart Energy, December, 2008.

8. http://www.theoildrum.com/node/3868

9. Julie LeFever, Lynn Helms; Bakken Formation Reserve Estimates- Executive Summary, 2008.

10. J. W. Schmoker, T. C. Hester; Oil Generation Inferred from Bakken Formation ResistivityBakken Formation, Williston Basin, North Dakota; SPWLA Thirtieth Annual Logging Symposium, June11-14, 1989 .

11. R. Rankin, M. Thibodeau, M.C Vincent, T.T. Palisch; Improved Production and Profitability Achieved with Superior Completions in Horizontal Wells: A Bakken/Three Forks Case History; SPE ATCE, Italy, 19-22 September 2010.

12. Julie A. LeFever; North Dakota Geological Survey Geologic Investigations No. 59 Bakken Formation Map Series , 2008

13. N. Buffington , J. Kellner, J.G King, B. David, A. Demarchos, L. Sheperd; New technology in the Bakken Play Increases the number of stages in Packer/Sleeve Completion; SPE western regional meeting, Anaheim, California, 27-29 May 2010.

14. www.OilandGasInvestors.com; October 2009.

15. R. Gaskari, S.D.Mohaghegh, J.Jalali; An Integrated Technique for Production Data Analysis with Application to Mature Fields; SPE 100562; SPE Gas Technology Symposium held in Calgary, Alberta, Canada, 15-17 May 2006. 
16. A. Kalantari-Dahaghi, S.D. Mohaghegh; Top-Down Intelligent Reservoir Modeling of New Albany Shale; SPE 125859; SPE Eastern Regional Meeting, Charleston, West Virginia, 23-25 September, 2009.

17. G.C.Thakur; What is reservoir management?; Journal of Petroleum Technology; Volume 48, Number 6; P 520-525; June 1996.

18. M.L. Wiggins and R.A. Startzman; an Approach to Reservoir Management; SPE 20747; 65th Annual Technical Conference and Exhibition of the Society of Petroleum Engineers, New Orleans, LA, September 23-26, 1990.

19. Arps, J.J.; Analysis of Decline Curves, Trans, AIME. 1945.

20. L. Helms; Horizonta Drilling, DMR Newsletter, Vol. 35, No. 1.

21. Office of Oil and Gas; Energy Information Administration.

22. DOE/NETL; www.netl.doe.gov/technologies

23. Production enhancement in Russian oil and gas fields utilizing horizontal, sidetrack, extended reach and multilateral wells, ATW 3-6 Feb-2006, Moscow

24. R. N. Heistand, H. G. Humphries; Direct Determination of Organic Carbon in Oil Shale, Analytical Chemistry, Vol. 48, No. 8, July 1976, p 1193. 


\section{Appendix A}

Results of History Matching-Predictive Modeling of Middle Bakken model and respective location of well's polygon in the model:
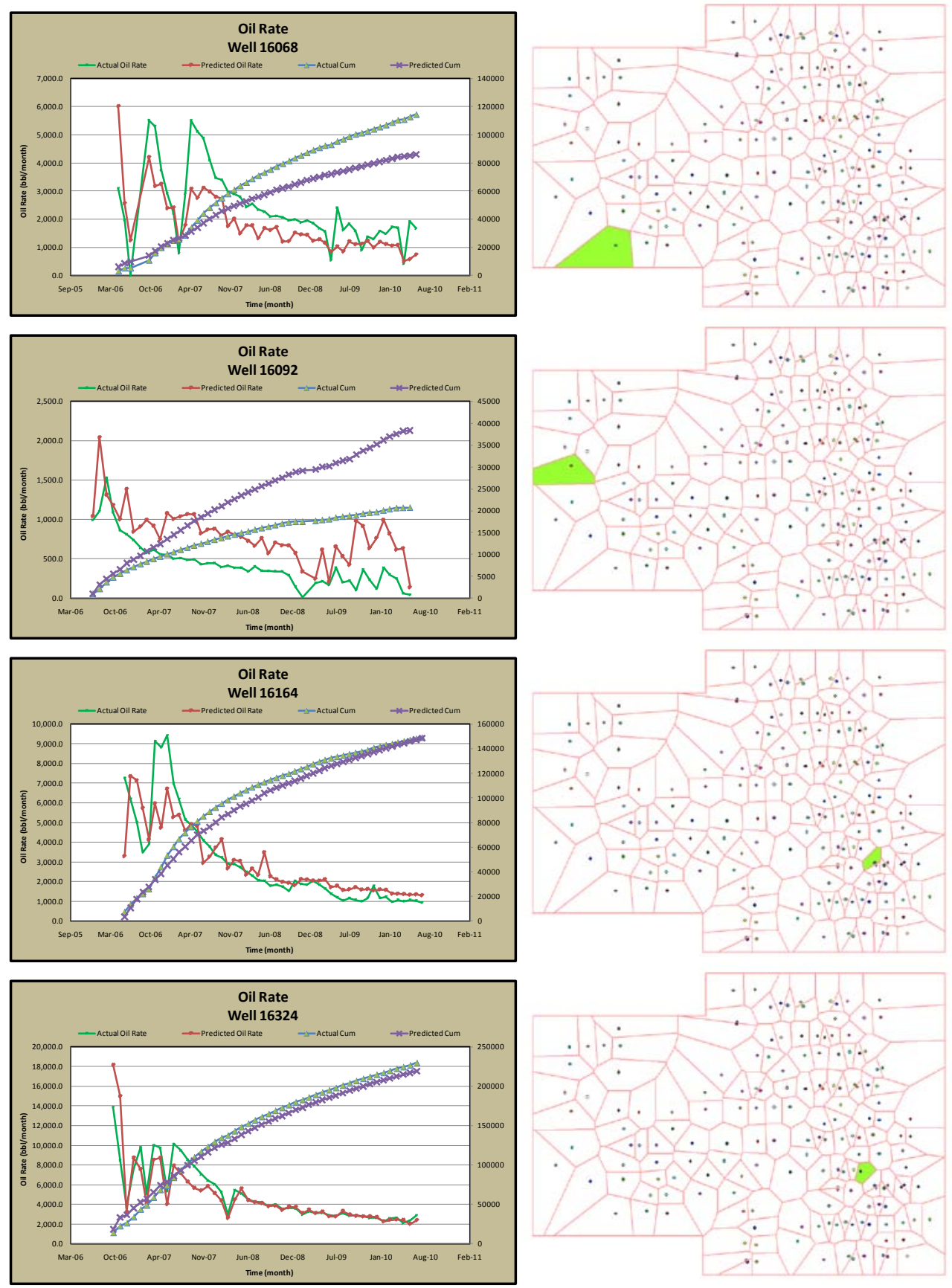

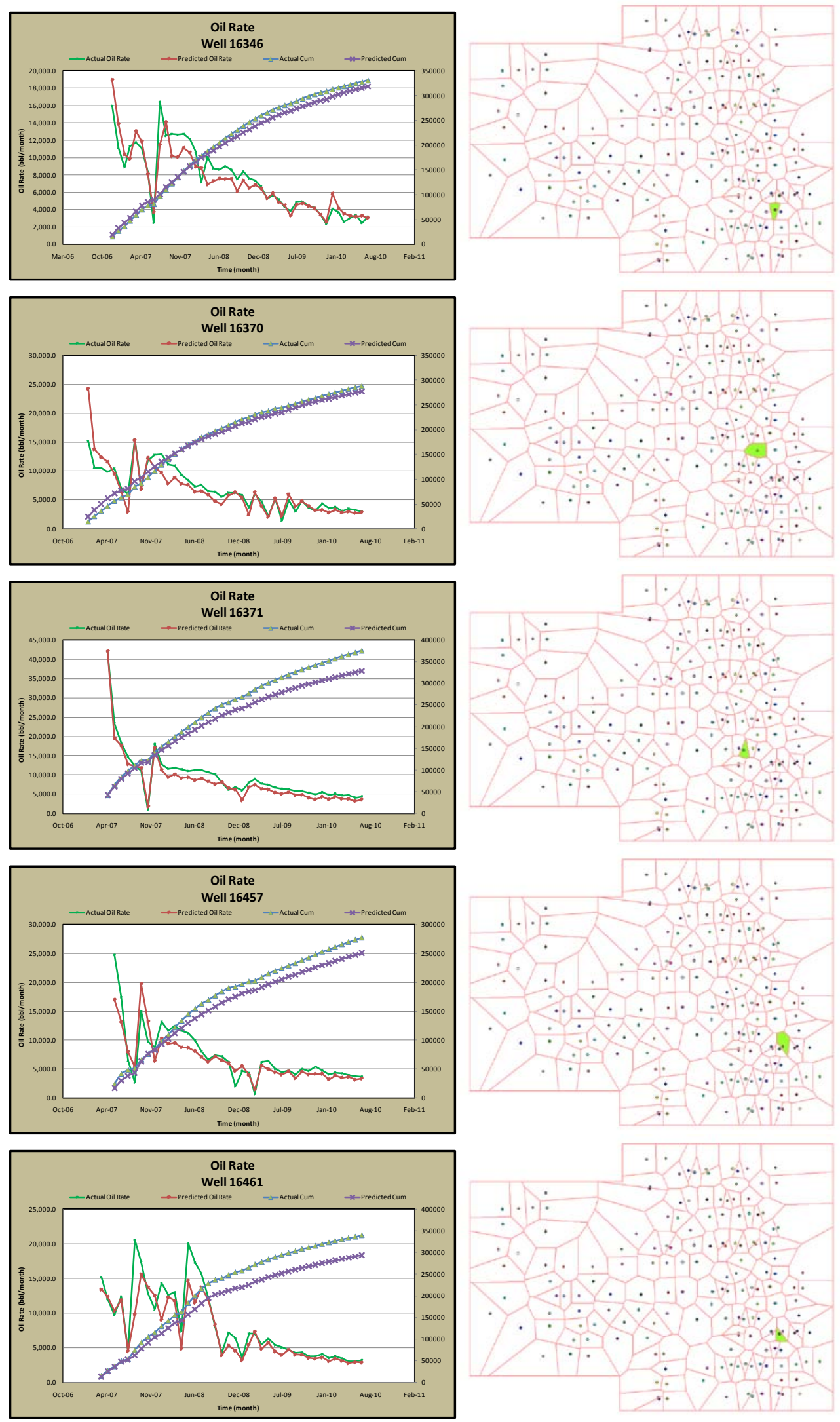

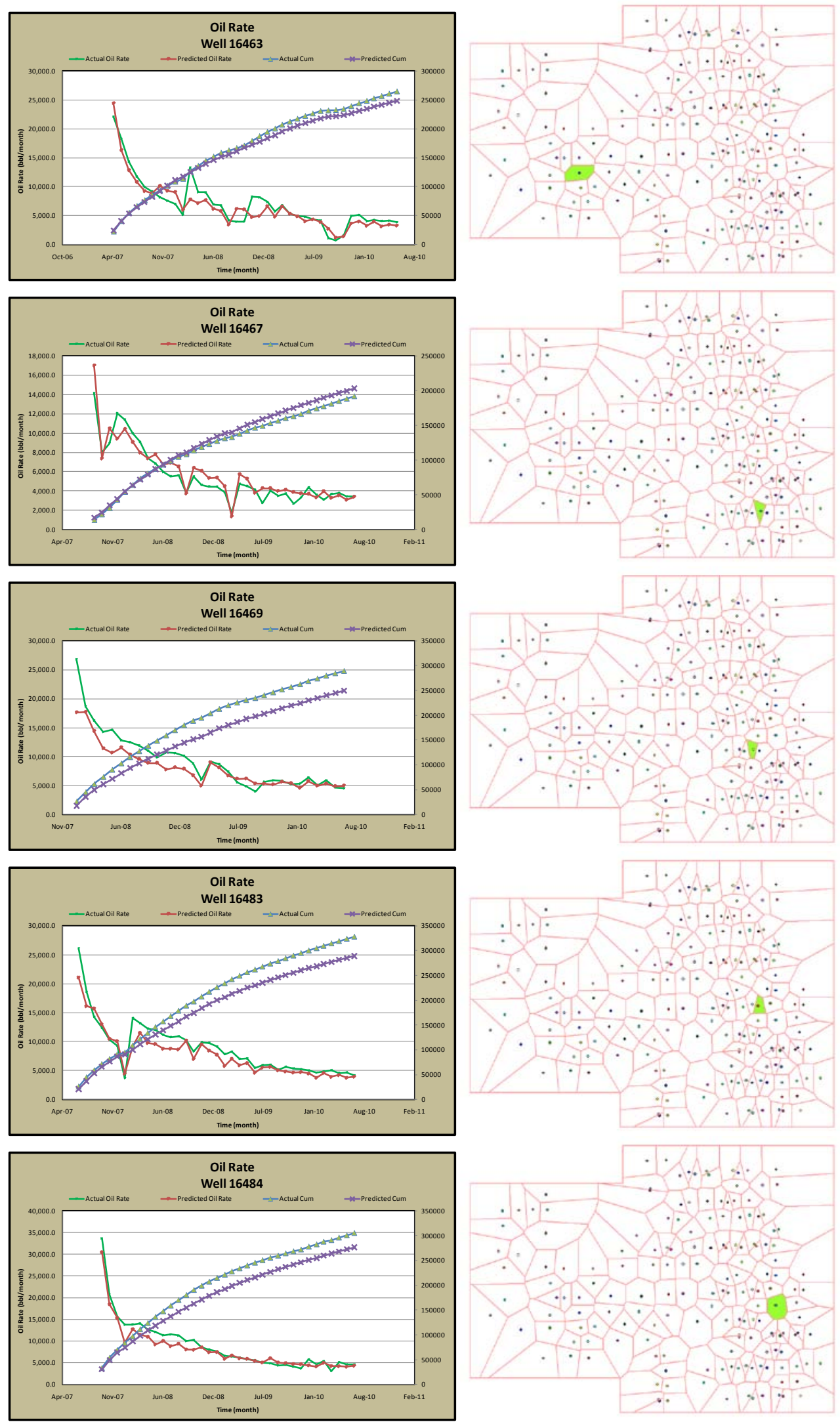

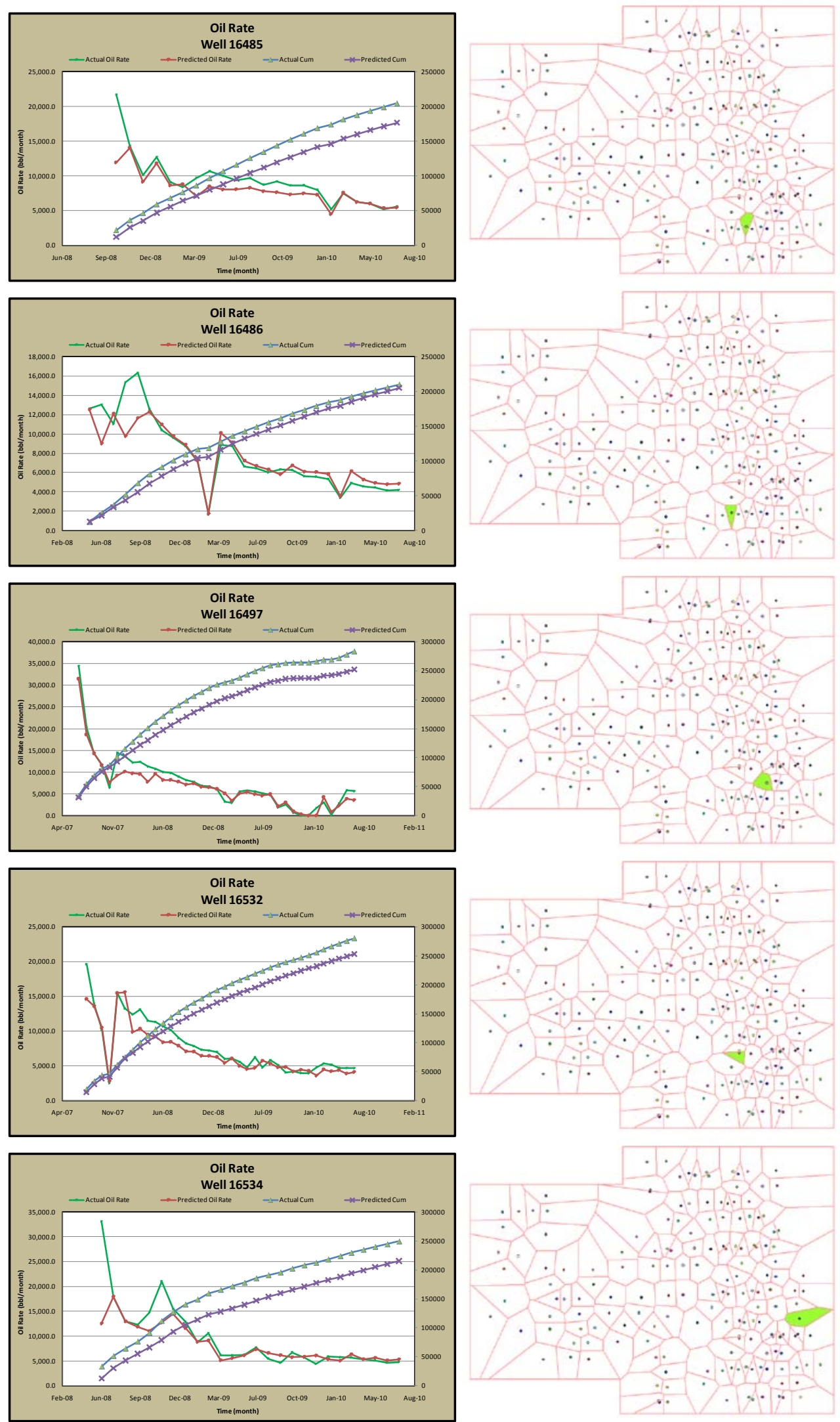

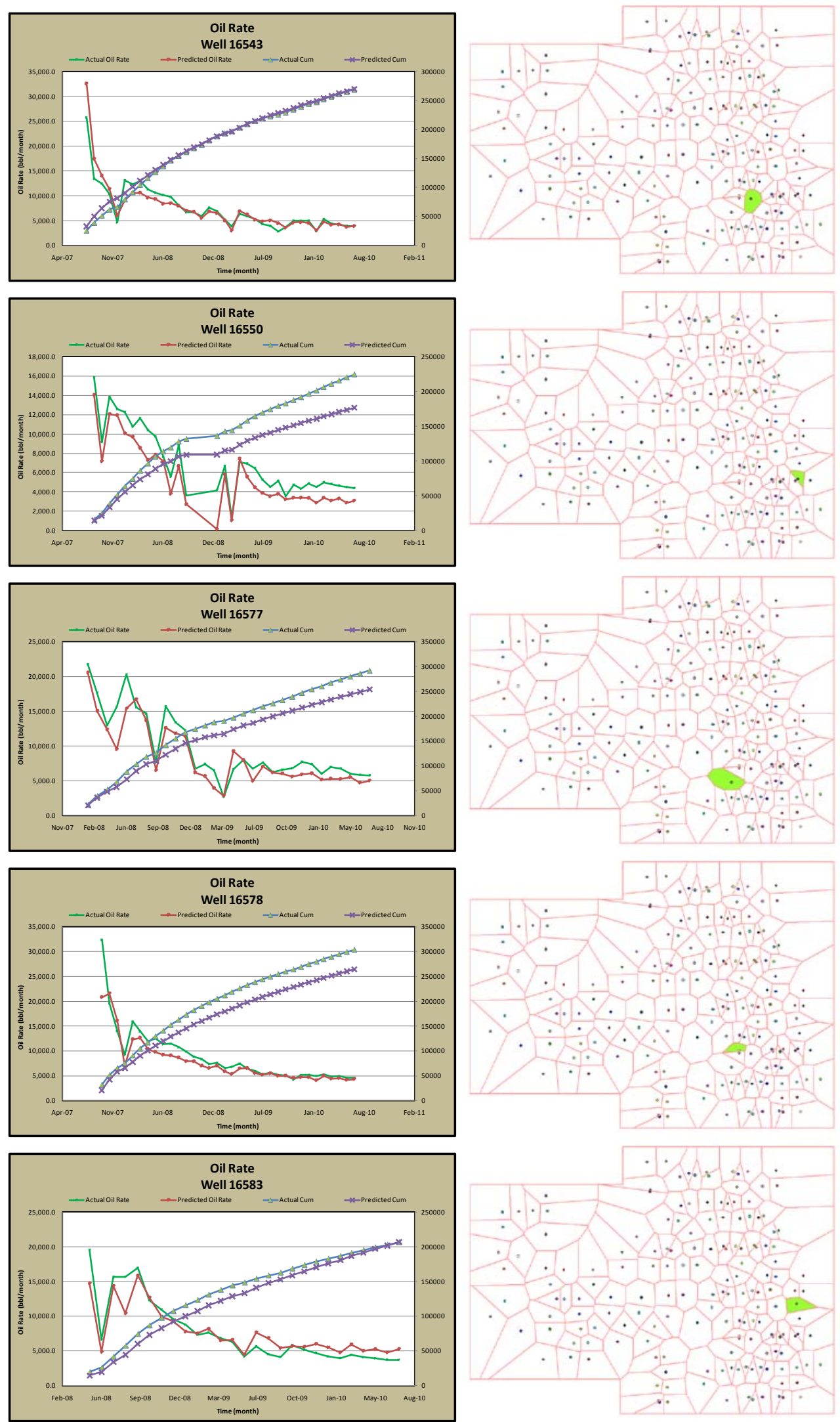

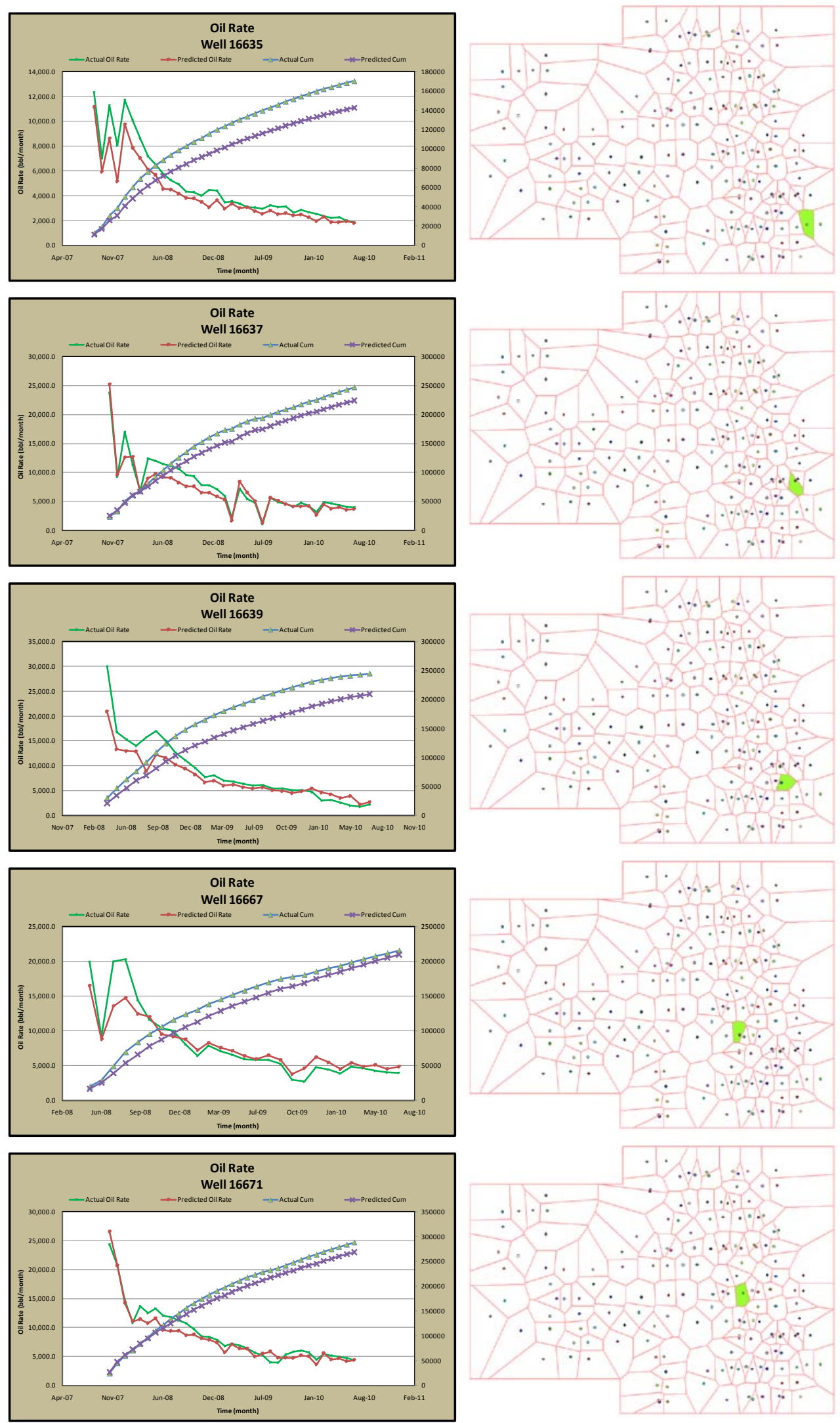

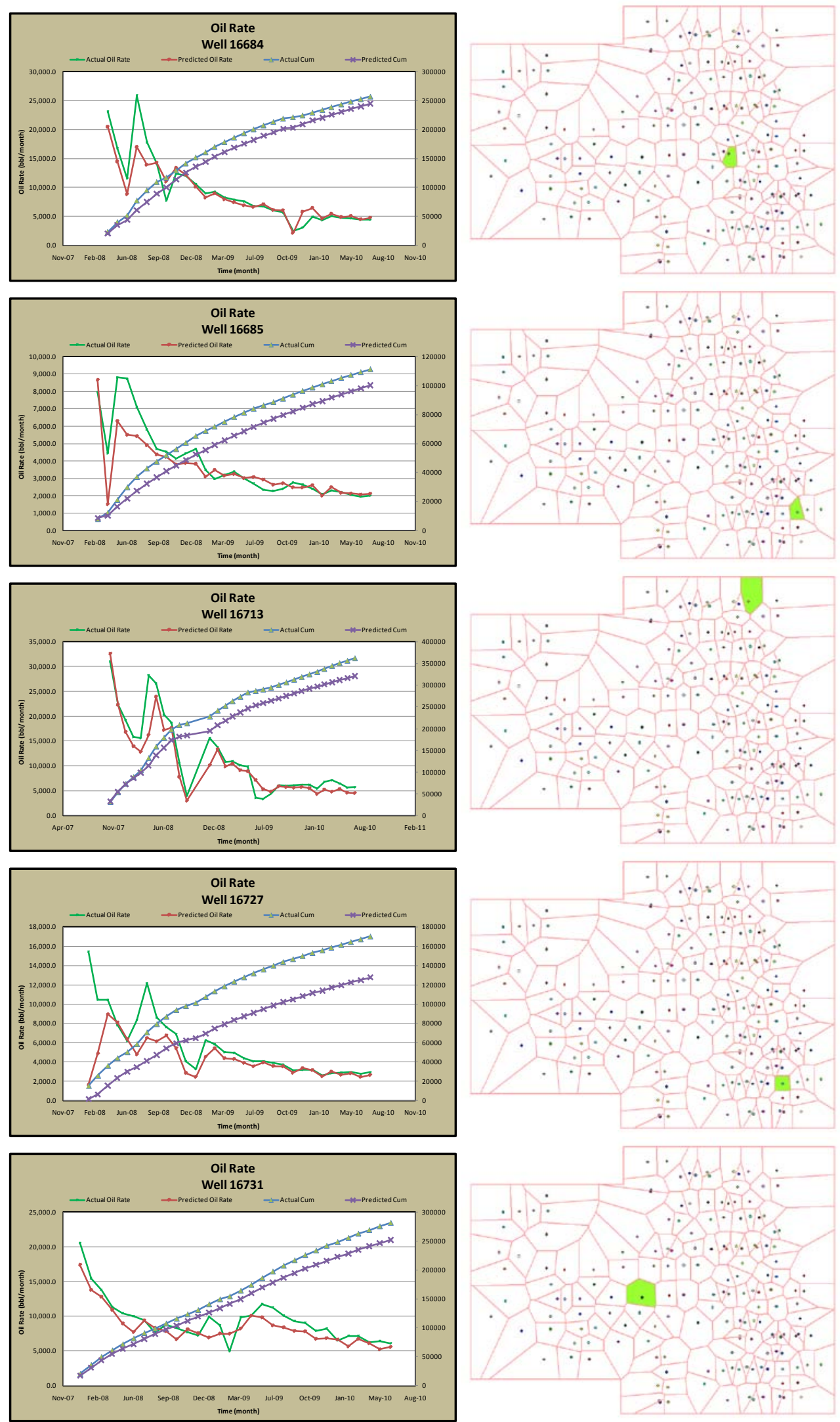

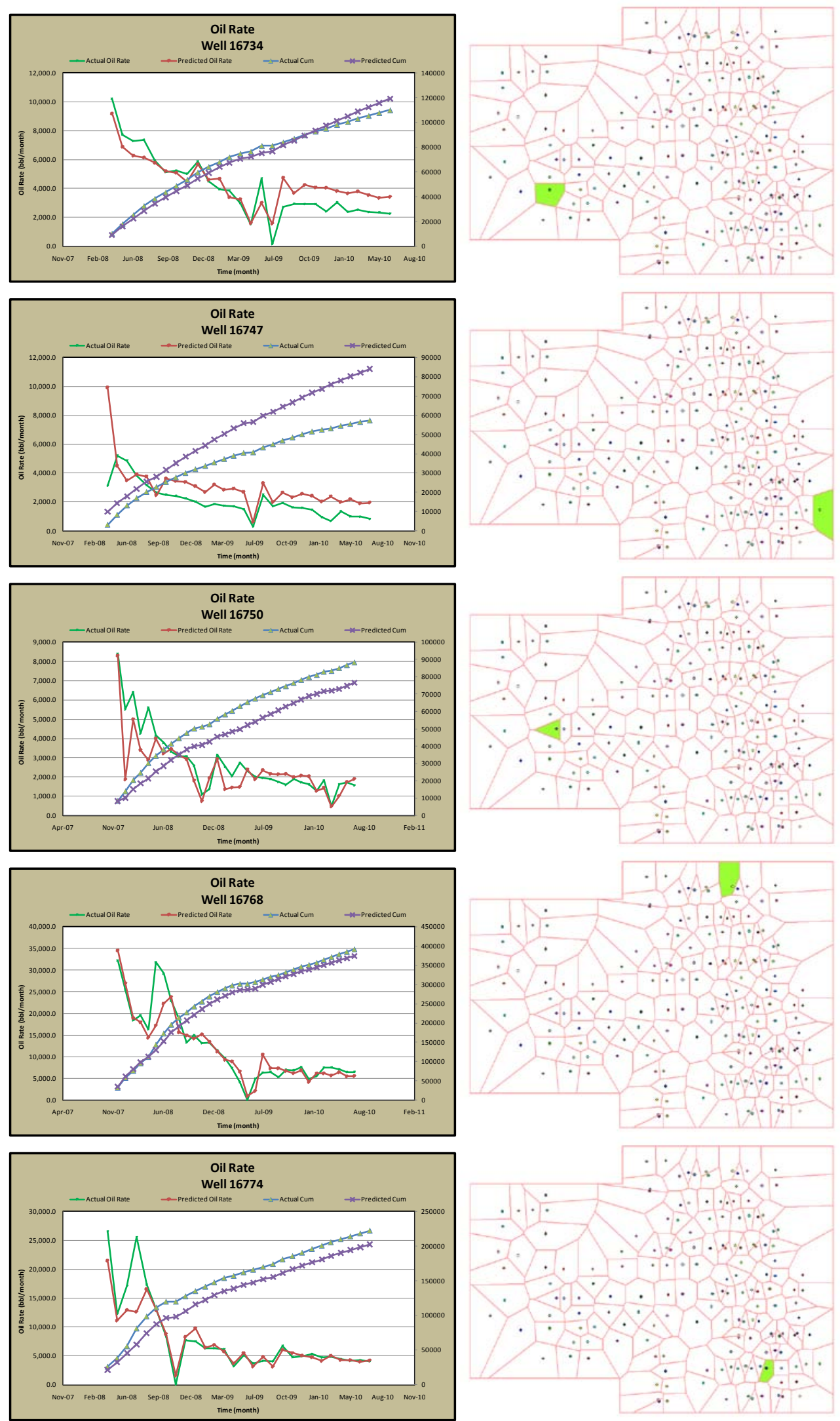

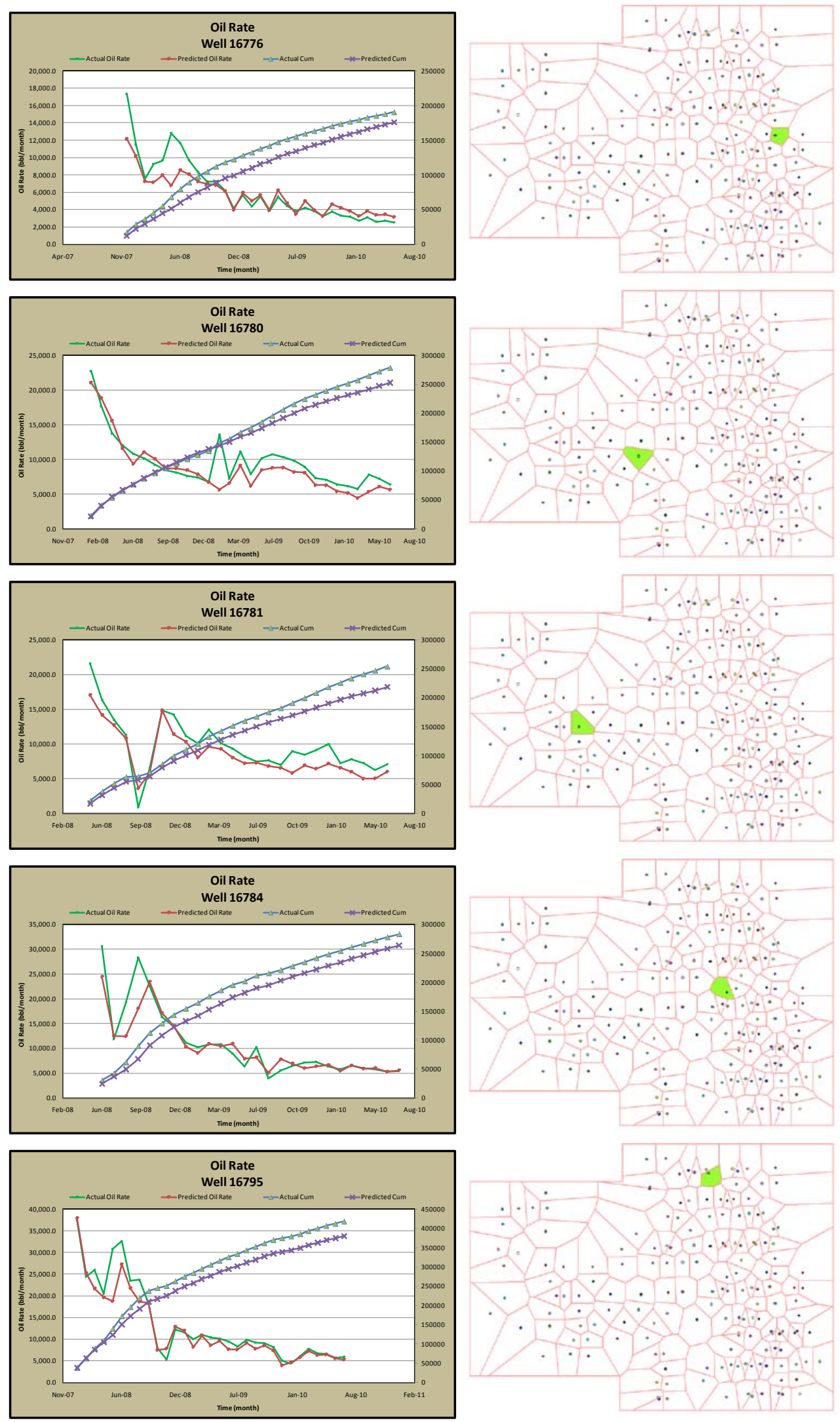

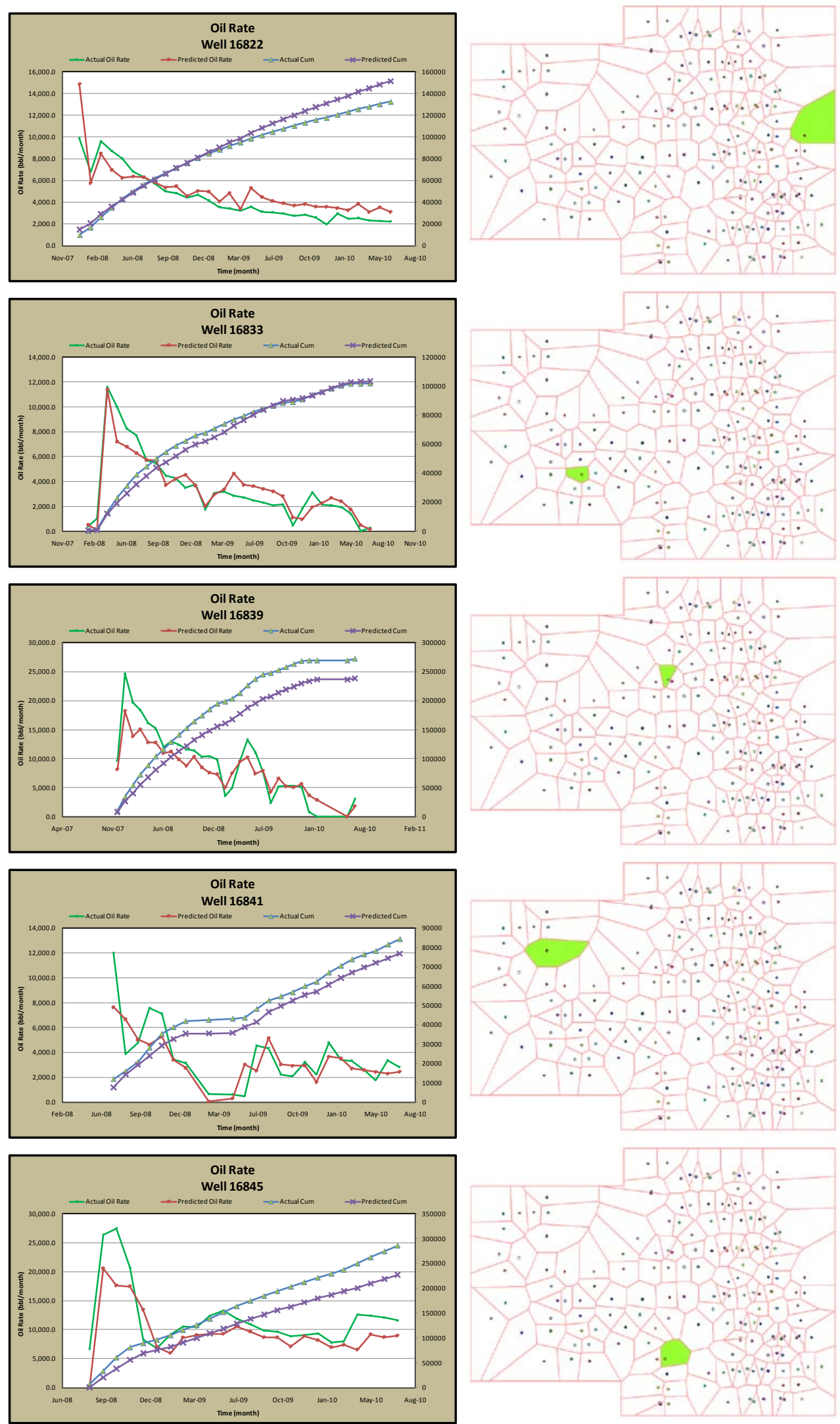

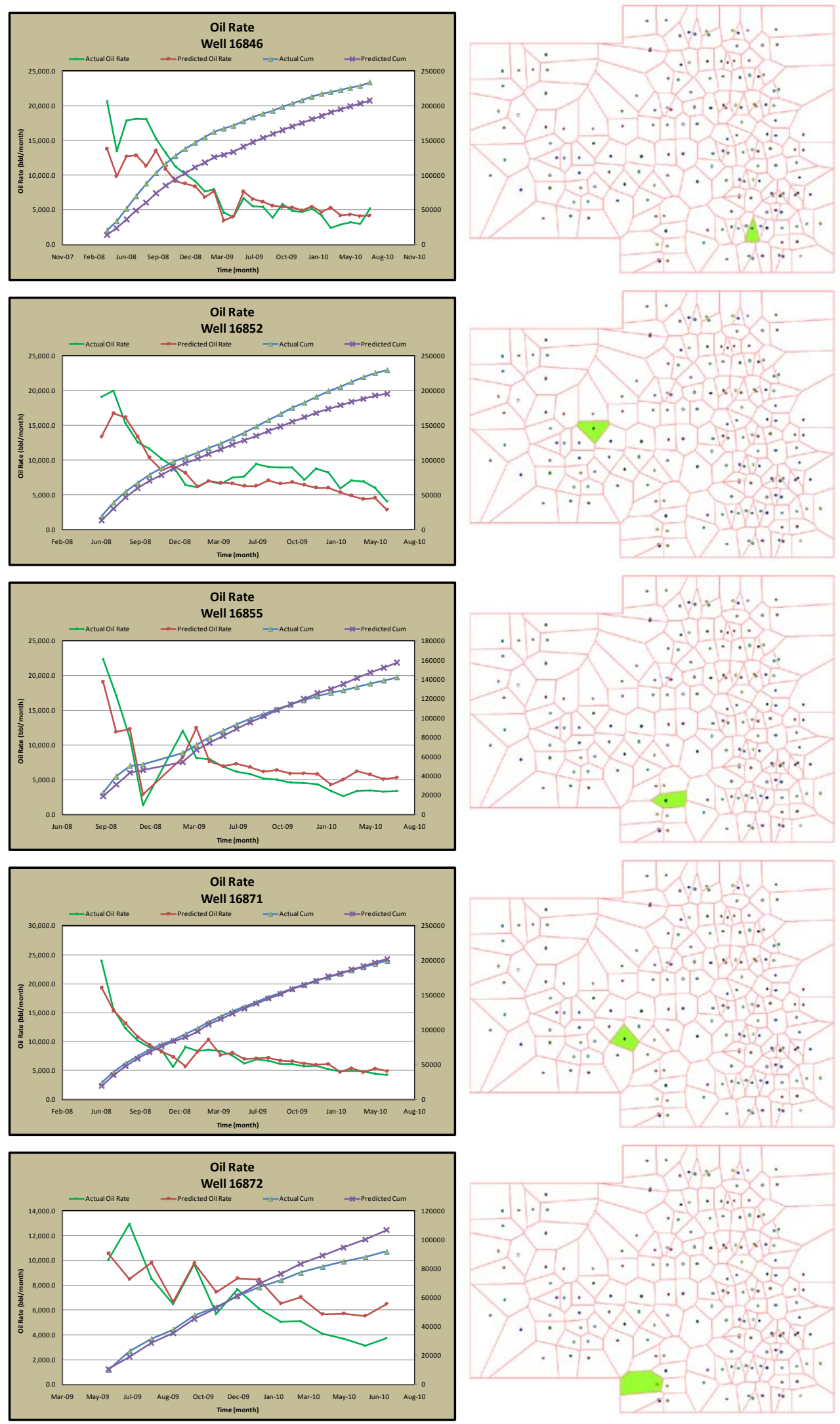

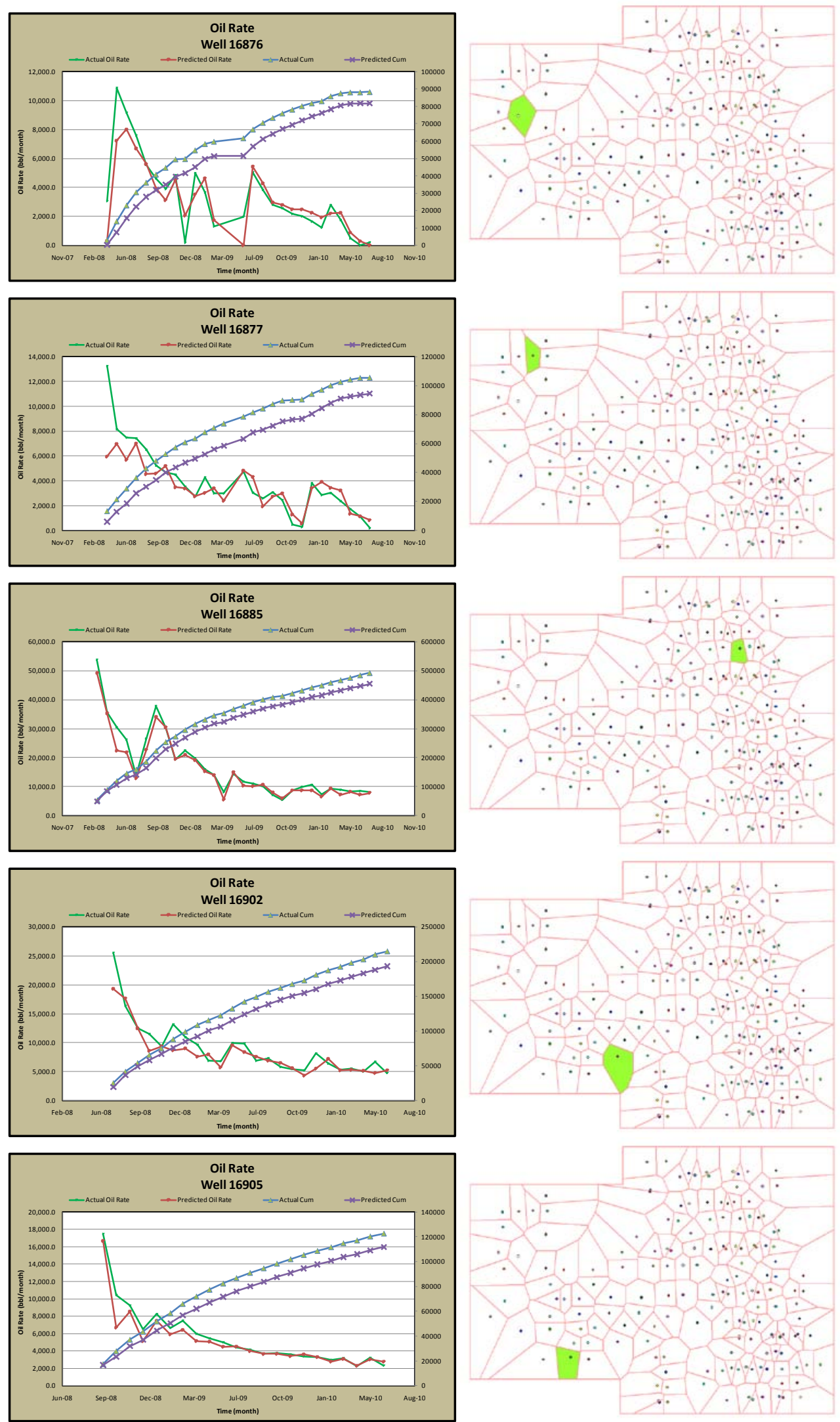

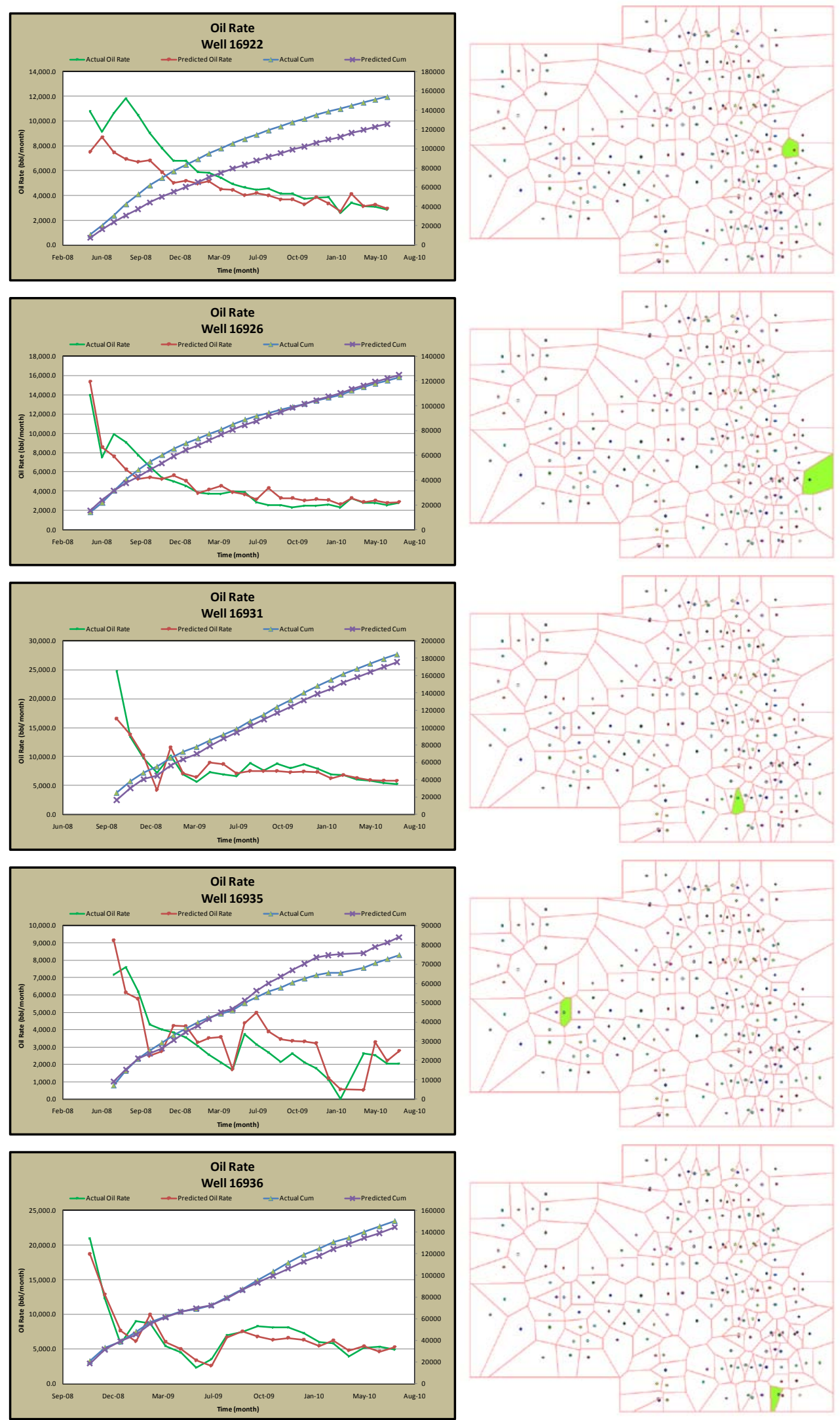

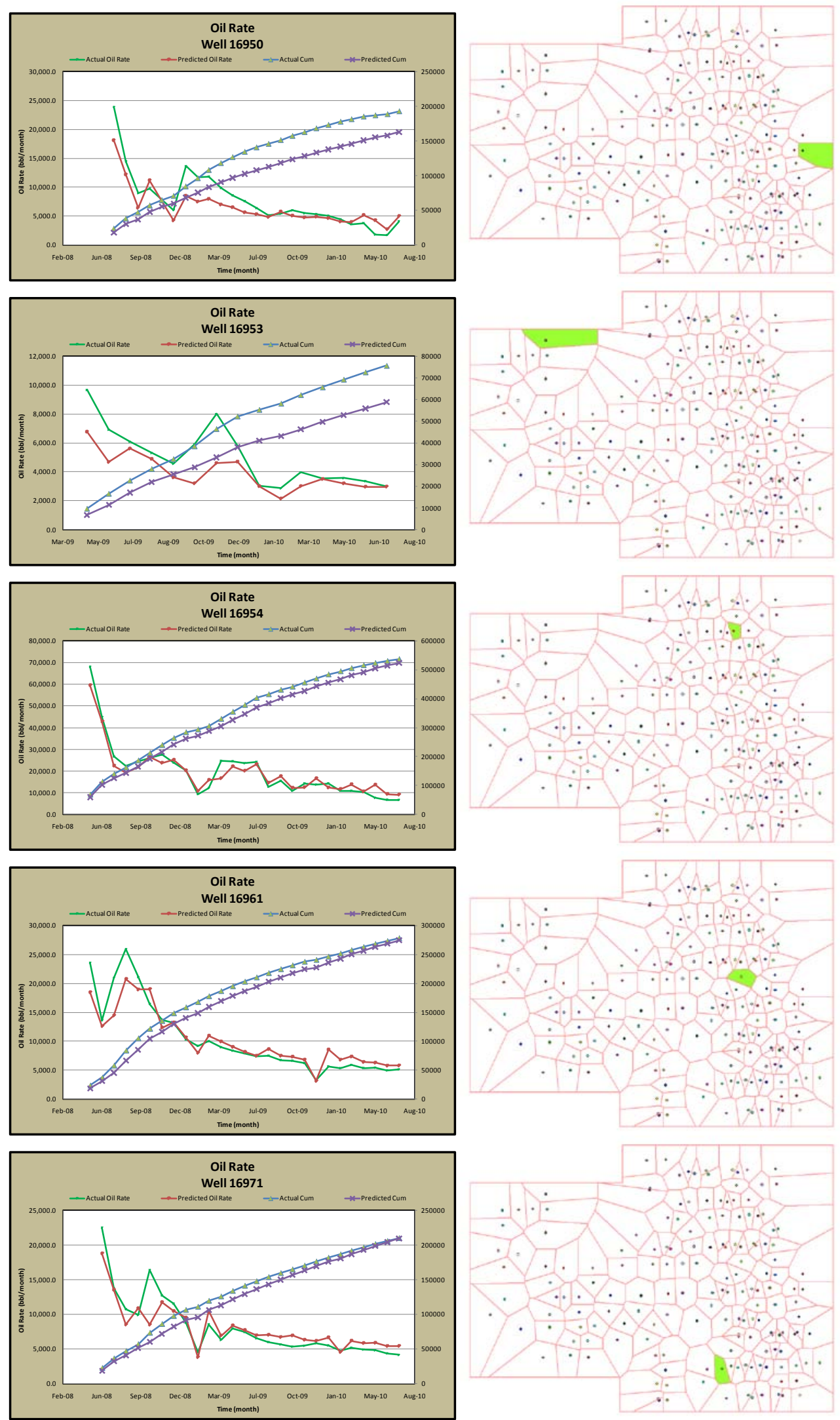

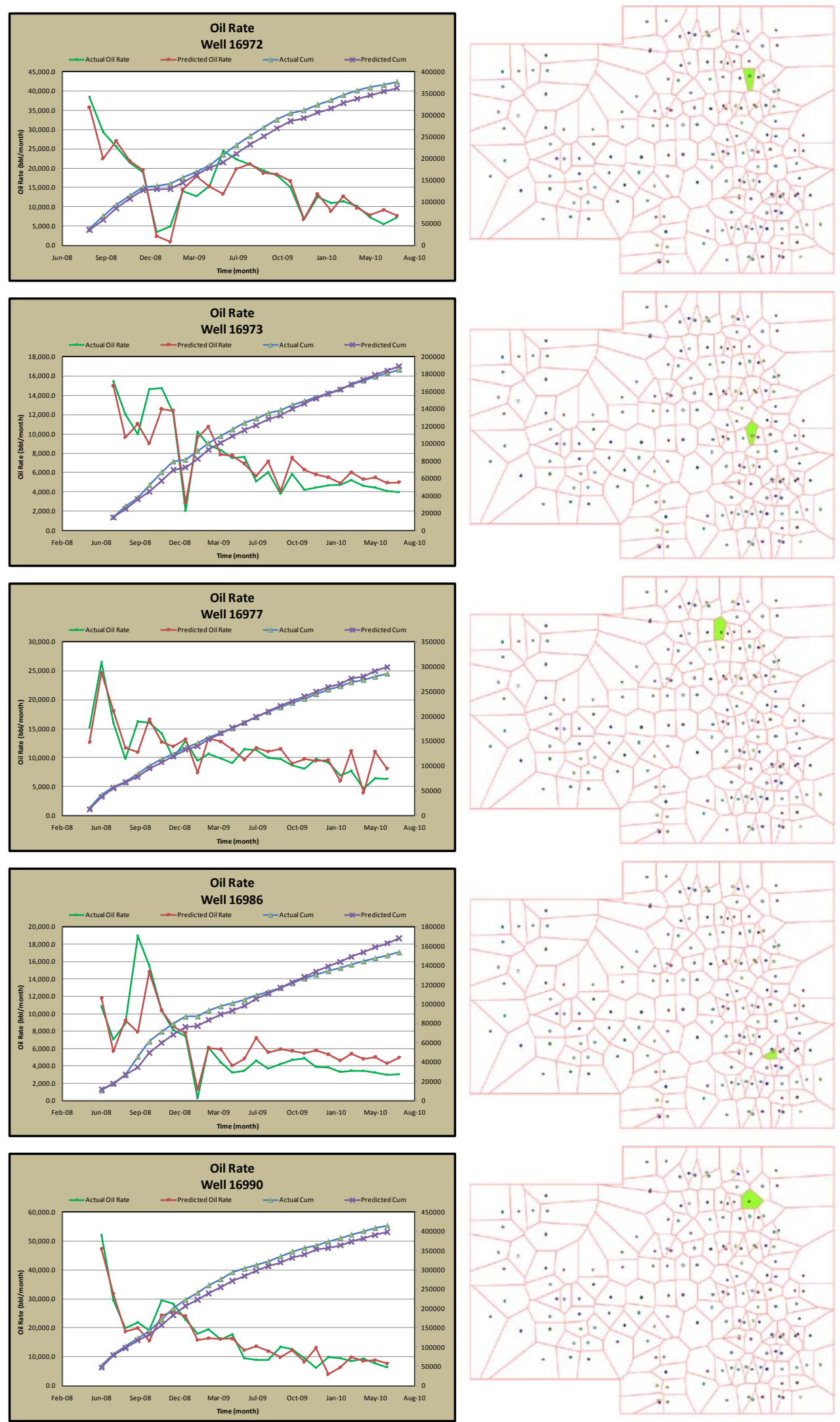

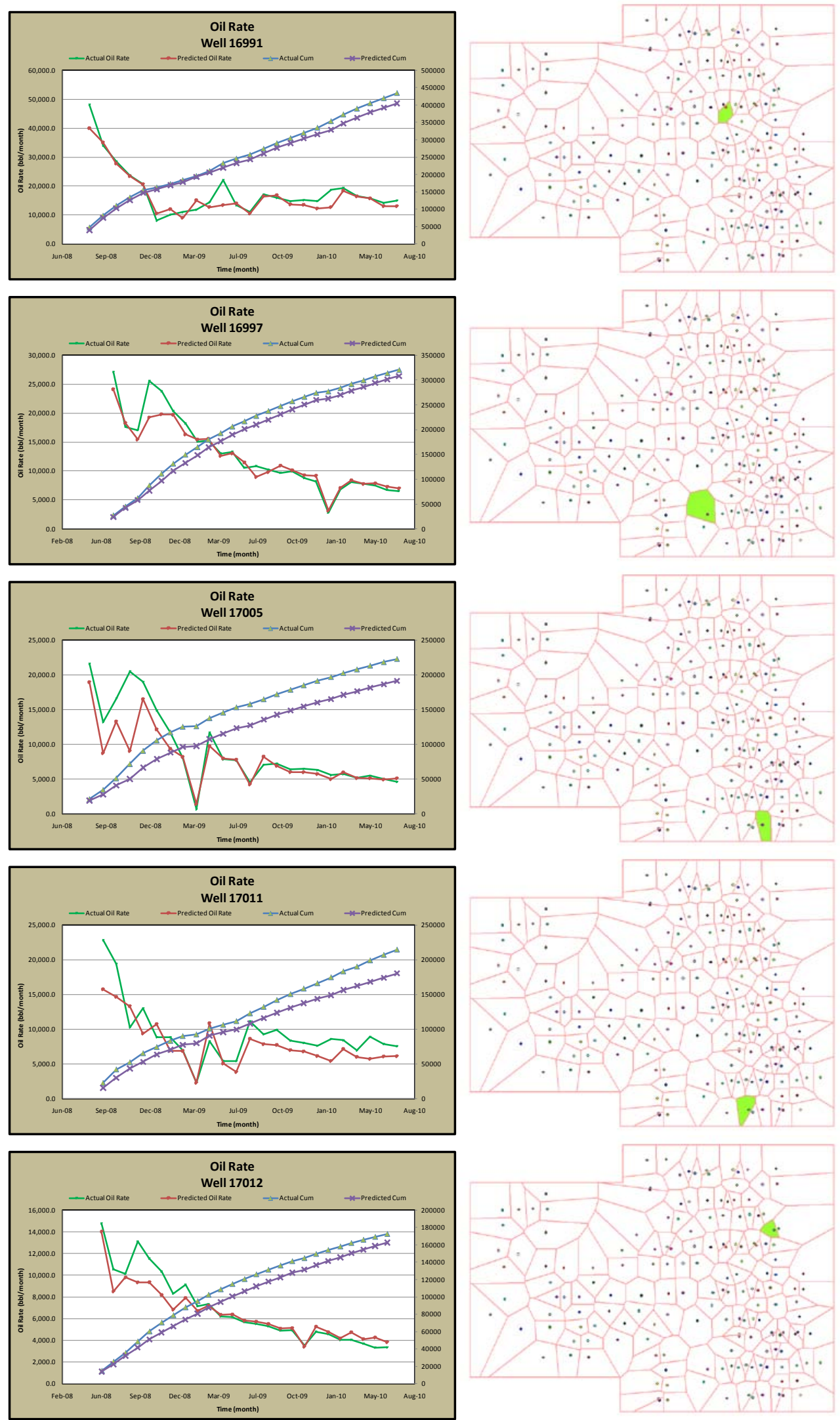

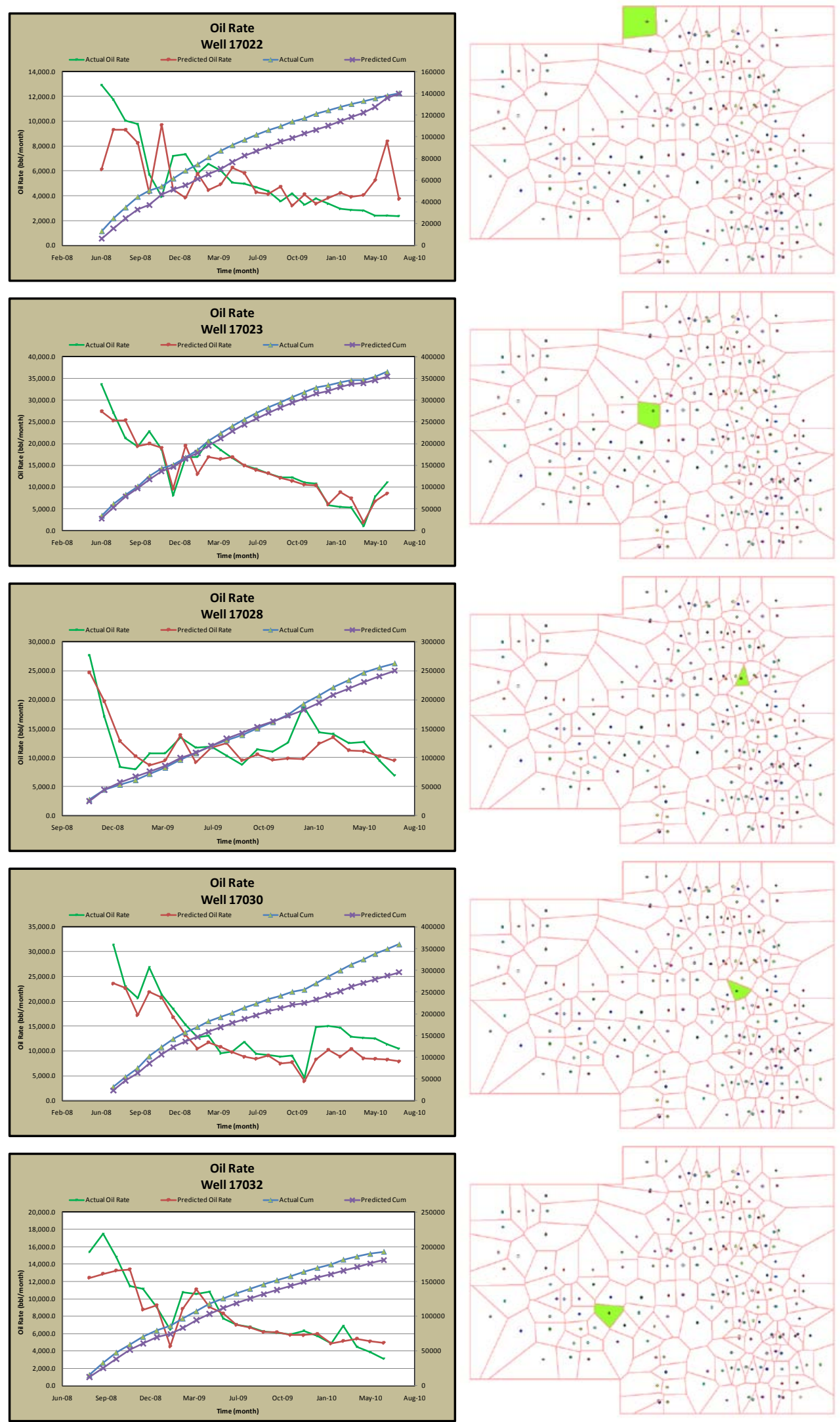

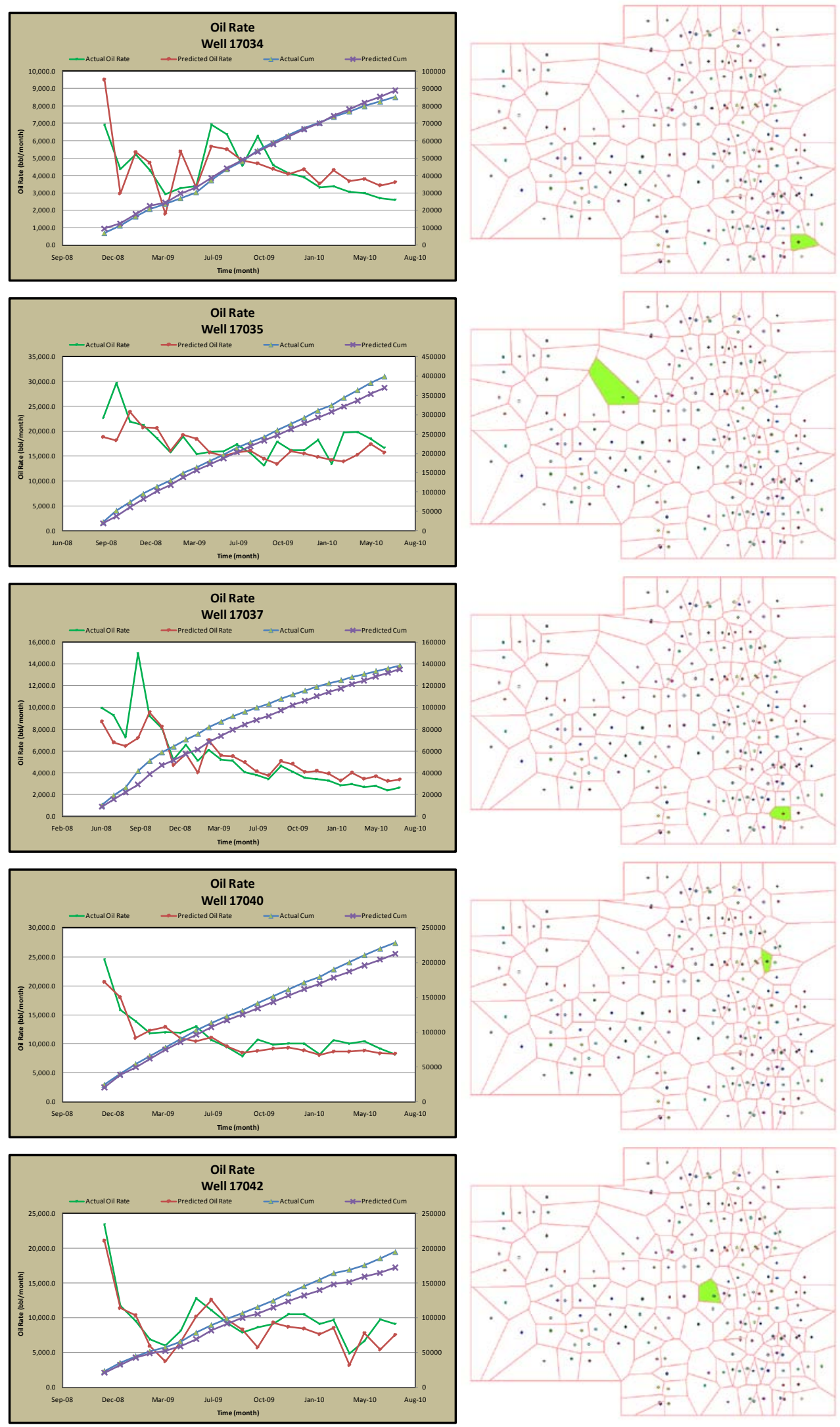

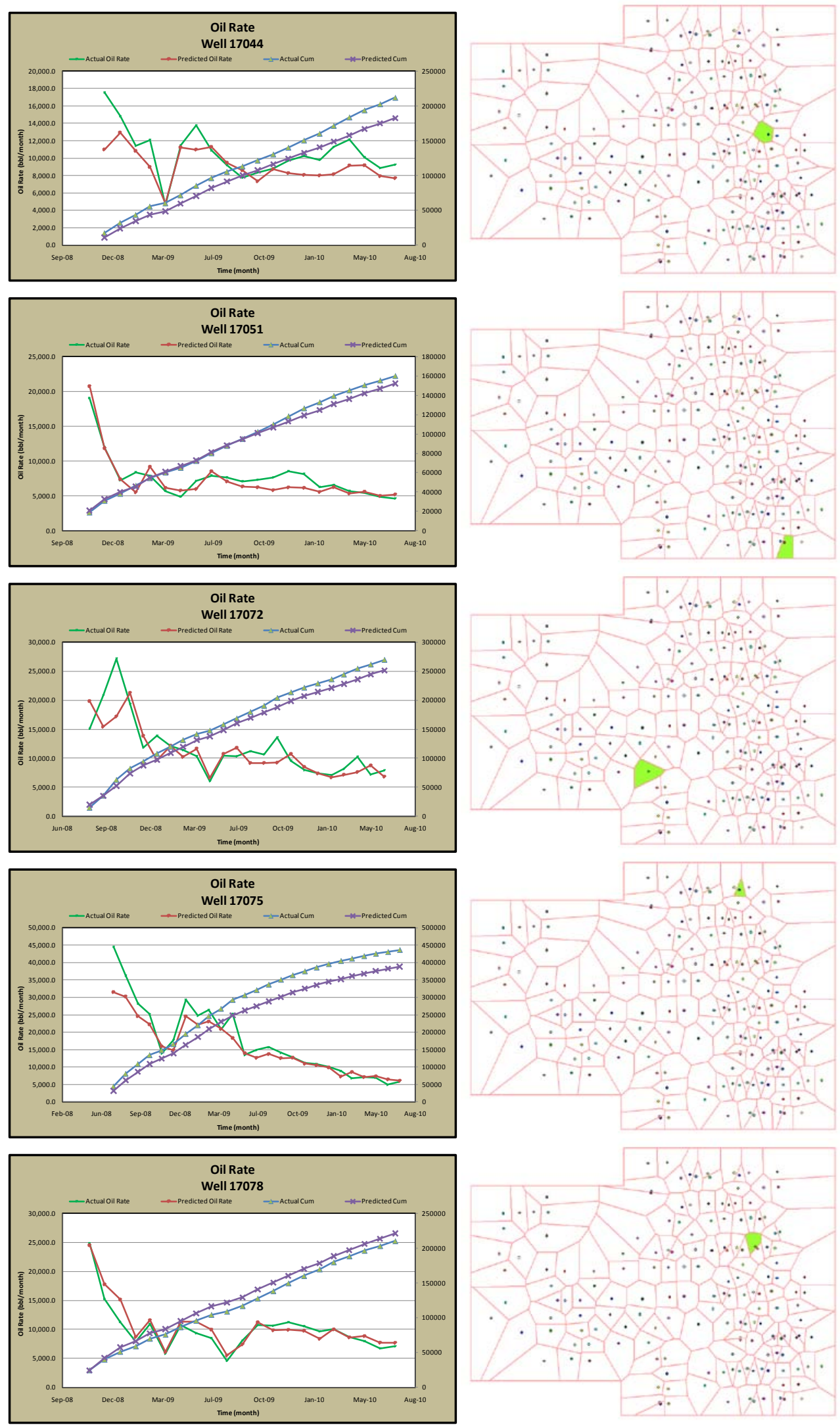

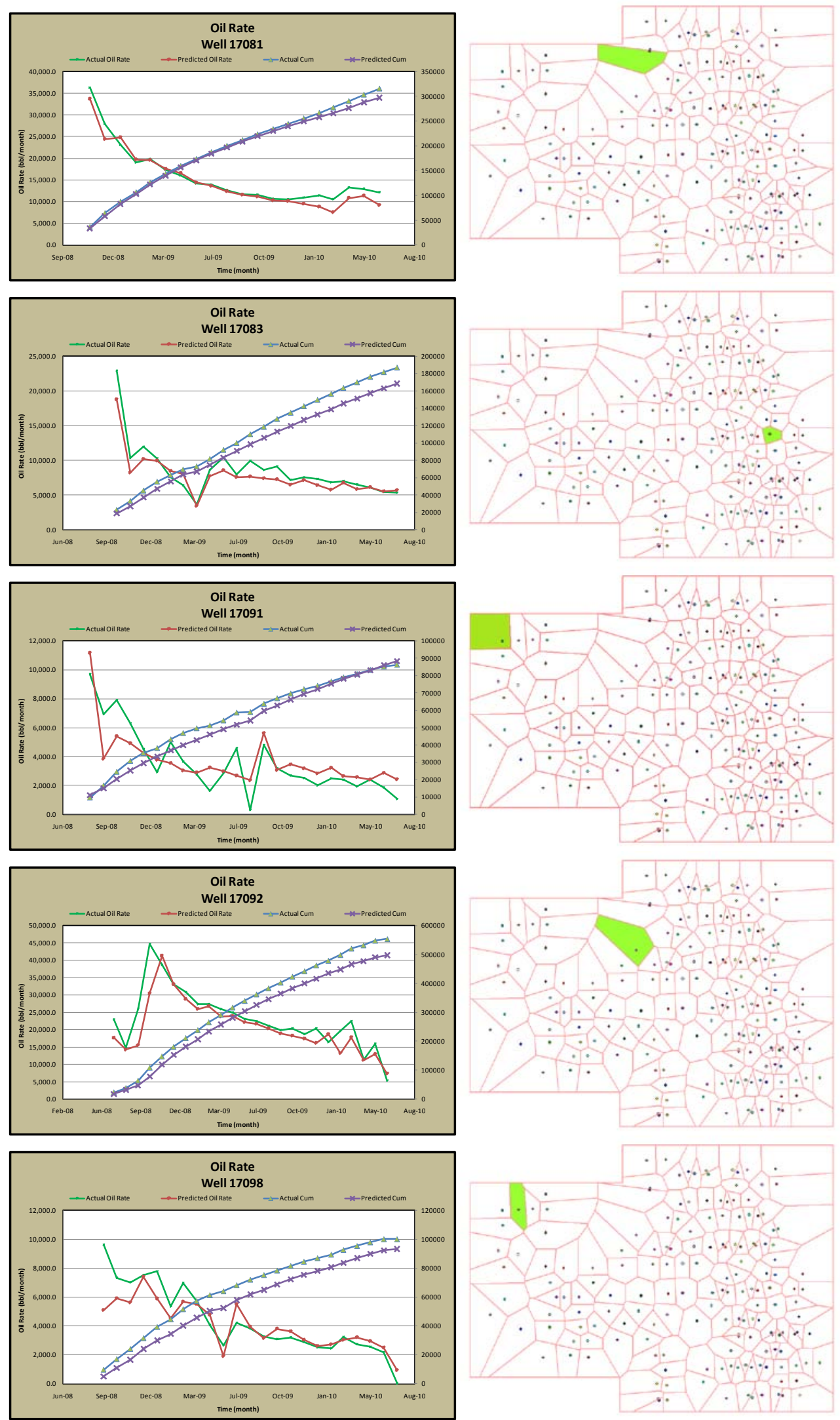

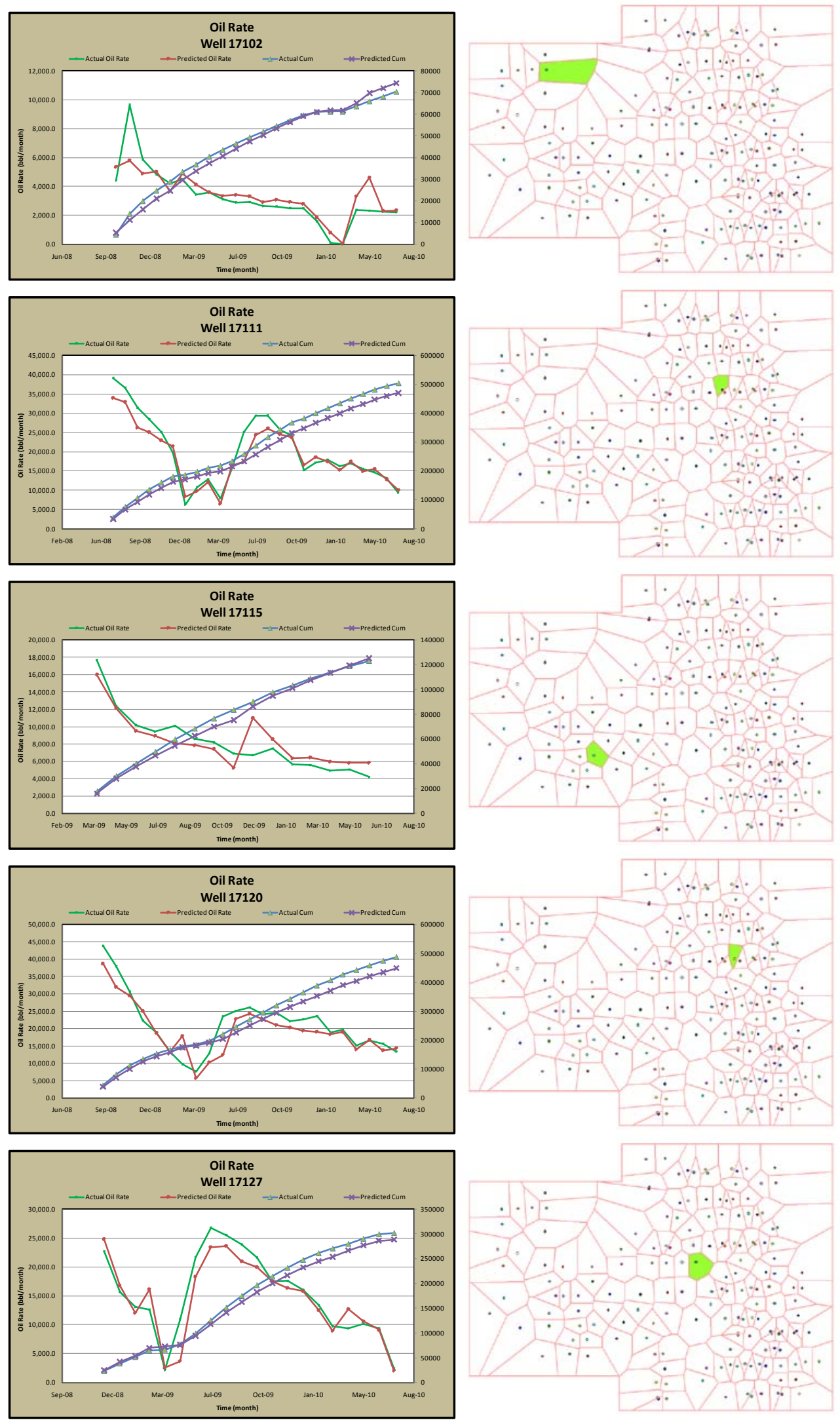

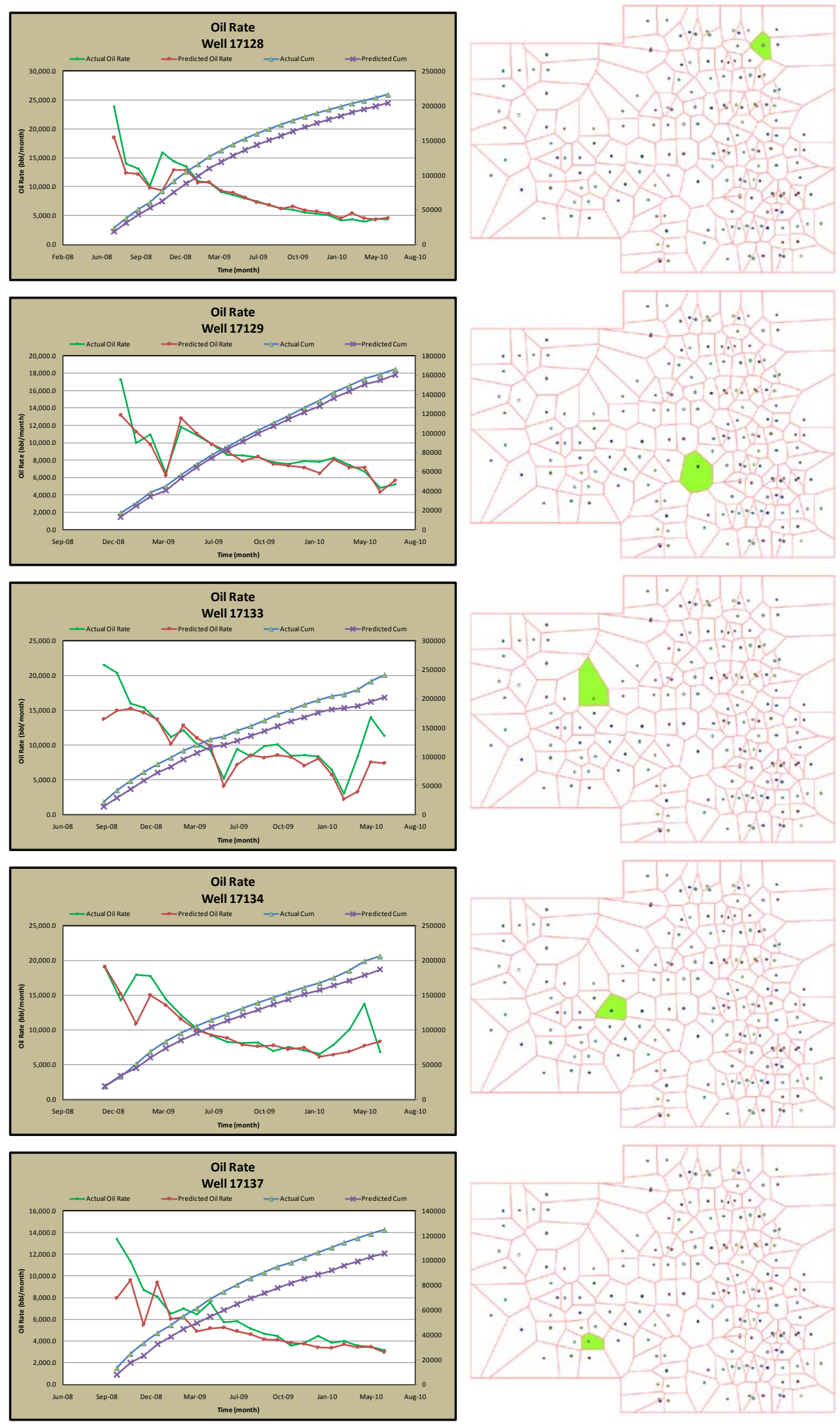

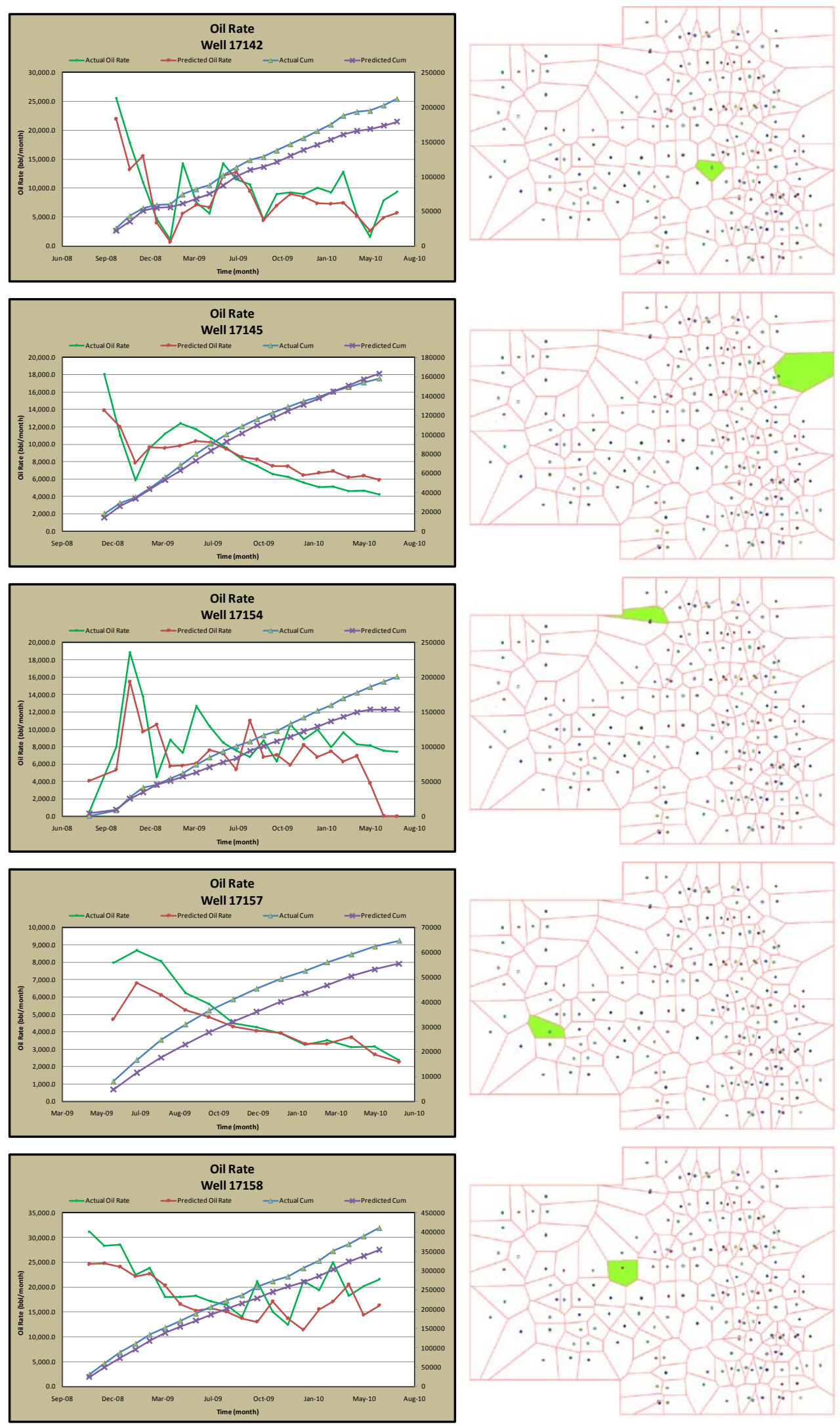

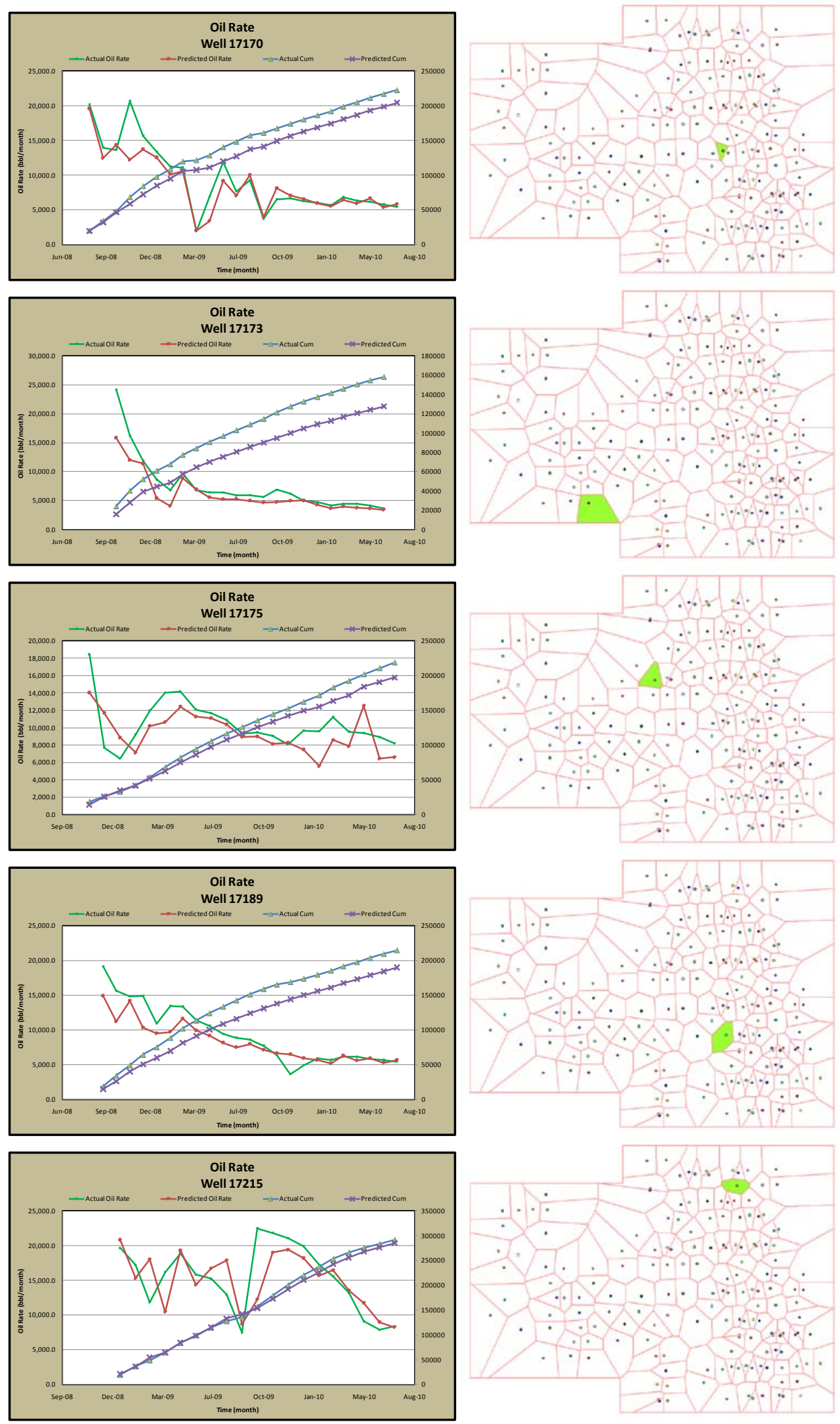

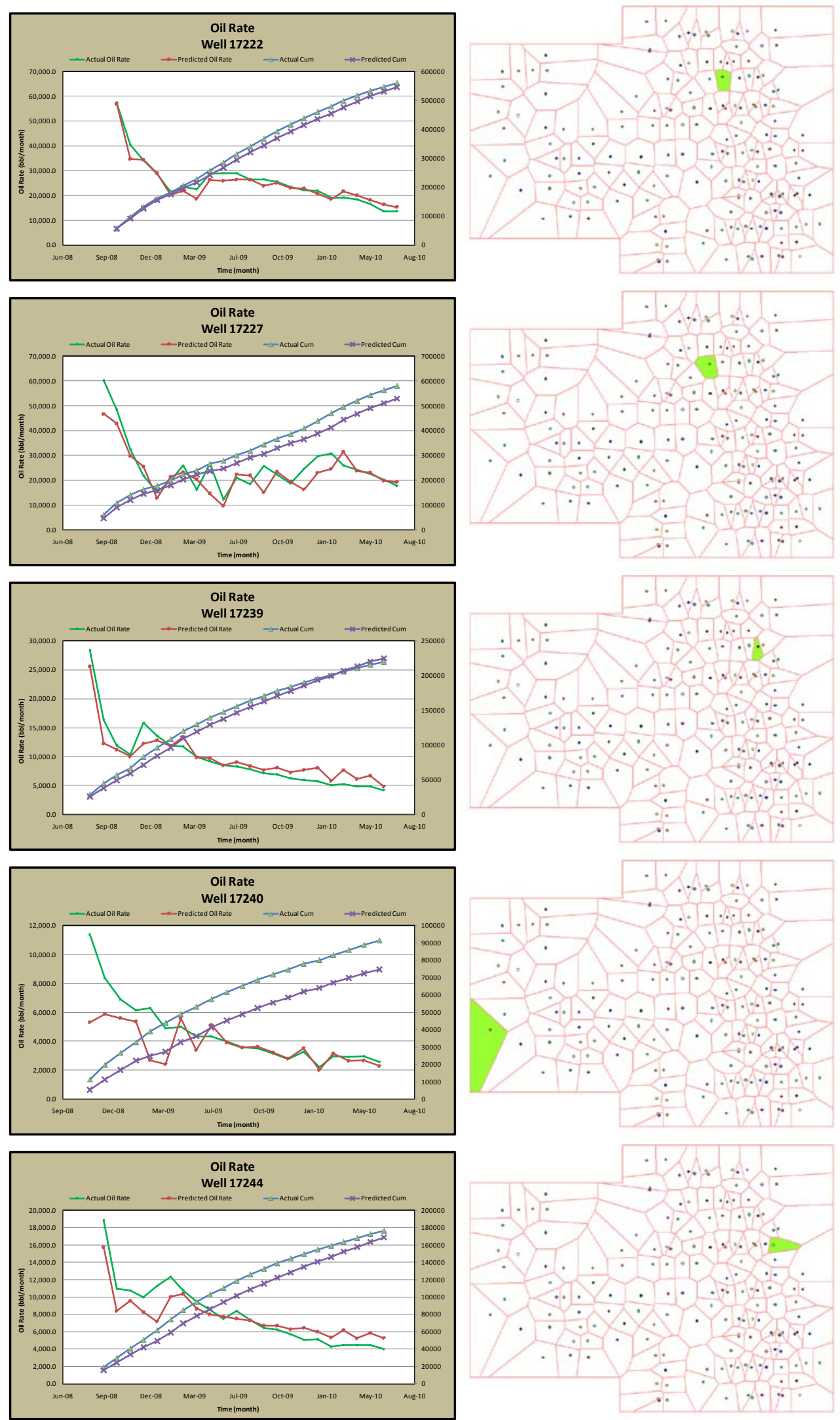

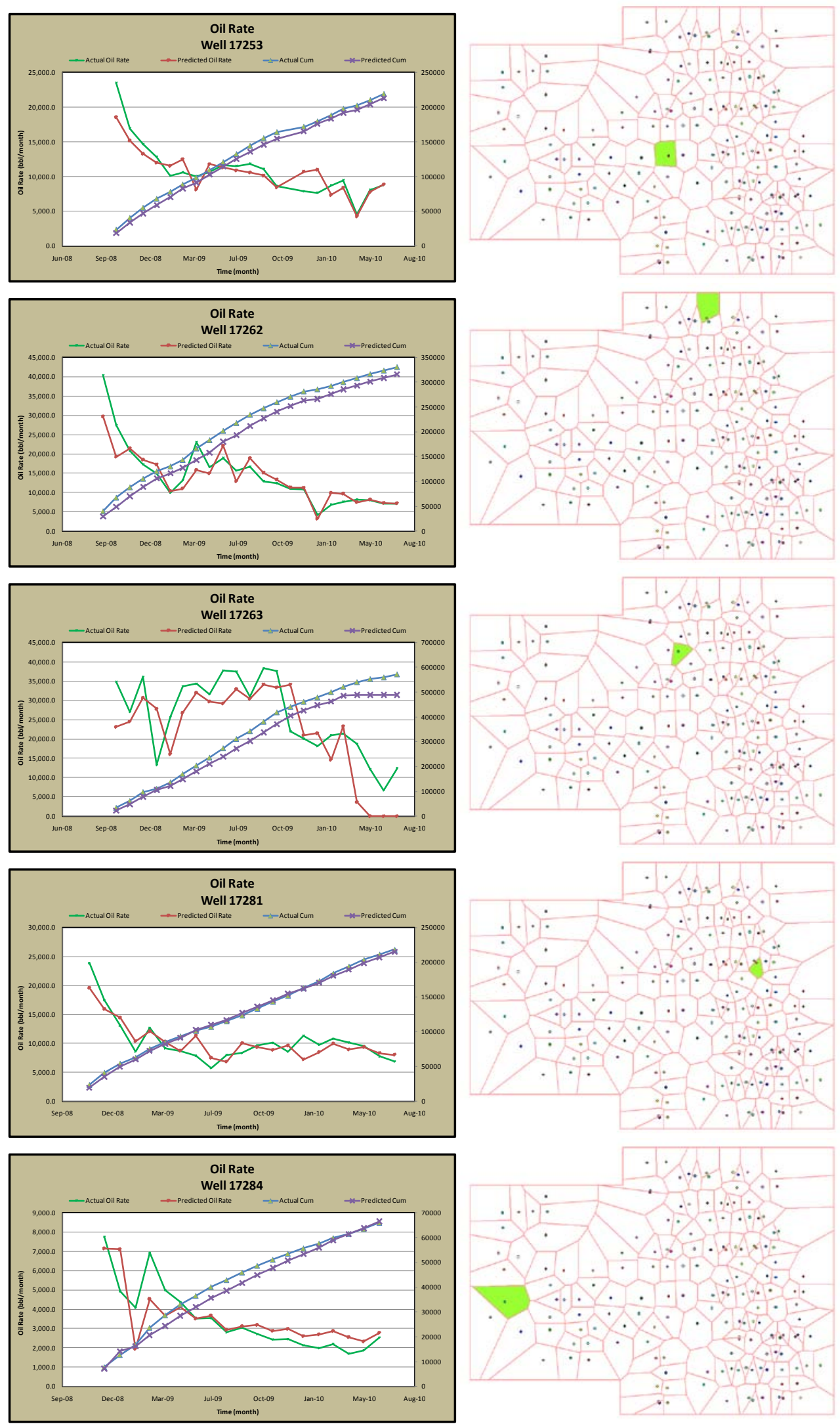

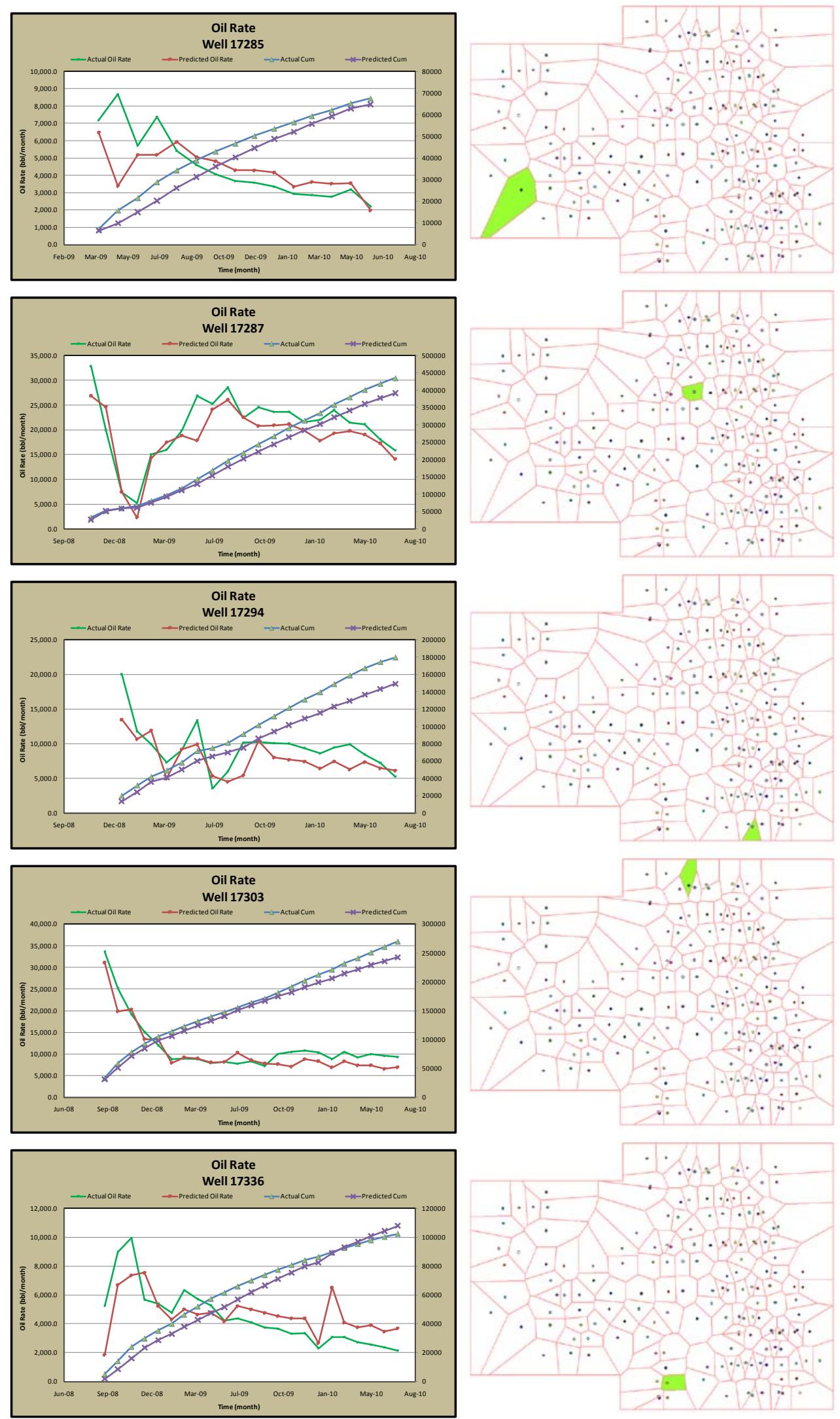

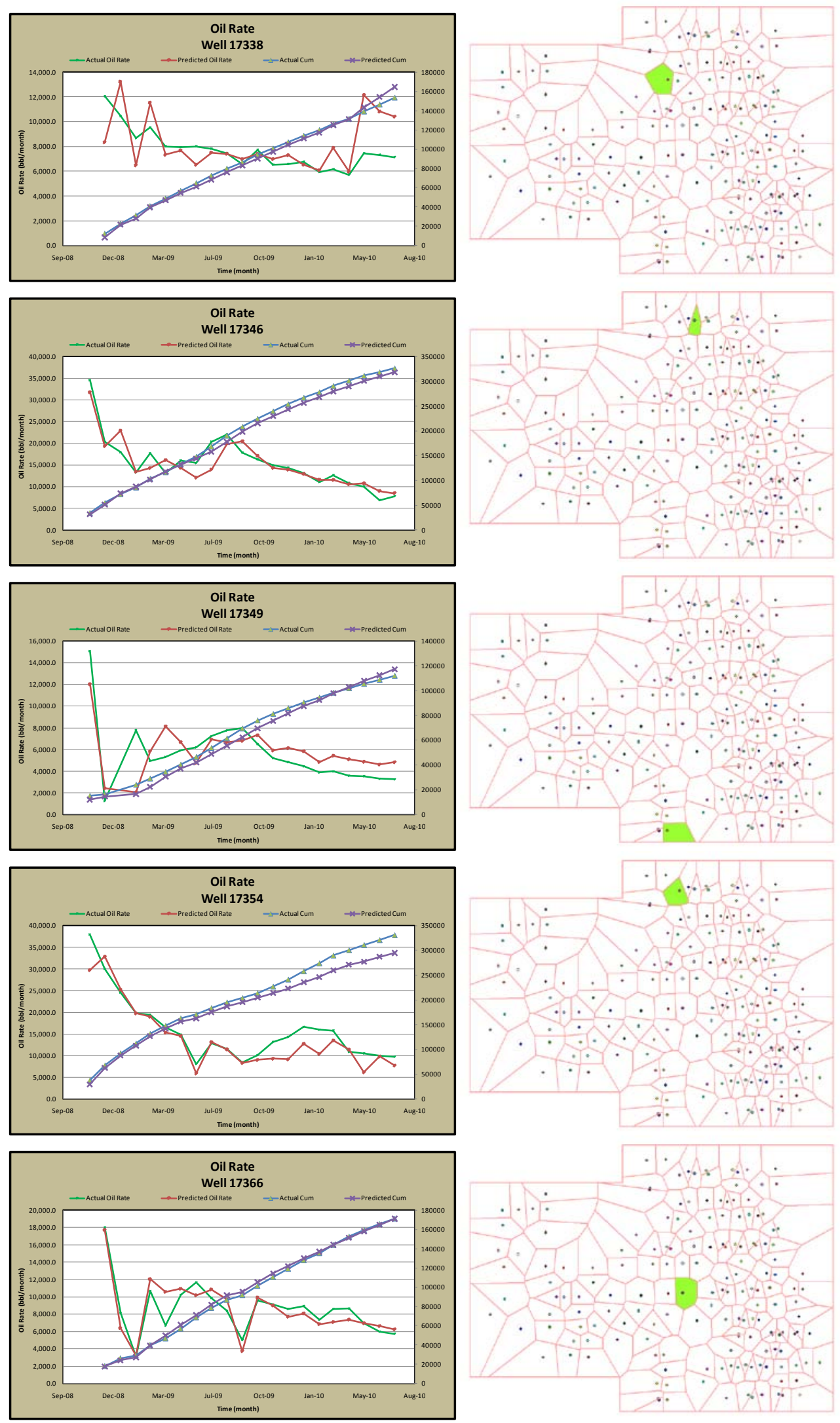

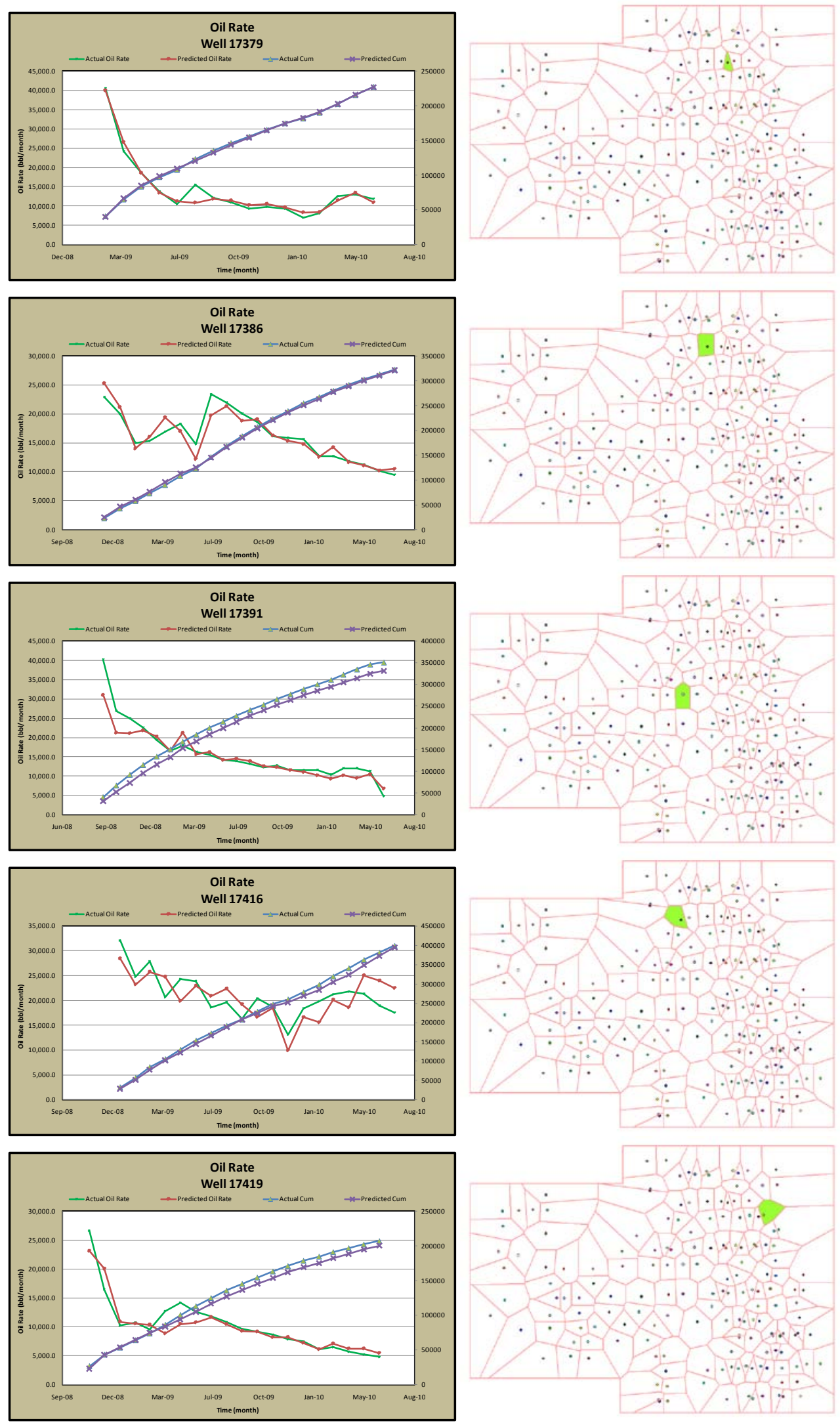

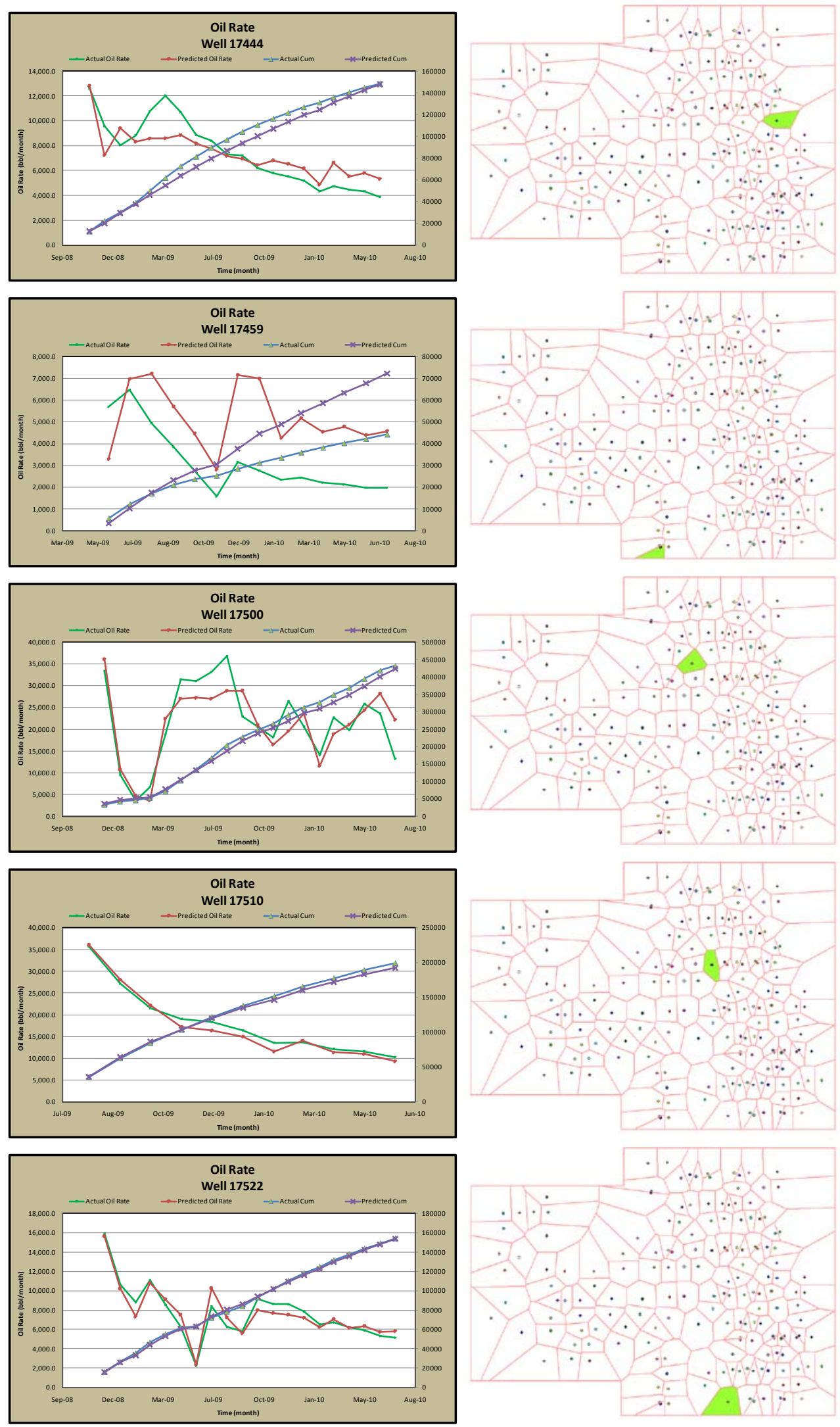

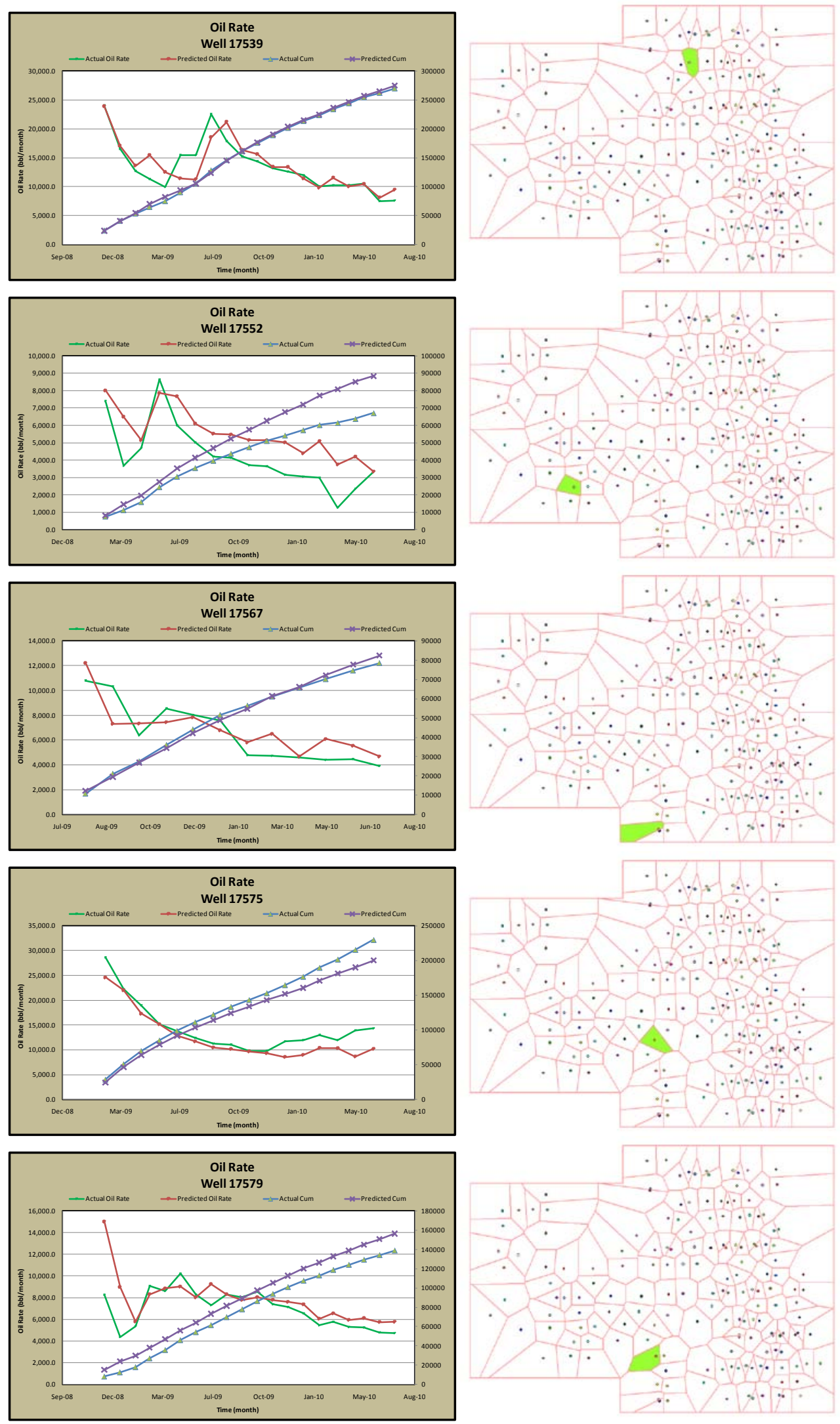

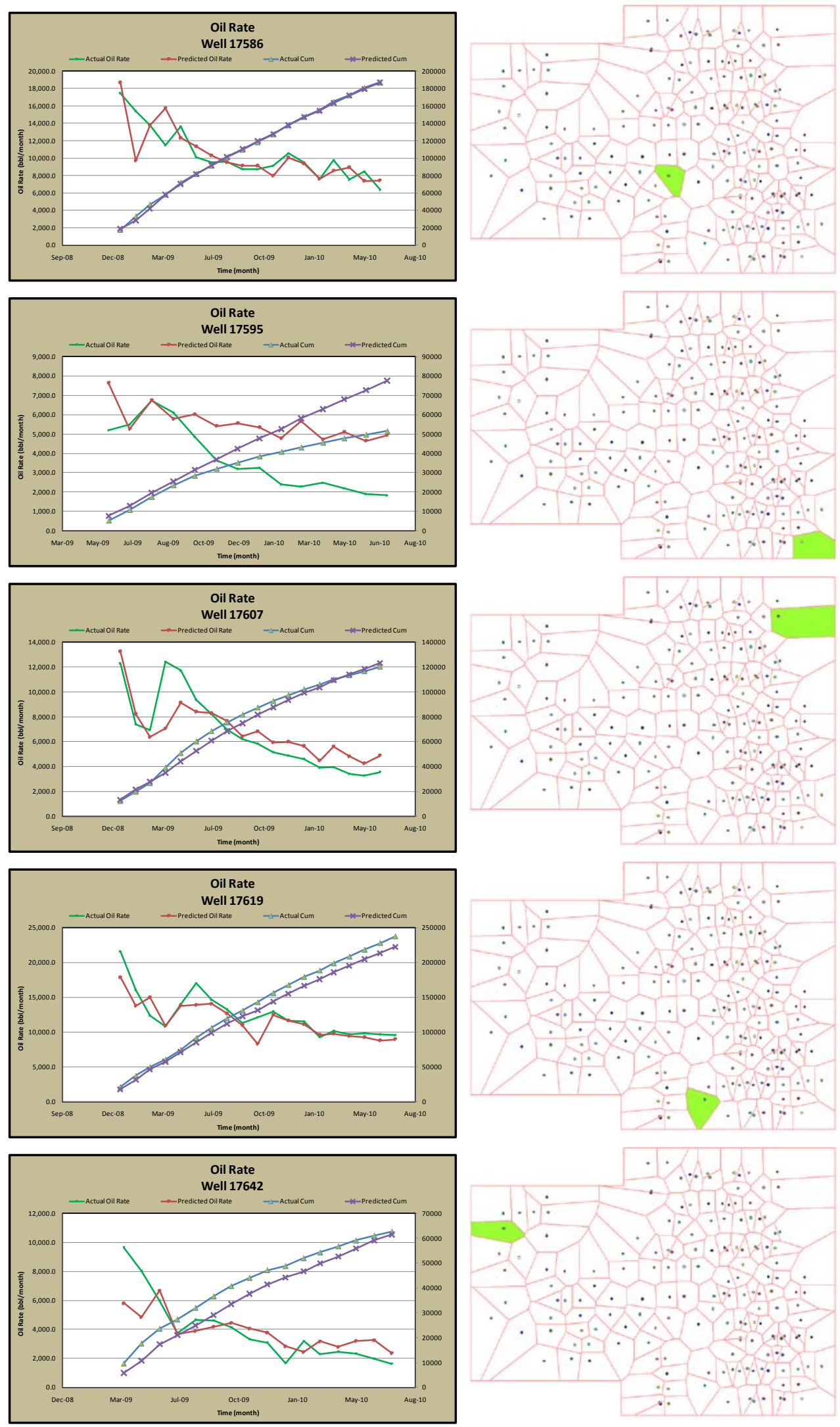

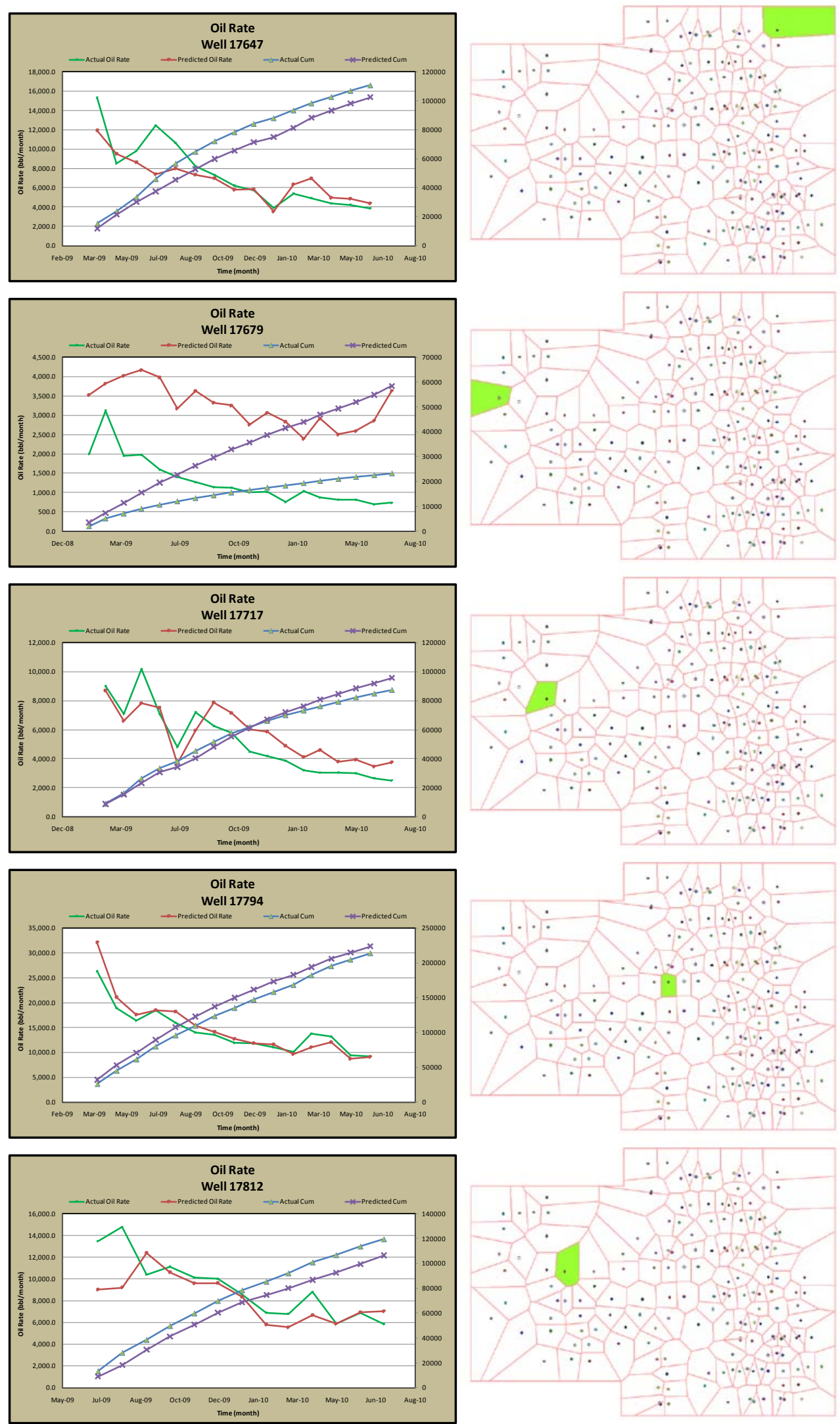

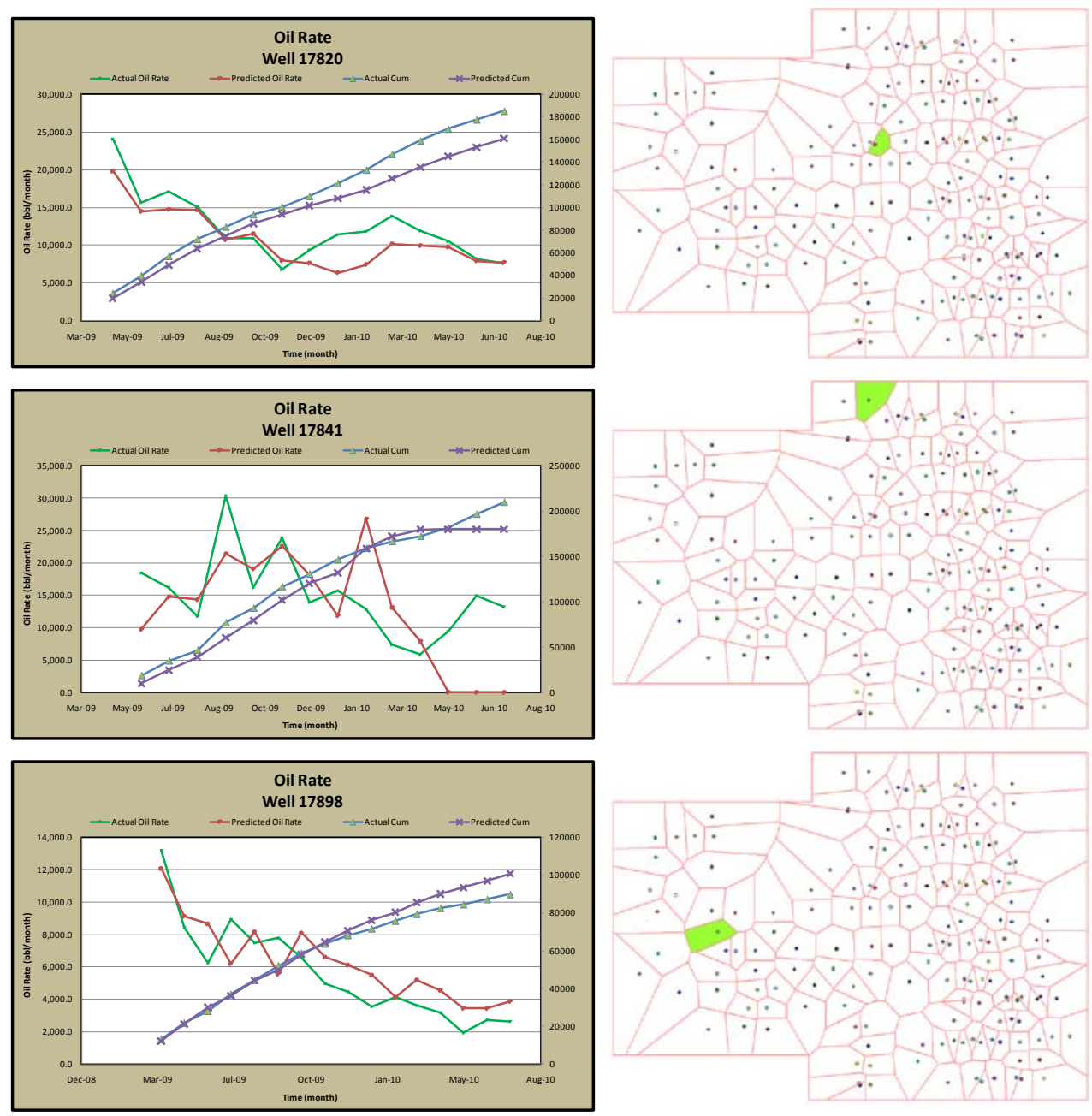
Results of History Matching-Predictive Modeling of Upper Bakken model and respective location of well's polygon in the model:
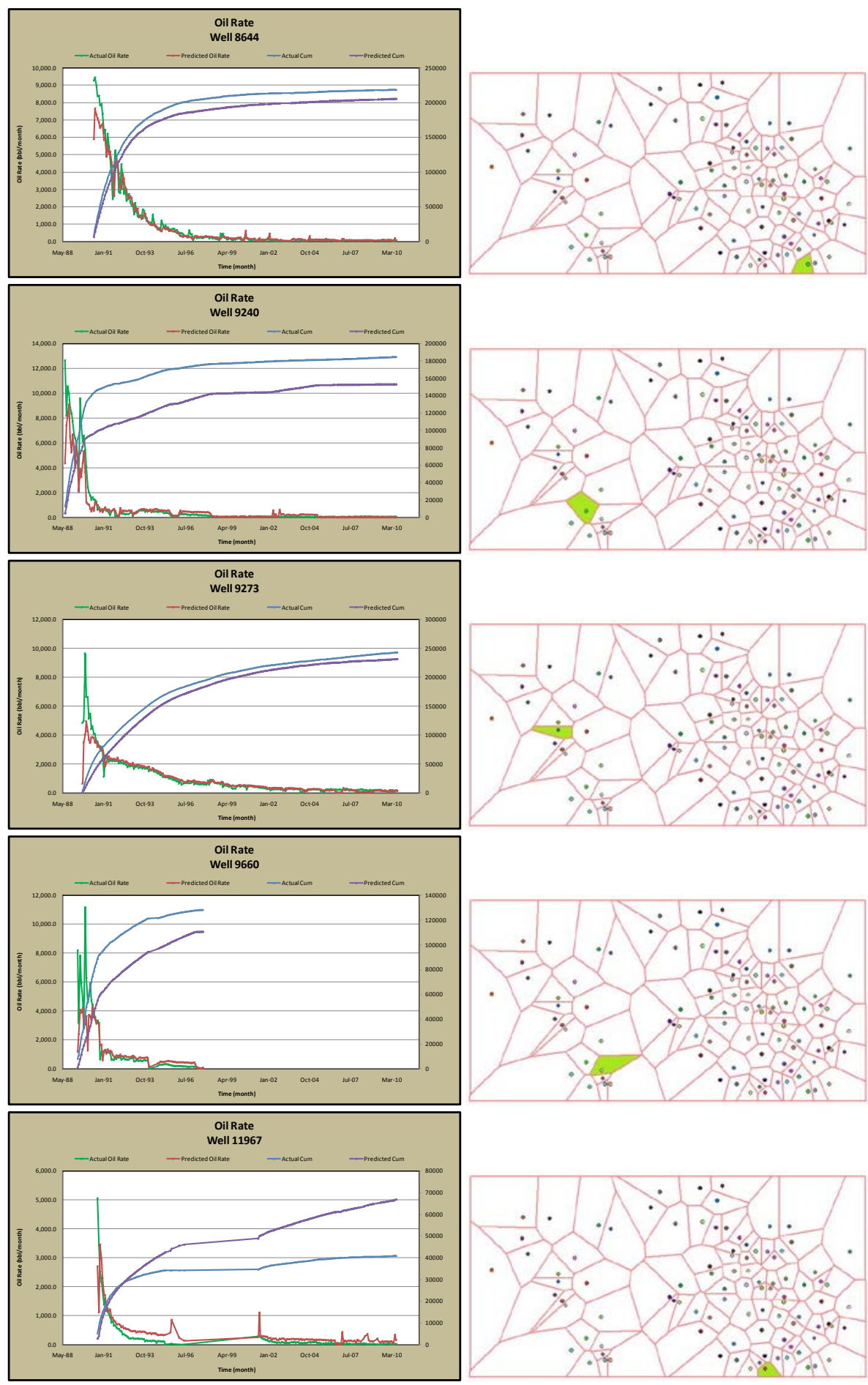


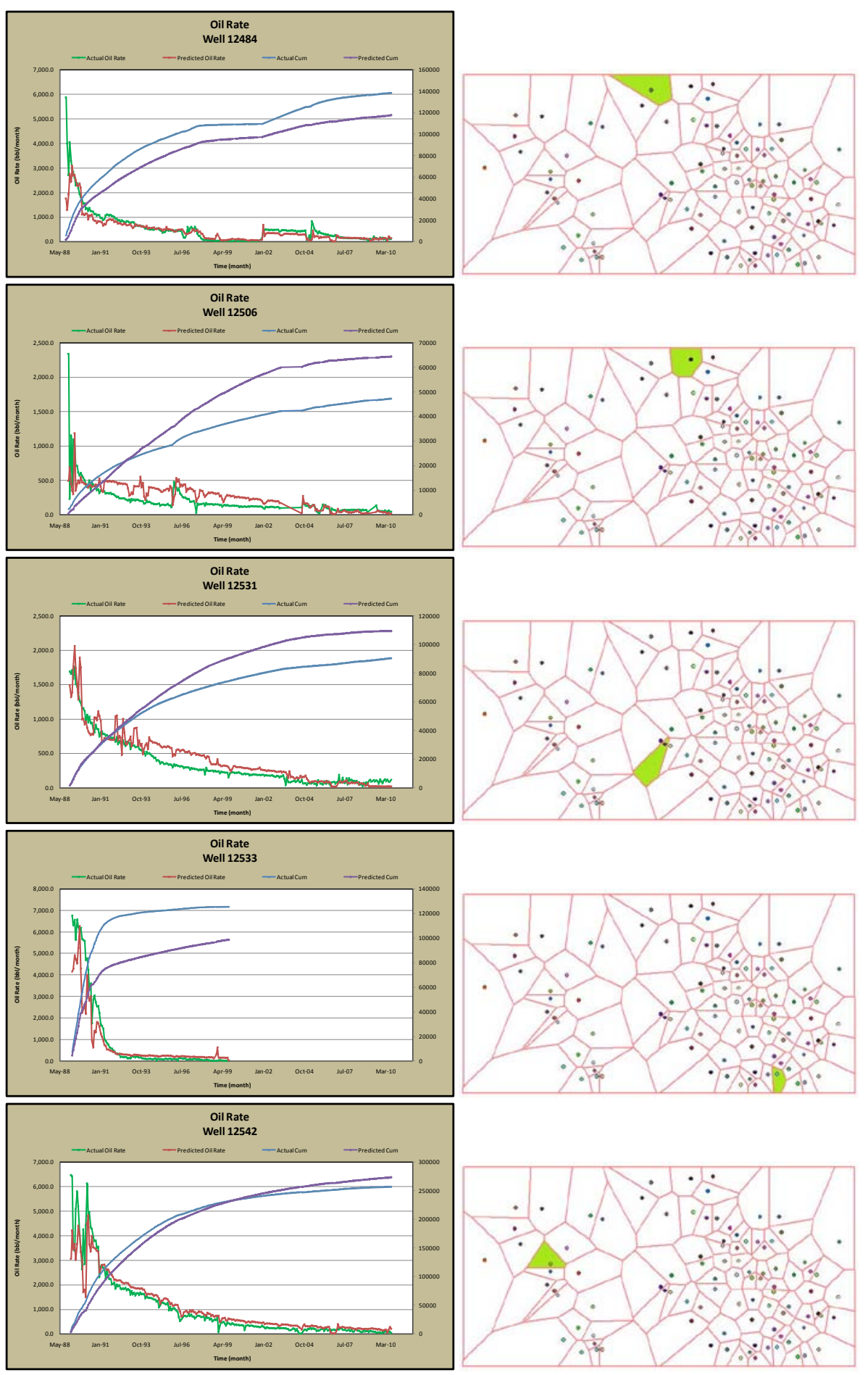




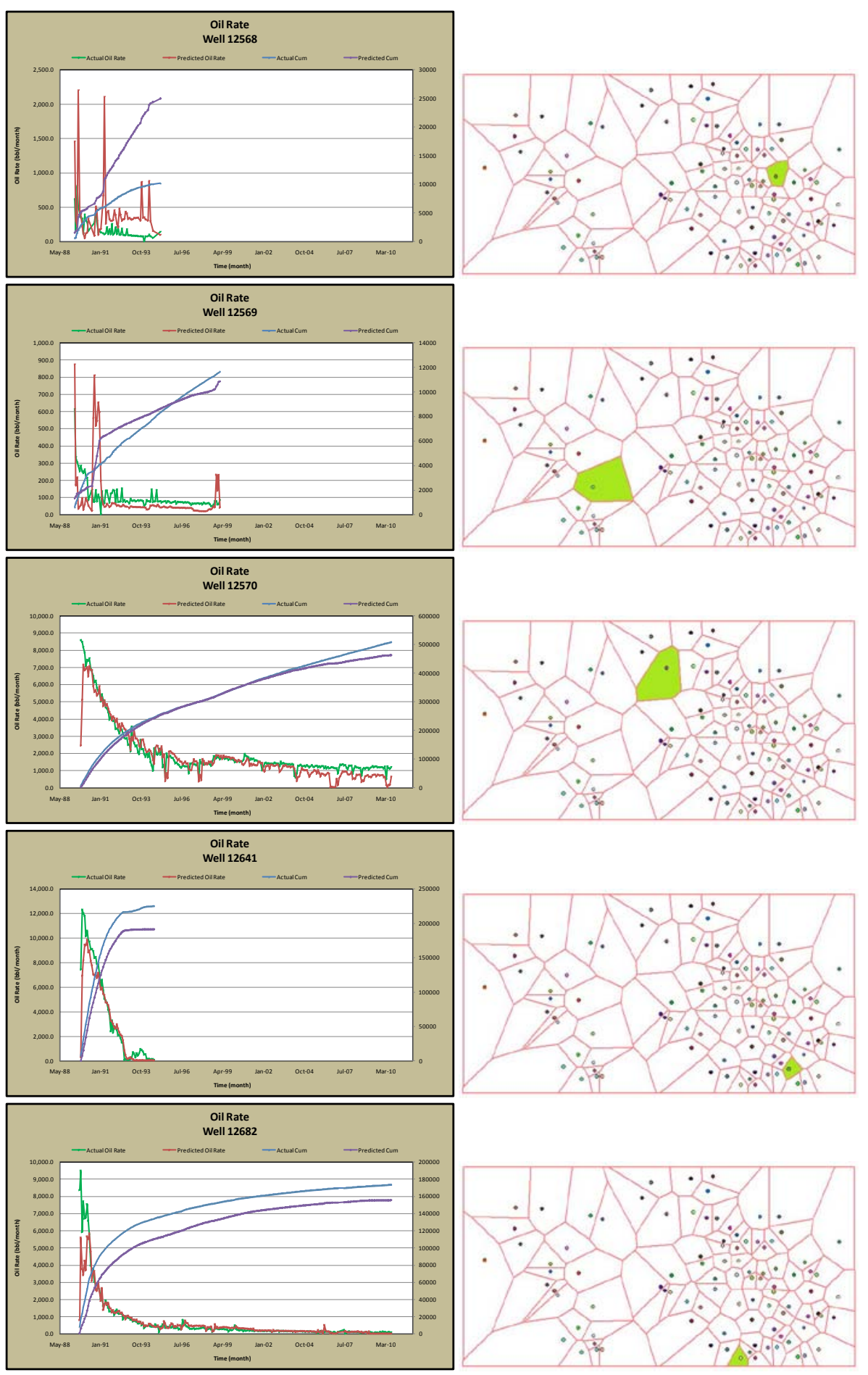




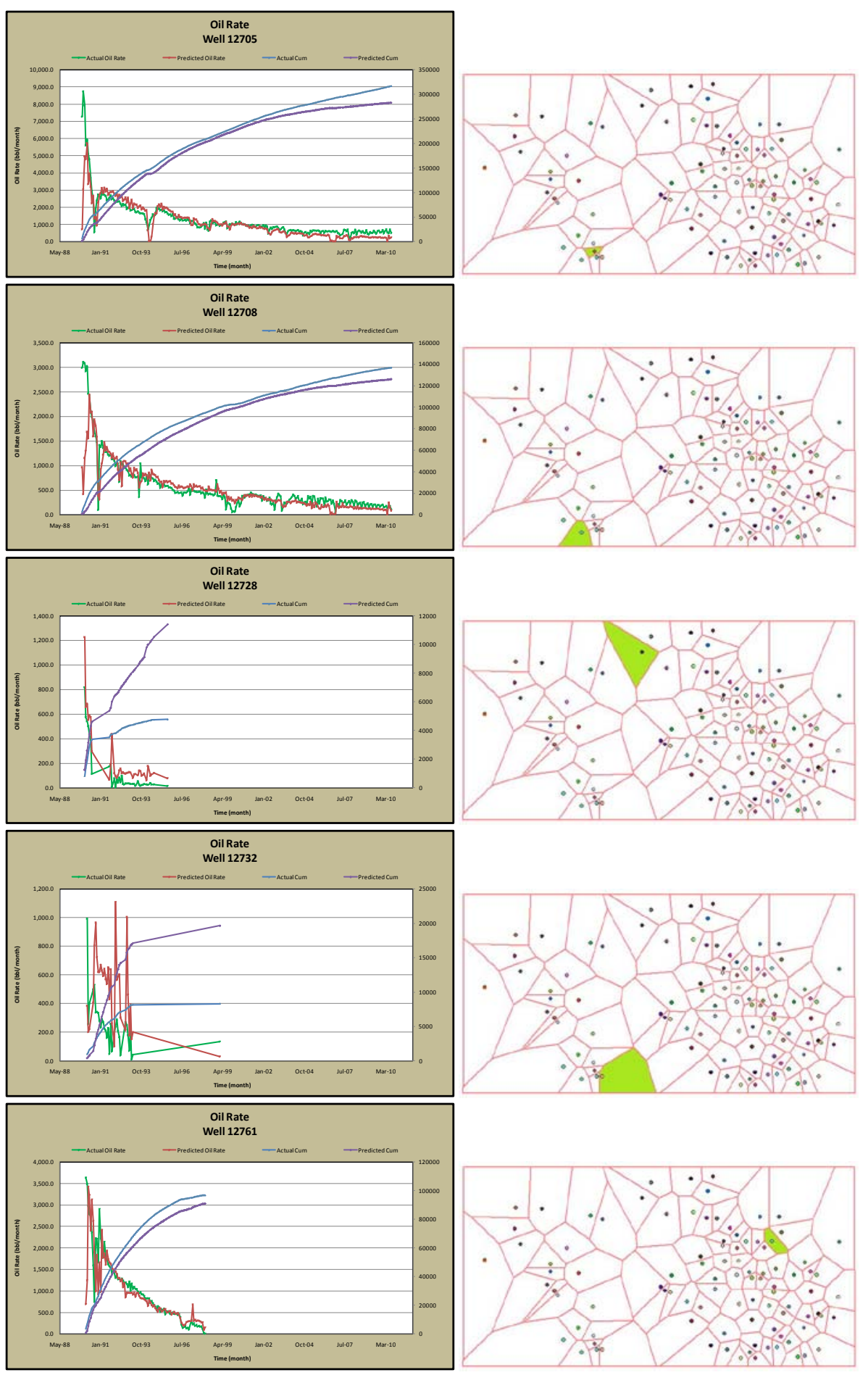




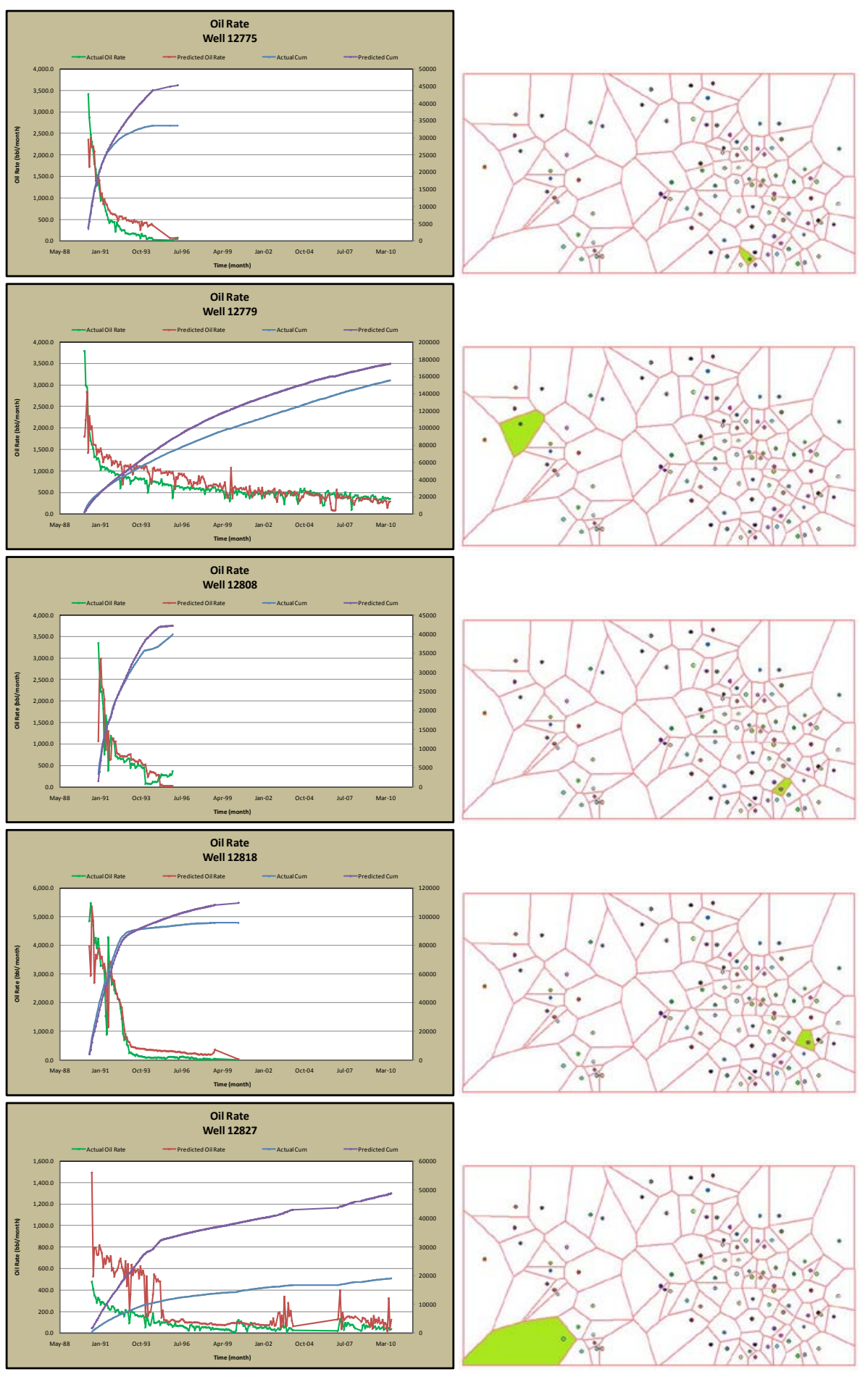




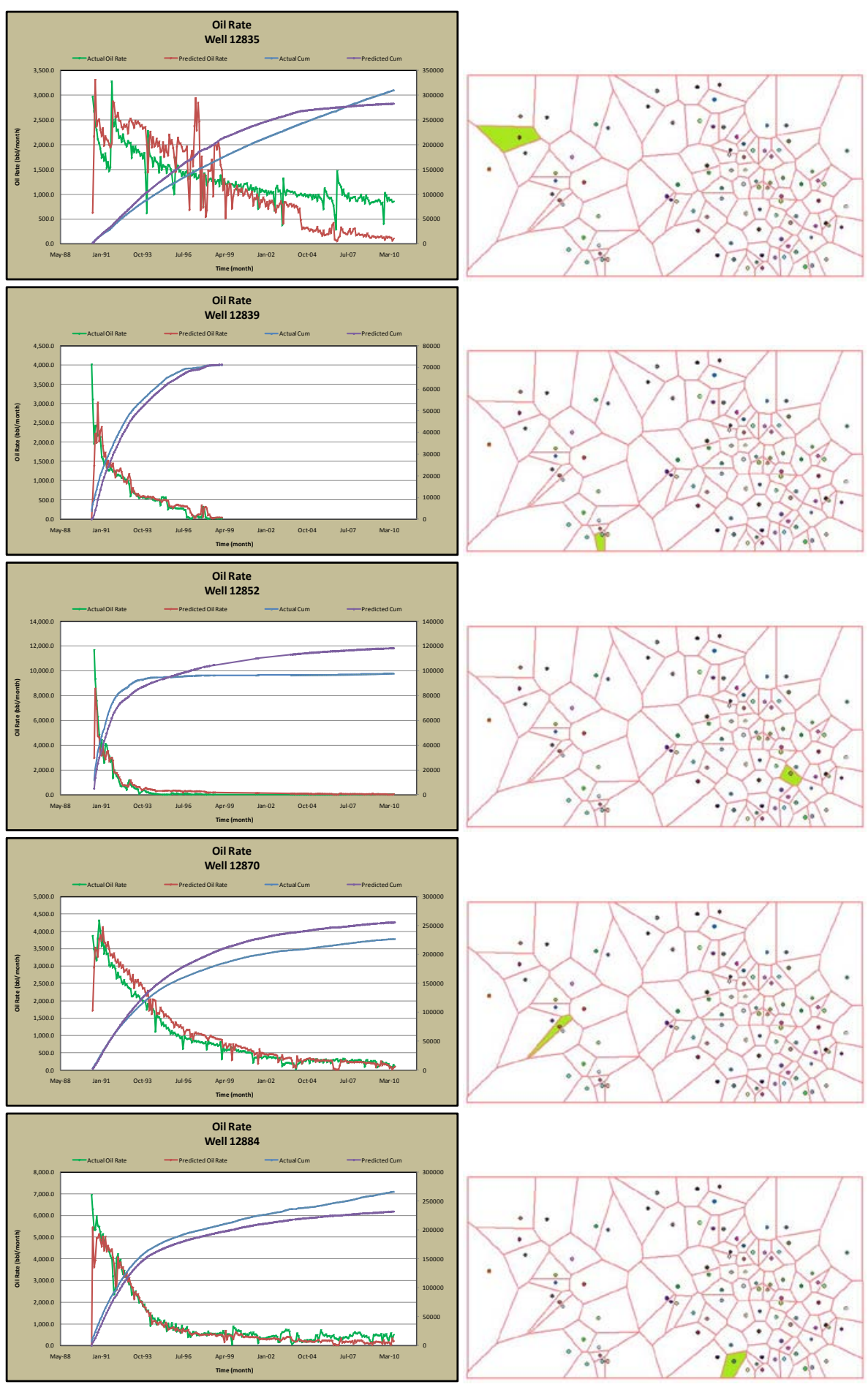




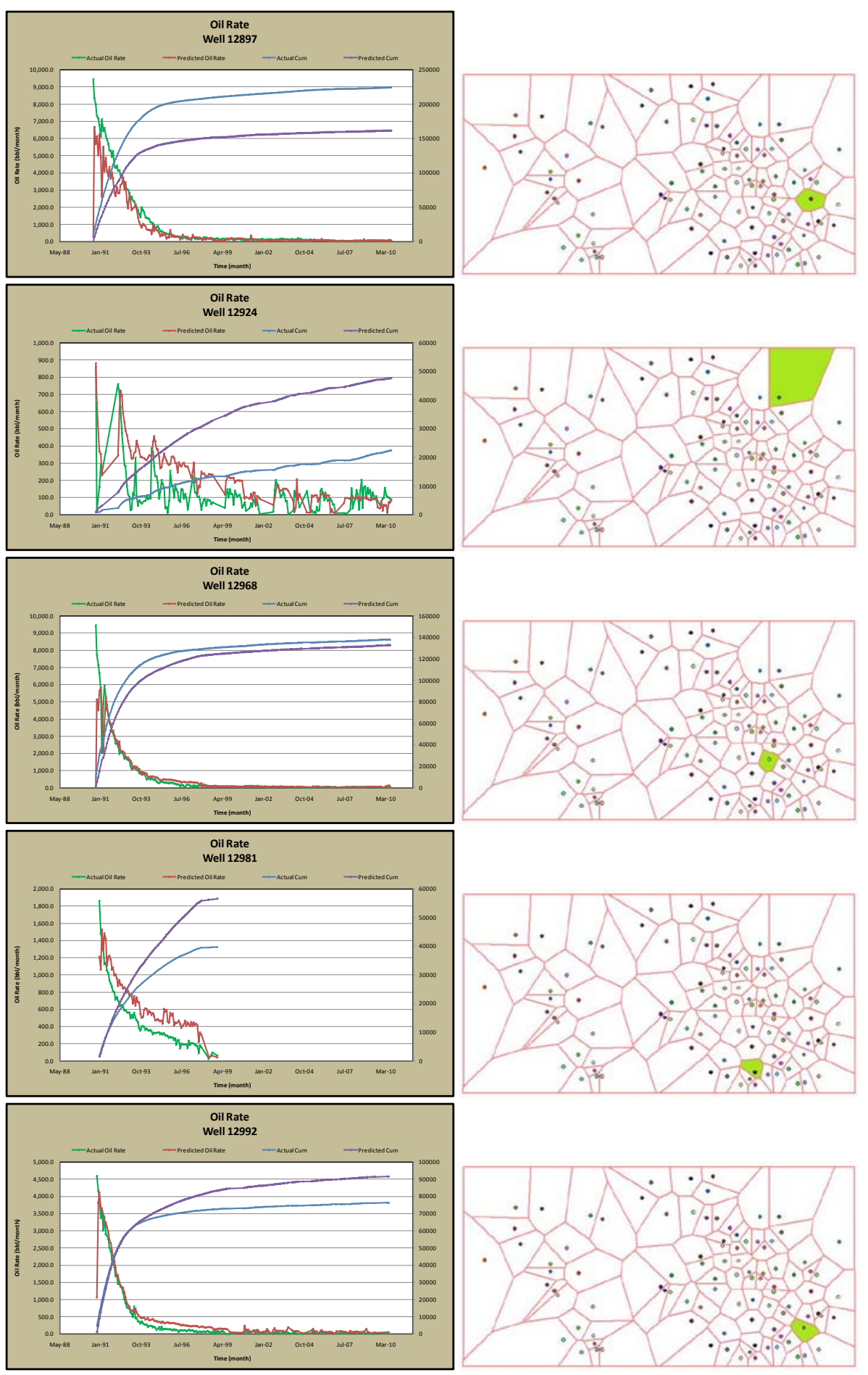




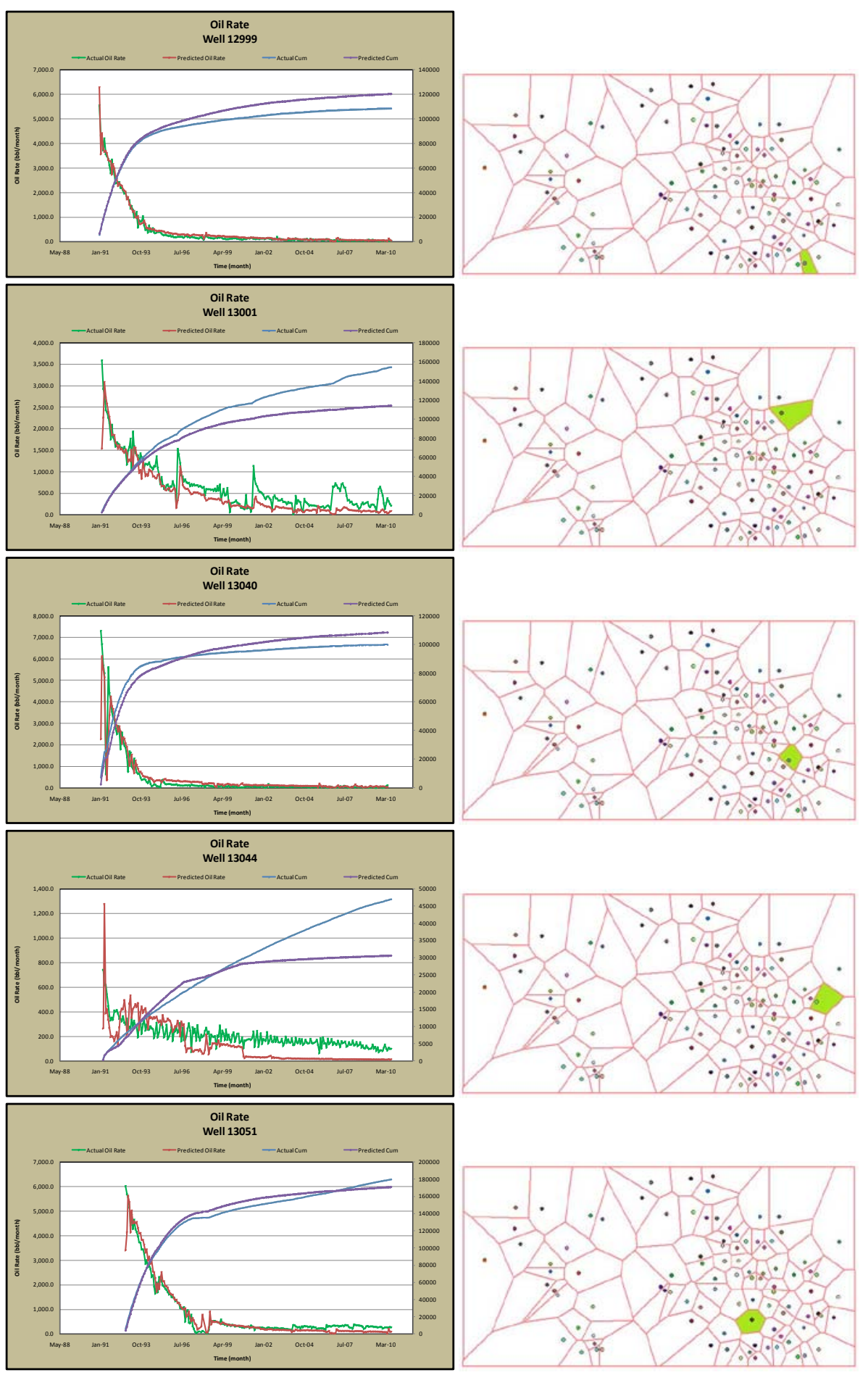



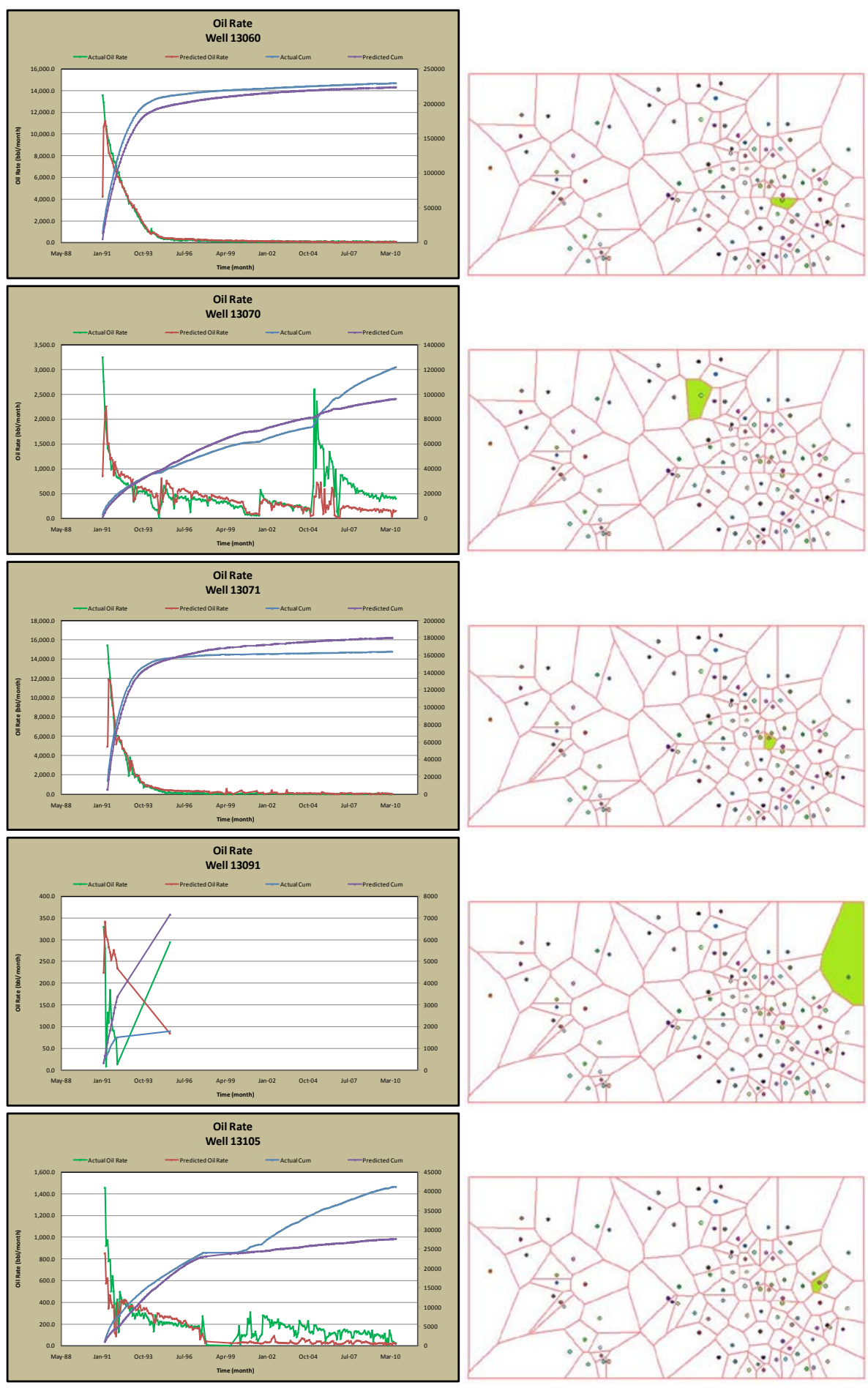


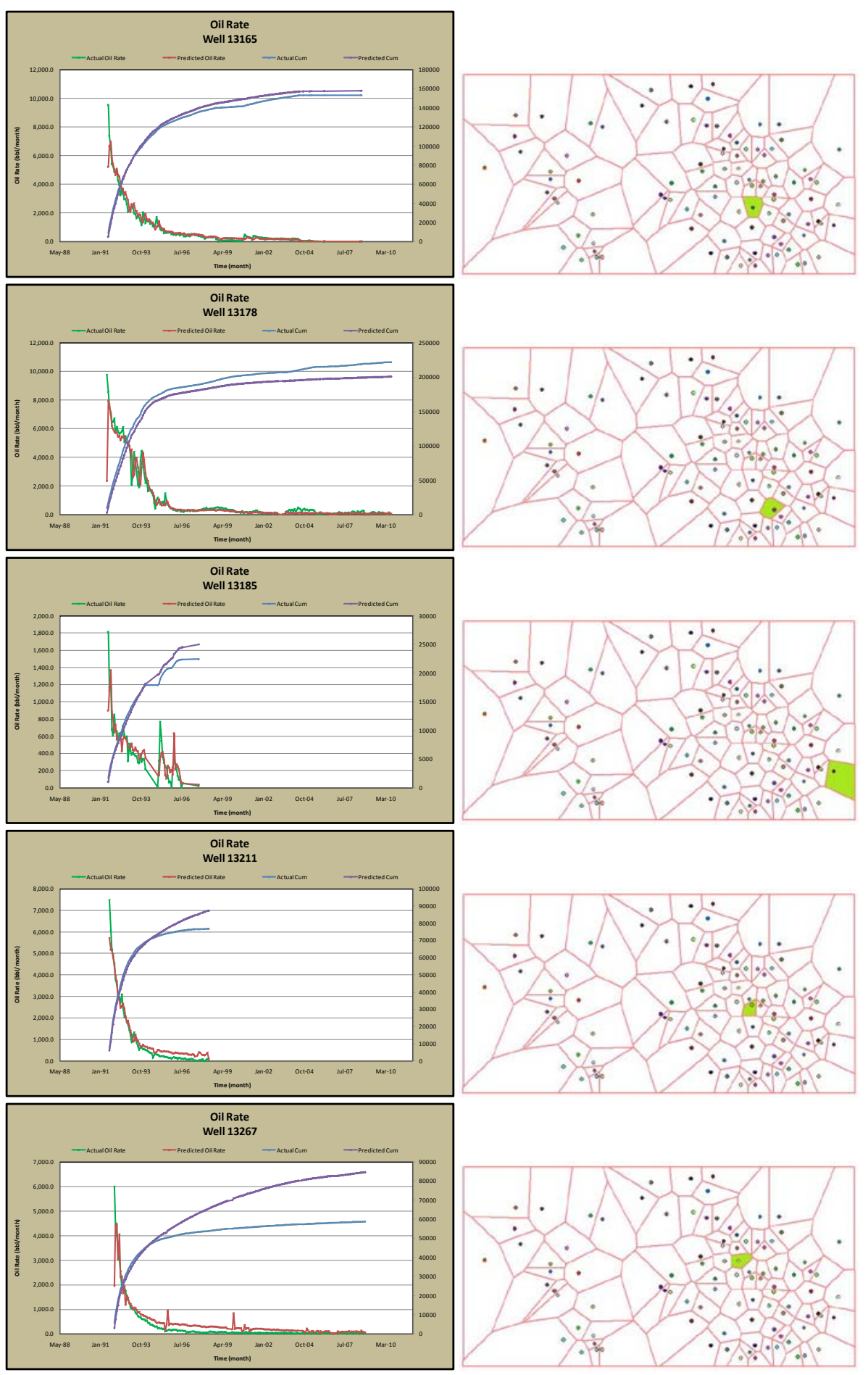




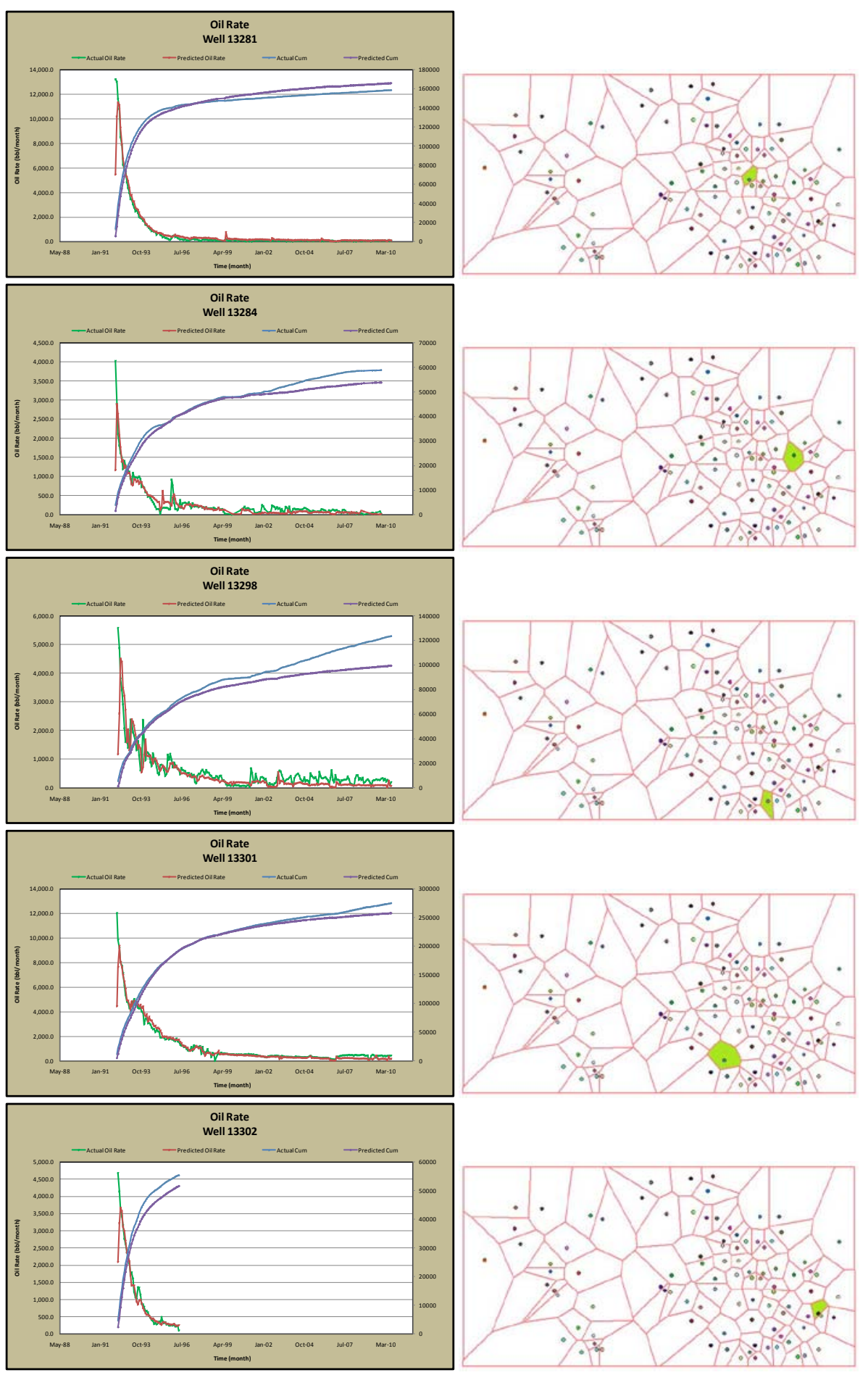




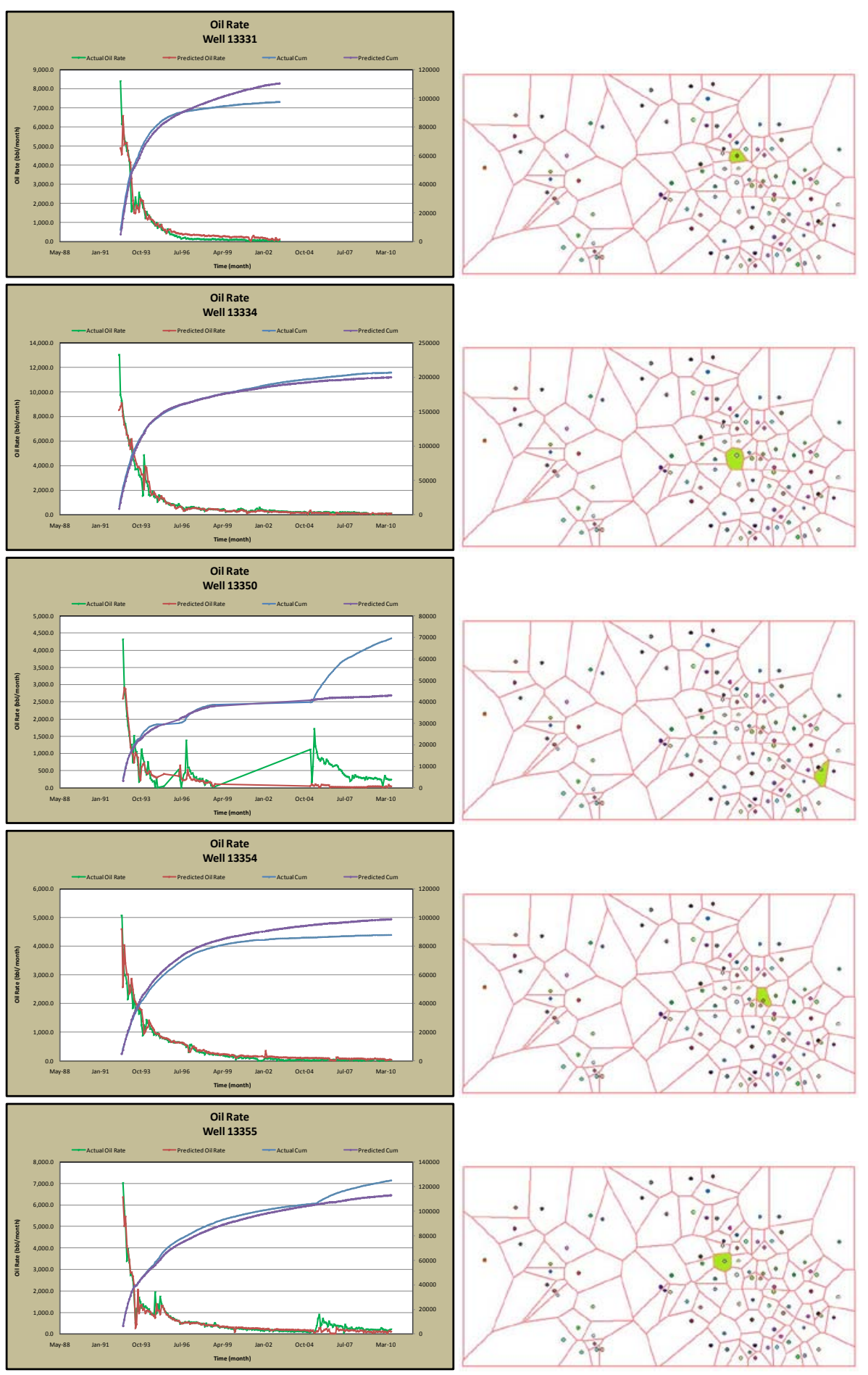




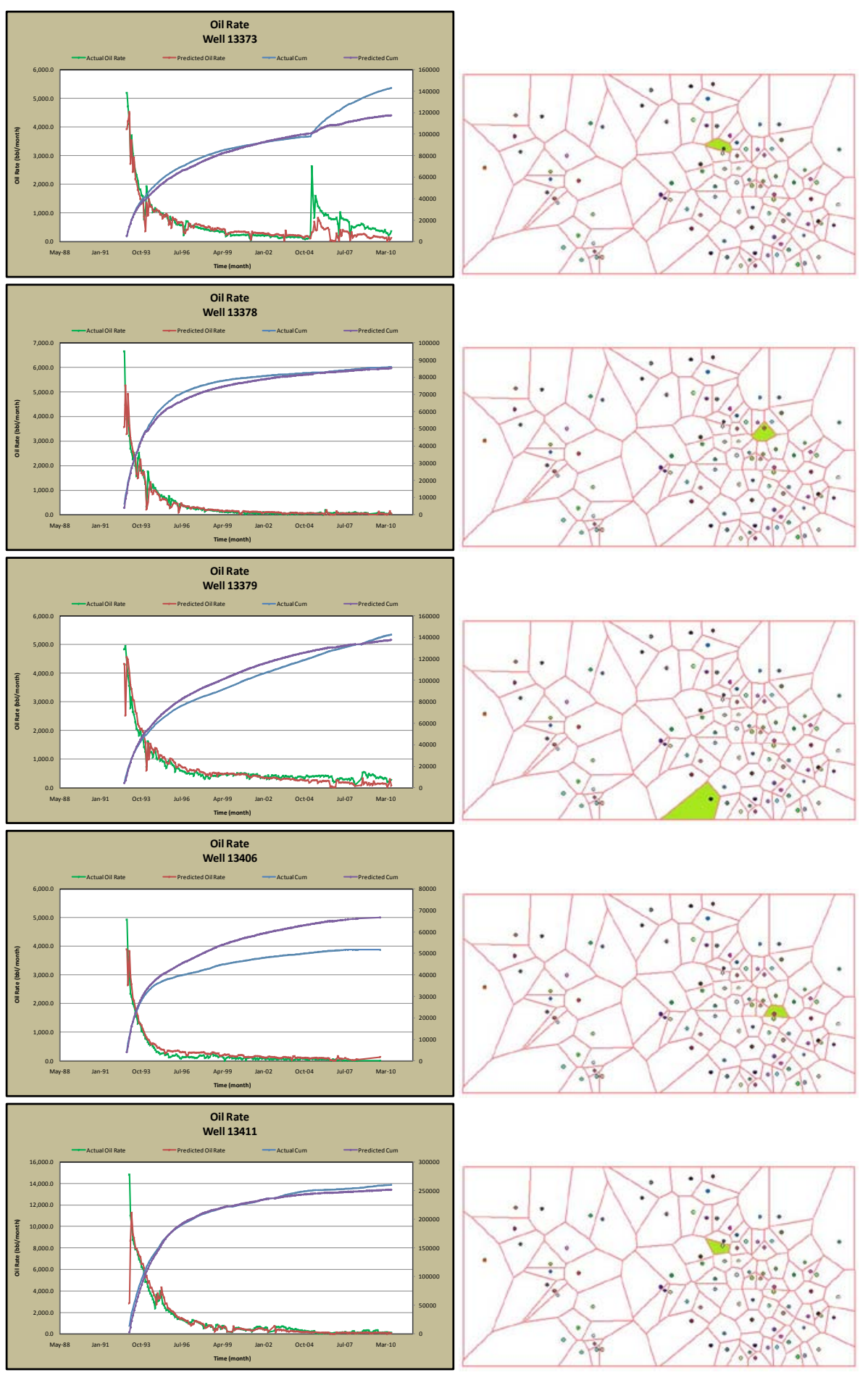



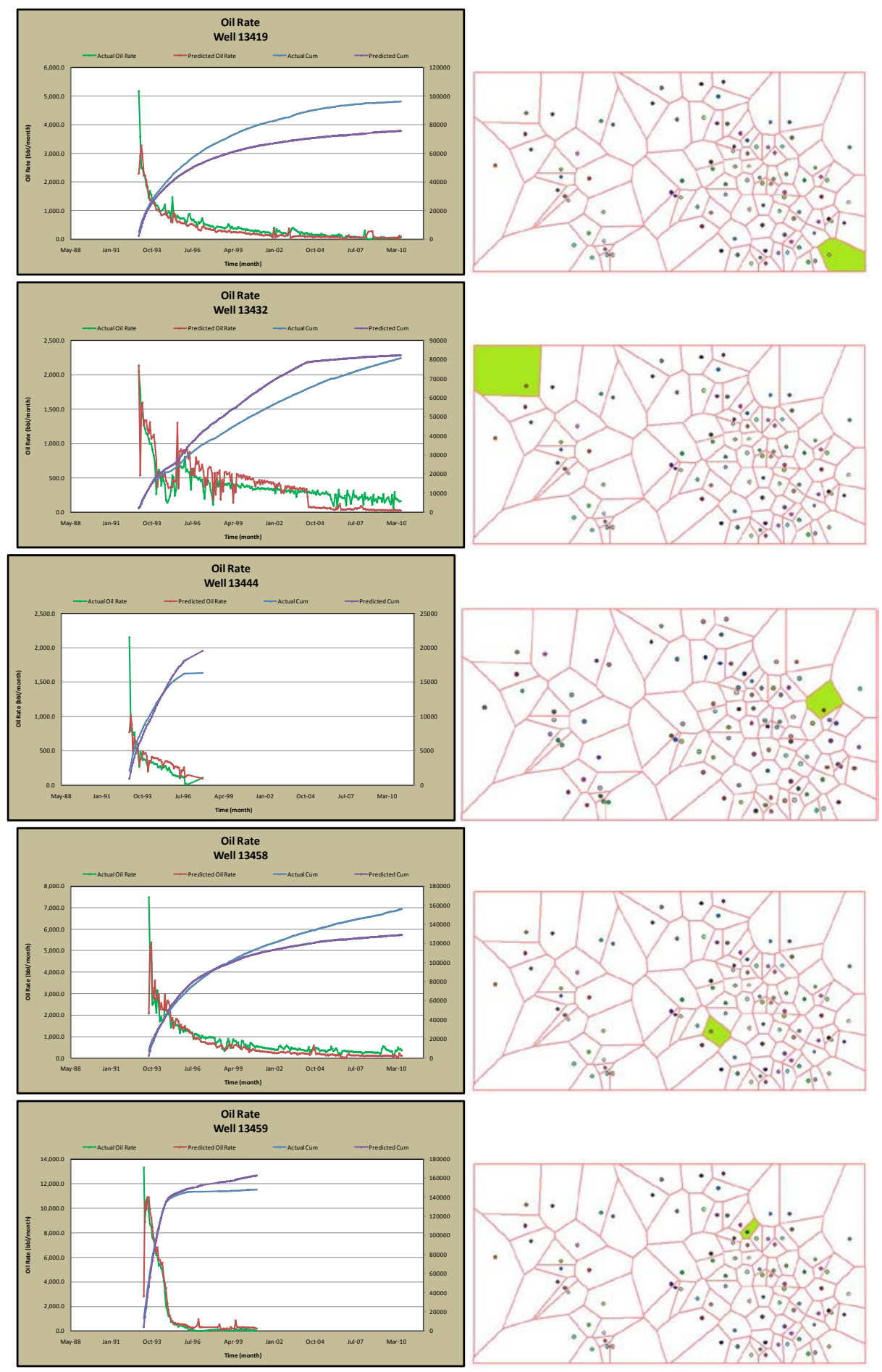


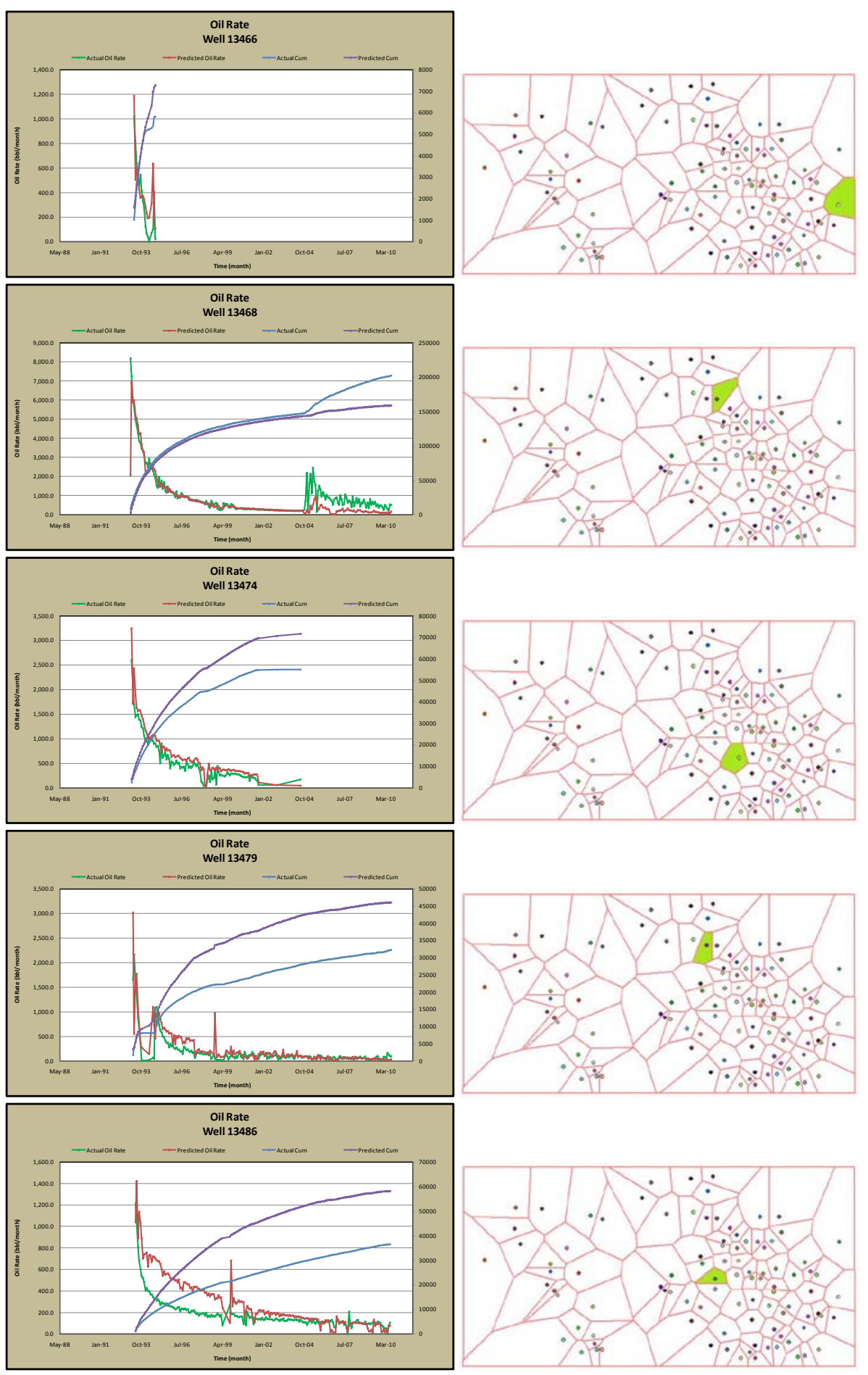




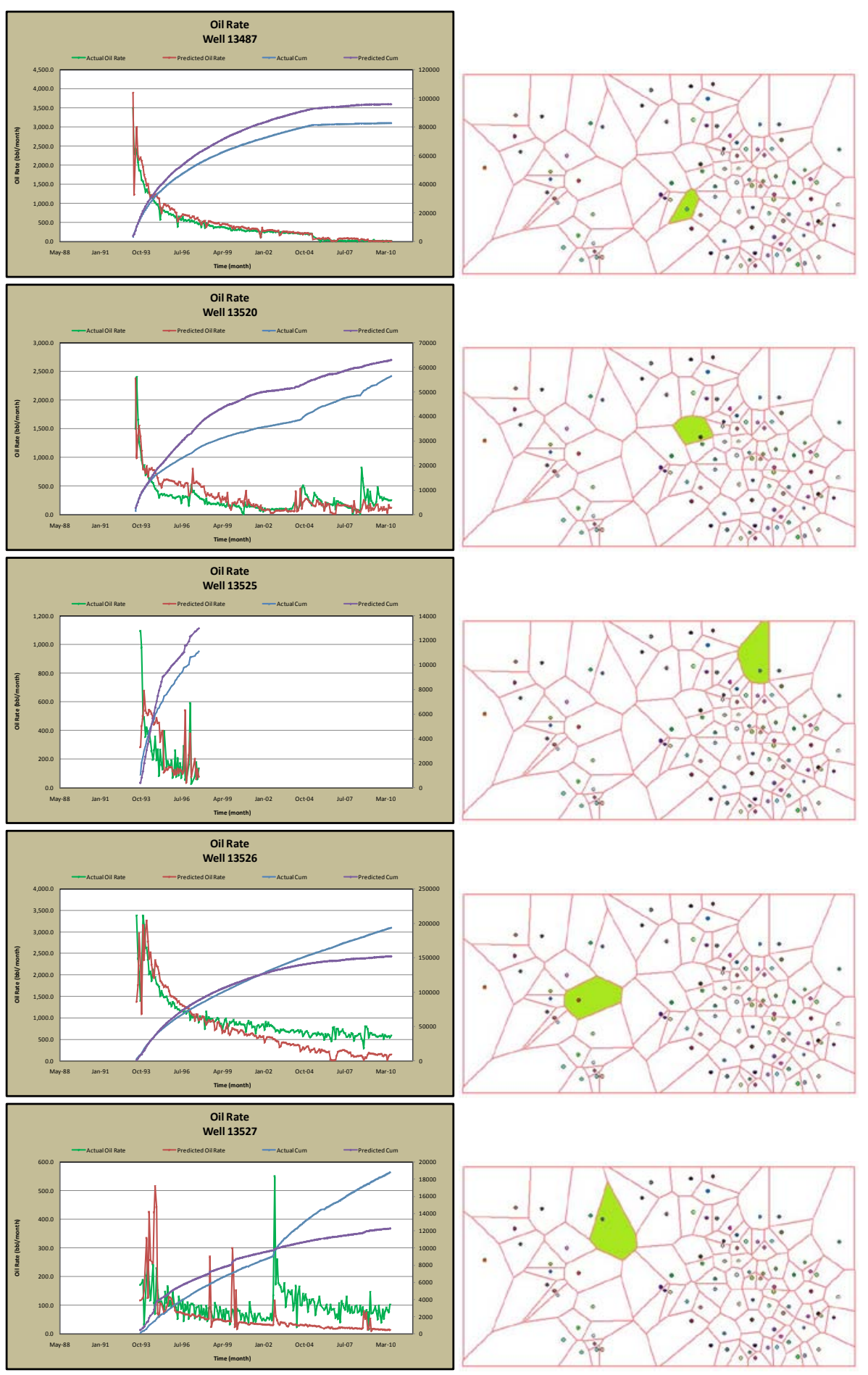




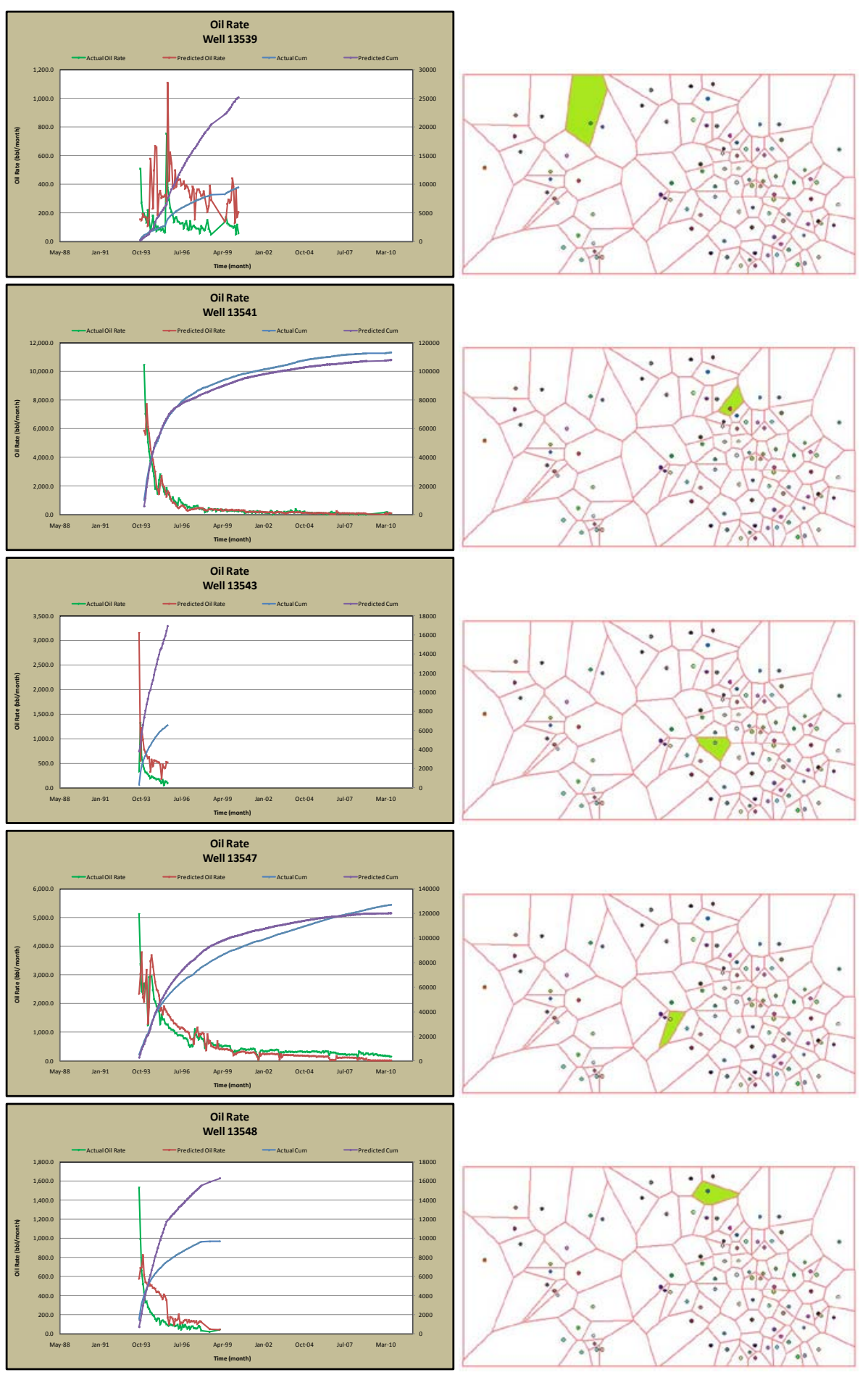




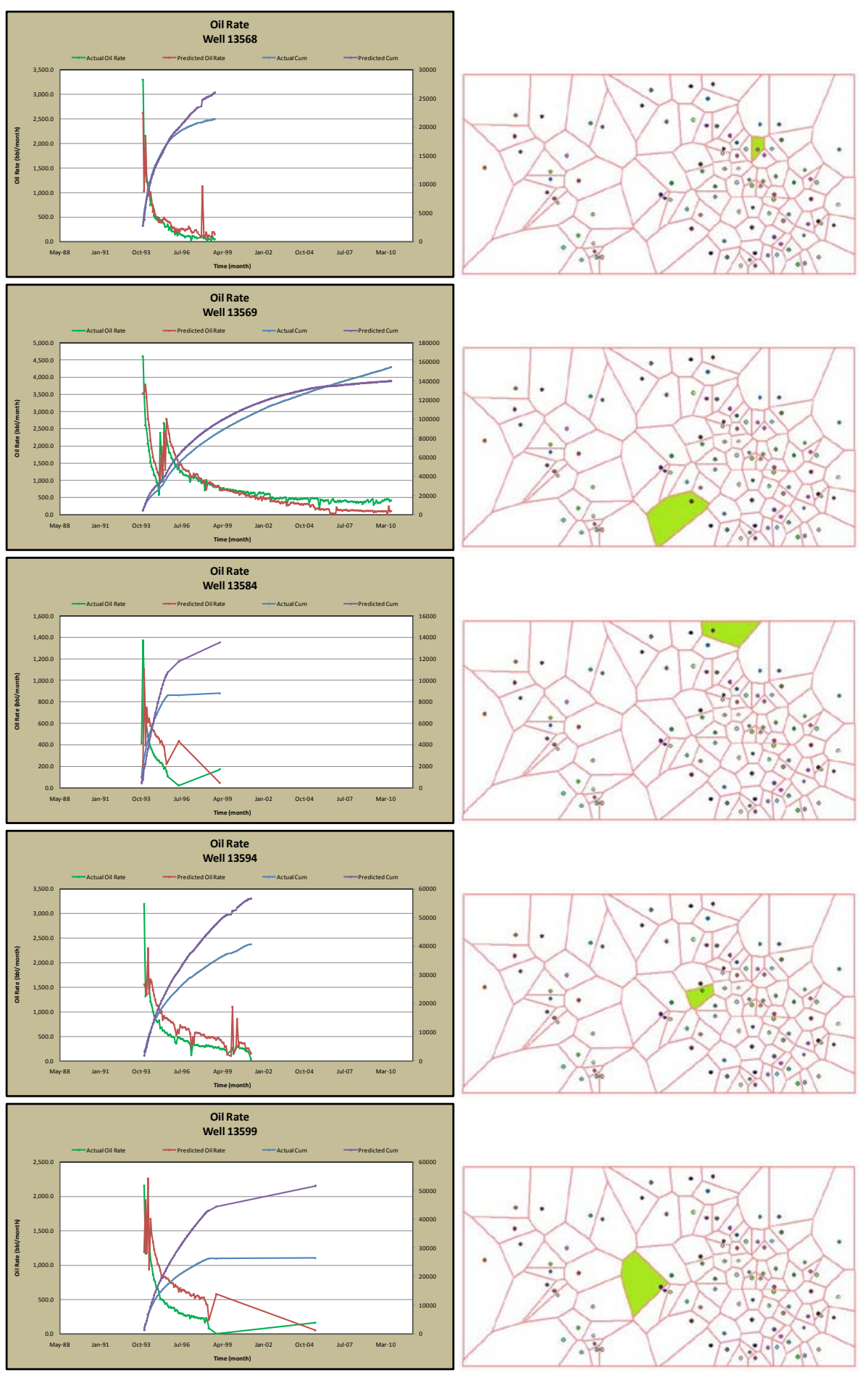



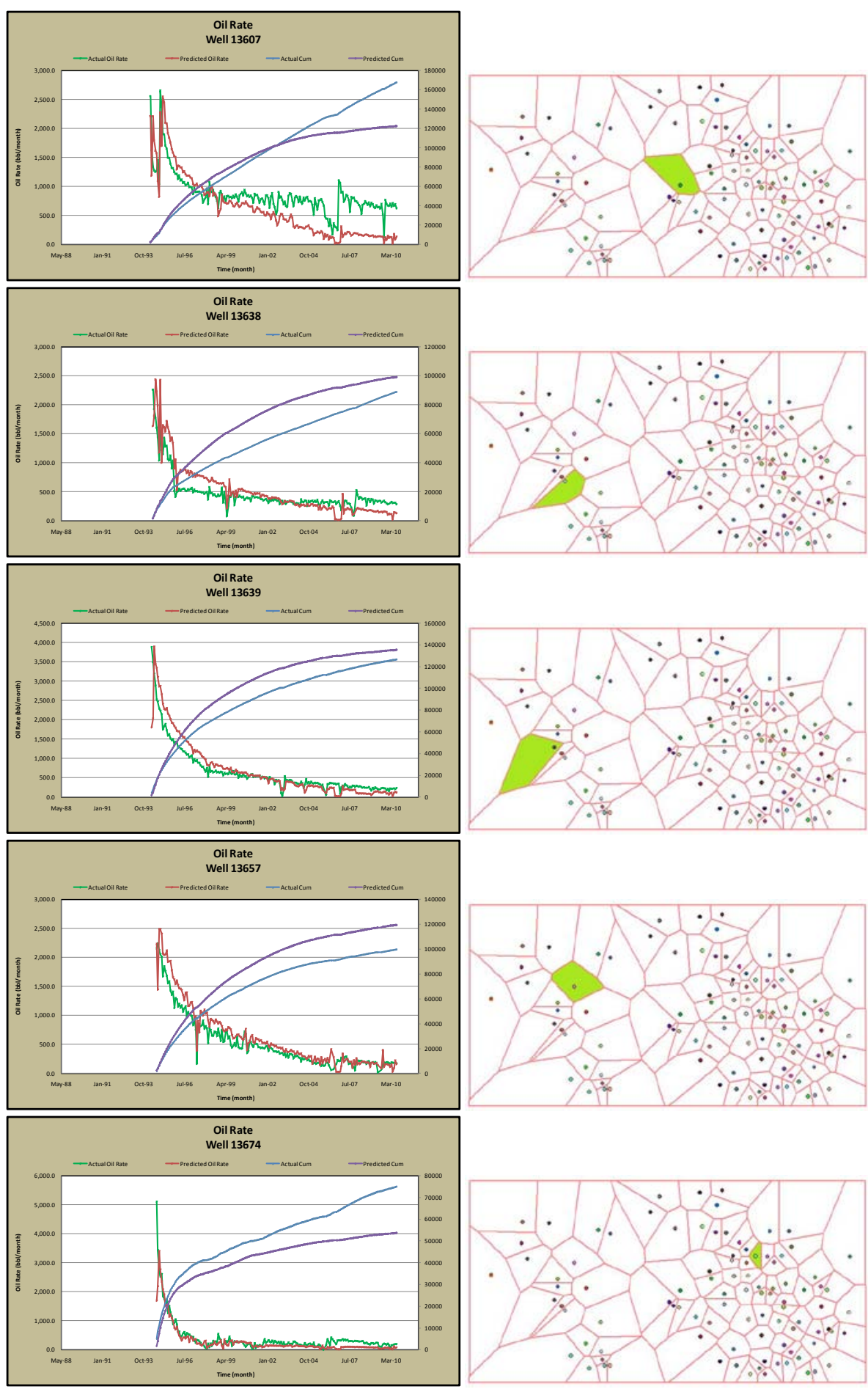

John H.

Hagen 